\title{
WestVirginiaUniversity
}

THE RESEARCH REPOSITORY @ WVU

Graduate Theses, Dissertations, and Problem Reports

2002

\section{Enhanced controls for oxy-fuel-fired batch tank during glass working period}

\author{
Ranjit Menon Unnikrishnan \\ West Virginia University
}

Follow this and additional works at: https://researchrepository.wvu.edu/etd

\section{Recommended Citation}

Unnikrishnan, Ranjit Menon, "Enhanced controls for oxy-fuel-fired batch tank during glass working period" (2002). Graduate Theses, Dissertations, and Problem Reports. 1293.

https://researchrepository.wvu.edu/etd/1293

This Thesis is protected by copyright and/or related rights. It has been brought to you by the The Research Repository @ WVU with permission from the rights-holder(s). You are free to use this Thesis in any way that is permitted by the copyright and related rights legislation that applies to your use. For other uses you must obtain permission from the rights-holder(s) directly, unless additional rights are indicated by a Creative Commons license in the record and/ or on the work itself. This Thesis has been accepted for inclusion in WVU Graduate Theses, Dissertations, and Problem Reports collection by an authorized administrator of The Research Repository @ WVU. For more information, please contact researchrepository@mail.wvu.edu. 


\title{
Enhanced Controls for Oxy-Fuel Fired Batch Tank During Glass Working Period
}

\author{
Ranjit Menon Unnikrishnan
}

\author{
Thesis submitted to \\ College of Engineering and Mineral Resources \\ at West Virginia University \\ in partial fulfillment of the requirements \\ for the degree of \\ Masters of Science in Mechanical Engineering
}

Eric K. Johnson, Ph.D.

John E. Sneckenberger, Ph.D., Chair

Charles F. Stanley, Ph.D.

Department of Mechanical and Aerospace Engineering

Morgantown, West Virginia

2002

Keywords: Batch Tank, Oxy-Fuel, Transient Controls, MATLAB 


\section{ABSTRACT \\ Enhanced Controls for Oxy-Fuel Fired Batch Tank During Glass Working Period \\ Ranjit Menon Unnikrishnan}

One of the most dynamic developments in the glass industry has been the use of oxy-fuel combustion for melting glass. This new technology has not only increased the energy efficiency of the glass industry, but also has reduced its environmental impacts.

A model has been developed to take into account the effect of pulling the glass for nine hours during the working period on the reduced amount of fuel required for the batch tank, as well as the resulting transients.

The two primary goals of this thesis were to develop a transient transfer function for the batch tank and to develop an enhanced controller by the classical approach for the glass working period. Modeling theory was used to develop the transient transfer function for the batch tank. An enhanced controller was designed that incorporates the average rate at which glass is pulled from the batch tank. 


\section{ACKNOWLEDGEMENTS}

First of all, I would like to thank my mother, Mrs. Renu Menon, for the inspiration and support provided during this endeavor.

I am greatly indebted to my research advisor, Dr. John E. Sneckenberger, for his invaluable support, guidance and knowledge. This task would not have been possible without his blessings.

I would like to thank my officemates, Padha, Asif and Paul, for their support. It was fun working with you guys. I would also like to thank my predecessors in the Glass Industry Assistance Project, James Rhodes and Guosheng Kang. Special thanks for laying a strong foundation.

Many thanks are also expressed to Mr. Jeff Herholdt, Manager of the Energy Efficiency Program of the West Virginia Development Office. This research project would not have been realized without the support extended through the Projects with Industry Program.

Much appreciation is extended to Mr. Harry Fontana of L. E. Smith Glass Company, Mr. Bob Jones of Eurotherm Controls and Mr. Mike Rhoades of Glassworks WV. Thanks for the invaluable information on the operating practices of the glass world. I would like to thank my committee members, Dr. Eric K. Johnson, Dr. Charles F. Stanley and Dr. John E. Sneckenberger, for providing valuable insights and contributions during the course of this project.

To all those named above, and others not named but not forgotten who have helped me realize this effort, my gratitude is boundless. Last, but not least, I would like to thank God for making me what I am. 


\section{TABLE OF CONTENTS}

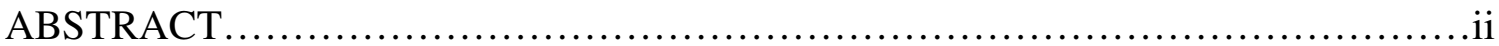

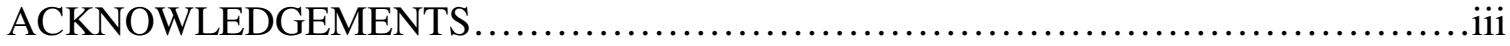

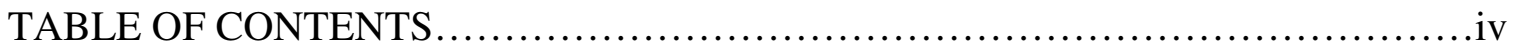

LIST OF FIGURES ............................................................

LIST OF TABLES ..............................................................

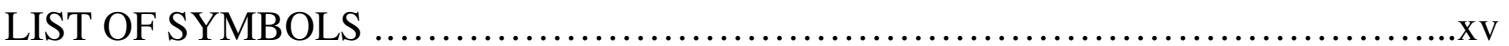

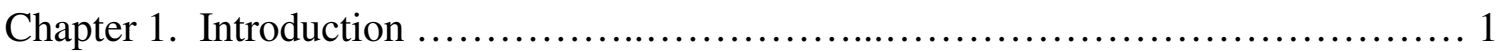

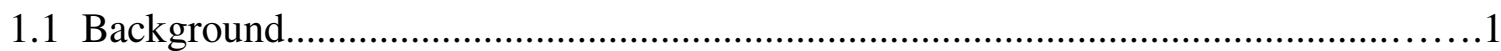

1.2 Industrial Connections........................................................................ 2

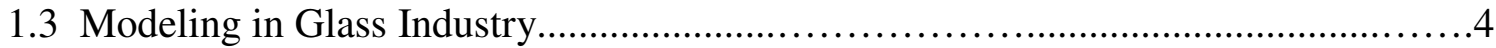

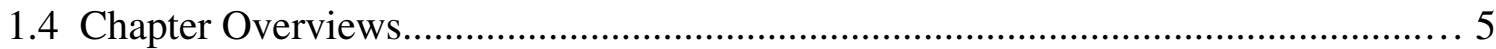

1.5 Research Focus..................................................................

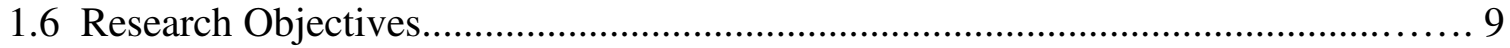

Chapter 2. Specifications of an Oxy-Fuel Batch Tank............................. 10

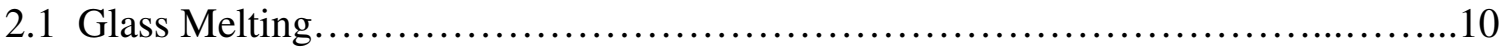

2.2 Comparison of Oxy-Fuel and Air-Fuel Combustion.............................10

2.3 Oxygen Enhanced Combustion Methods..................................... 14

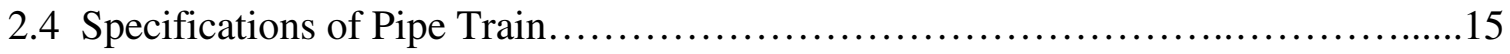

2.4.1 Introduction........................................................ 15

2.4.2 Pipe Train Design...............................................17

2.5 Specifications of Burner..................................................

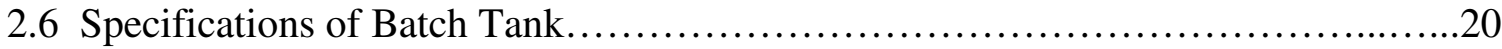

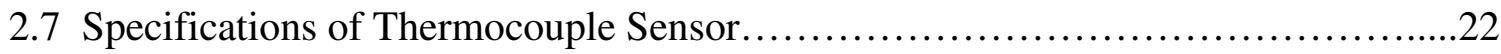

Chapter 3. Transfer Function for Batch Tank Components.............................24

3.1 Transfer Function for Electric-Actuated Control Valve............................24

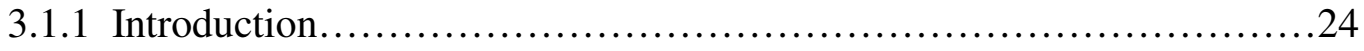

3.1.2 Principle of Current-to-Position Converter..........................25 
3.1.3 Transfer Function of Current-to-Voltage Converter.....................25

3.1.4 Transfer Function for Secondary Controller..........................26

3.1.5 Electric-Actuated Control Valve...................................27

3.1.6 Actuator Part of Control Valve......................................28

3.1.7 Principle of AC Motor............................................29

3.1.8 Transfer Function of AC Motor......................................... 30

3.1.9 Calculation of Moment of Inertia of Rotor and Gearhead................32

3.1.10 Transfer Function Model for Current-to-Position Converter ...............34

3.1.11 Transfer Function of Parallel Link Mechanism...........................37

3.1.12 Position Feedback Potentiometer in Actuated Valve......................38

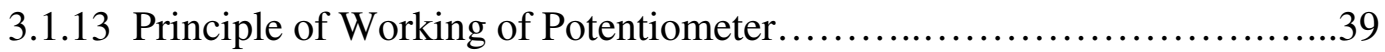

3.1.14 Transfer Function of Potentiometer.................................40

3.1.15 Principle of Working of Flow Part of Control Valve....................41

3.1.16 Transfer Function of Flow Part of Control Valve for Natural Gas.........43

3.1.17 Transfer Function for Electric-Actuated Control Valve...................44

3.2 Transfer Function of Burner.......................................... 46

3.3 Transfer Function of Thermocouple......................................47

Chapter 4. Transfer Function Model for Oxy-Fuel Fired Batch Tank.....................51

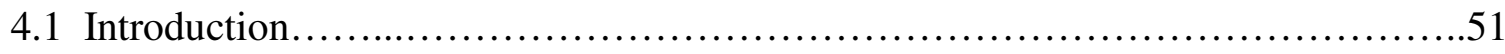

4.2 Transient Observations for Oxy-Fuel Fired Batch Tank..........................53

4.3 Transfer Function Model for Batch Tank during Melting and Conditioning Periods............................................. 55

4.3.1 Calculation of Thermal Resistance for Radiant Heat Transfer from Hot Gases to Glass...............................................56

4.3.2 Calculation of Thermal Capacitance for Radiant Heat Transfer from Hot Gases to Glass..................................................57

4.3.3 Calculation of Thermal Resistance for Glass Transfer Function............58

4.3.4 Calculation of Thermal Capacitance for Glass Transfer Function .........59

4.3.5 Development of Transfer Function for Glass..........................60

4.4 Transfer Function Model for Batch Tank during Working Period...................63 
4.5 Overall Transfer Function for Batch Tank

4.5.1 Overall Transfer Function for Batch Tank during Working Period.........67

4.6 Closed-Loop Transfer Function for Batch Tank...............................68

4.6.1 Closed-Loop Model of the Batch Tank during Working Period............69

4.7 Economic Aspects of Transient Controls for Batch Tank.......................70

Chapter 5. Controller Design for Oxy-Fuel Batch Tank ............................74

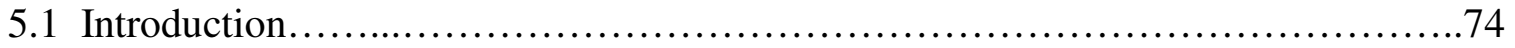

5.2 Discussion of Responses............................................ 74

5.3 Controller Design.................................................... 76

5.3.1 Controller Design for Working Period..............................77

Chapter 6. Approach to Results............................................ 80

6.1 Analysis using MS Excel.............................................. 80

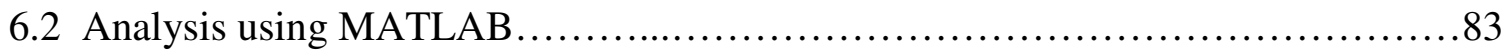

6.3 Temperature Acquisition using LabVIEW ................................. 85

Chapter 7. Summary and Results ........................................... 87

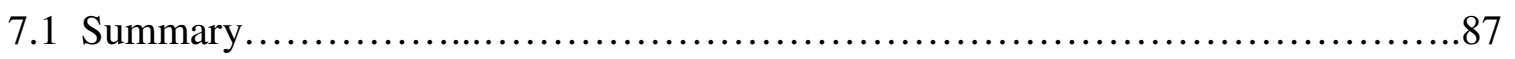

7.1.1 Main Objectives................................................ 87

7.1.2 Main Approach......................................................87

7.1 .3 Results................................................... 87

Chapter 8. Contributions and Future Research ..................................94

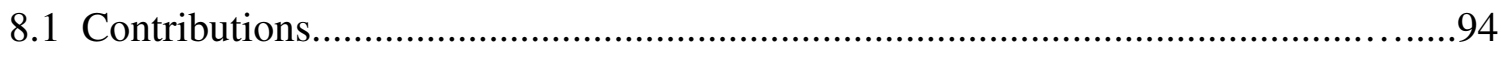

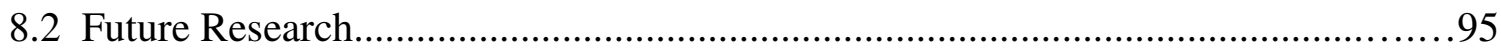

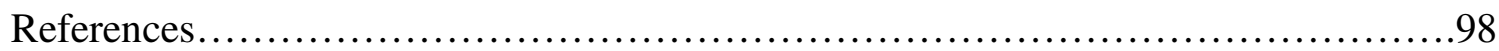

Appendix A - MATLAB and Simulink Code for Batch Tank Model..................102

Appendix B - MATLAB and Simulink Code for Controller ........................105 
Appendix C - Transfer Function Model for Electric-Actuated Control Valve

for Oxygen...................................................... 107

Appendix D - Calculation of Transient Aspects during Glass Working Period..........109

Appendix E - MATLAB Code for Calculation of Savings from Enhanced Controller..116

Appendix F - Development of Transfer Function for Plant and Design of Controller for Melting and Conditioning Periods ..............................118

Appendix G - LabVIEW Application for Acquiring Temperature ....................127

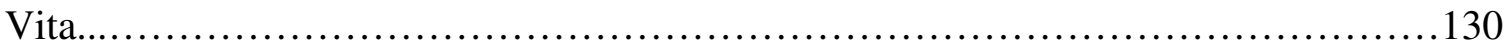




\section{LIST OF FIGURES}

Figure 2.1 Picture of Pipe Trains ............................................... 16

Figure 2.2 Schematic of Pipe Train showing Different Elements......................17

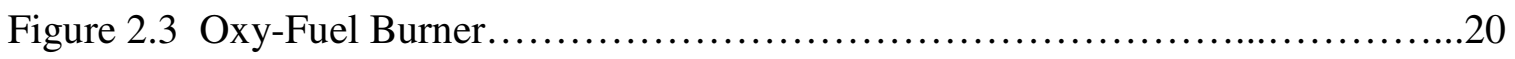

Figure 2.4 Schematic of an Oxy-Fuel Fired Batch Tank..............................21

Figure 3.1 Block Diagram of Pipe Train showing Control Valve and Controllers........27

Figure 3.2 Picture of an Electric-Actuated Flow Controlled Valve ....................28

Figure 3.3 Picture of an Electric Actuator..........................................29

Figure 3.4 Wiring Diagram of AC Motor.......................................... 30

Figure 3.5 Schematic of Motor and Gearhead......................................... 32

Figure 3.6 Simplified Block Diagram of Current-to-Position Converter..................35

Figure 3.7 Angular-Motion Potentiometer........................................... 39

Figure.3.8 Characteristics of Feedback Potentiometer................................40

Figure 3.9 Sectional View of Control Valve for Gases.............................41

Figure 3.10 Schematic of Control Valve showing Two Motions.........................42

Figure 3.11 Various Flow Possibilities Obtainable by Manipulating Control Handle and

Core-adjusting Knob........................................................ 43

Figure 3.12 Valve Flow Characteristics of Control Valve in Natural Gas Pipe...........43

Figure 3.13 Block Diagram Representation of Control Valve .........................44

Figure 3.14 Unit Step Input of Current from Primary Controller........................45

Figure 3.15 Unit Step Response of Electric-Actuated Control Valve...................45

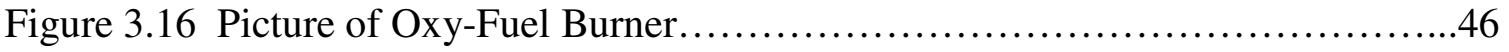

Figure 3.17 Temperature-Voltage Relation for Type-K Thermocouple.................48 
Figure 3.18 Step Increase in Temperature Input to Thermocouple..................50

Figure 3.19 Step Response to Temperature Increase of Thermocouple.................50

Figure 4.1 Time Profile of Measured Temperature and Flow Rate of Natural Gas with

Current Controller.............................................................. 51

Figure 4.2 Time Profile of Level of Glass and Weight of Glass Inside Batch Tank.....52

Figure 4.3 Schematic of Oxy-Fuel Fired Batch Tank showing Three Modes of

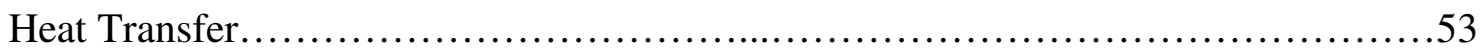

Figure 4.4 Effect of Pulling of Glass on Volume of Glass in Tank and

Area of Walls in Contact with Glass............................................54

Figure 4.5 Schematic of Different Heat Transfer Resistances and Capacitances.........55

Figure 4.6 Response of Batch Tank Model during Melting and Conditioning Periods

for Step Input in Energy of 100,000 Btu/hr...............................63

Figure 4.7 Time Profile of Heat Transfer Resistance of Glass $\left(R_{G}\right) \ldots \ldots \ldots \ldots \ldots \ldots \ldots .64$

Figure 4.8 Time Profile of Heat Transfer Capacitance of Glass $\left(\mathrm{C}_{\mathrm{G}}\right) \ldots \ldots \ldots \ldots \ldots \ldots .64$

Figure 4.9 Block Diagram of Batch Tank Transfer Function during Working Period....68

Figure 4.10 Closed-Loop Model for Oxy-Fired Batch Tank ........................68

Figure 4.11 Typical Glass Manufacturer's Cost Breakdown.........................70

Figure 4.12 Time Profiles of Measured Temperature and Flow Rate of Natural Gas with

Present and Enhanced Controllers........................................... 71

Figure 4.13 Time Profile of Measured Temperature and Flow Rate of Oxygen with

Present and Enhanced Controllers........................................... 72

Figure 4.14 Comparison of Energy Consumptions with Present and

Enhanced Controls........................................................ 73 
Figure 5.1 Root Locus Plot of Overall Batch Tank Transfer Function during

Working Period......................................................... 75

Figure 5.2 Bode Plot of Overall Batch Tank Transfer Function during Working Period...75

Figure 5.3 Response of Closed-Loop Transfer Function during Working Period

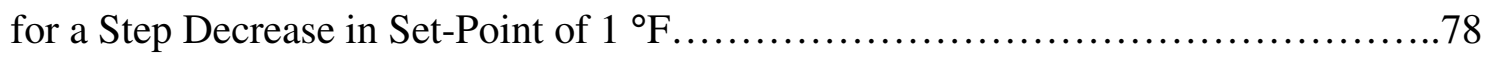

Figure 5.4 Root Locus Plot of Closed-Loop Transfer Function during

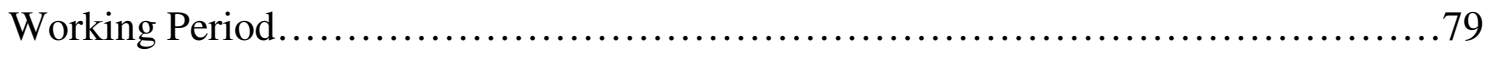

Figure 5.5 Bode Plot of Closed-Loop Transfer Function during Working Period........79

Figure 7.1 Time Profile of Level of Glass and Weight of Glass inside Batch Tank.....88

Figure 7.2 Time Profile of Heat Transfer Resistance of Glass $\left(\mathrm{R}_{\mathrm{G}}\right) \ldots \ldots \ldots \ldots \ldots \ldots \ldots . \ldots 8$

Figure 7.3 Time Profile of Heat Transfer Capacitance of Glass $\left(\mathrm{C}_{\mathrm{G}}\right) \ldots \ldots \ldots \ldots \ldots \ldots . \ldots . \ldots . \ldots$

Figure 7.4 Response of Closed-Loop Transfer Function during Working Period for a

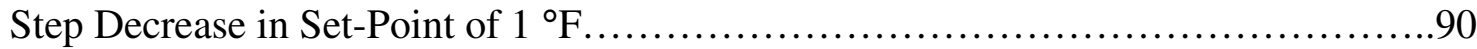

Figure 7.5 Time Profiles of Temperature and Flow Rate of Natural Gas with Present

and Enhanced Controllers..................................................... 91

Figure 7.6 Time Profiles of Temperature and Flow Rate of Oxygen with Present

and Enhanced Controllers.................................................. 92

Figure 7.7 Comparison of Energy Consumptions with Present and

Enhanced Controllers......................................................93

Figure A.1 Simulink Model for Equivalent Transfer Function of Electric-Actuated

Control Valve.

Figure A.2 Simulink Model for Transfer Function of Electric-Actuated

Control Valve. 
Figure B.1 Simulink Model for Closed-Loop Batch Tank Transfer Function during

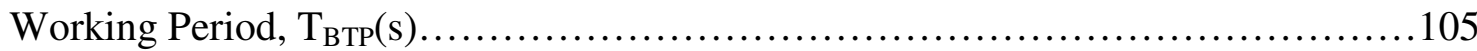

Figure B.2 Simulink Model for Plant Transfer Function during

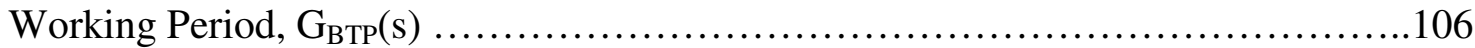

Figure C.1 Valve Flow Characteristics of Electric-Actuated Control Valve in

Oxygen Pipe Train........................................................ 107

Figure C.2 Block Diagram Representation of Control Valve for Oxygen...............108

Figure F.1 Block Diagram of Batch Tank Transfer Function during

Melting and Conditioning Periods........................................... 118

Figure F.2 Response of Closed-Loop Transfer Function for Melting for a

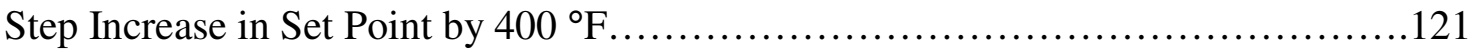

Figure F.3 Root Locus Plot of Closed-Loop Transfer Function for Melting.............122

Figure F.4 Bode Plot of Closed-Loop Transfer Function for Melting................ 122

Figure F.5 Response of Closed-Loop Transfer Function for Cooling for a

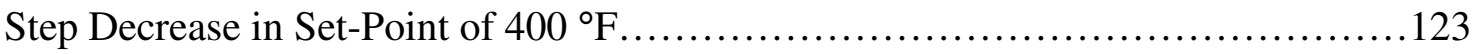

Figure F.6 Bode Plot of Closed-Loop Transfer Function for Cooling ................ 124

Figure F.7 Simulink Model for Closed-Loop Batch Tank Transfer Function

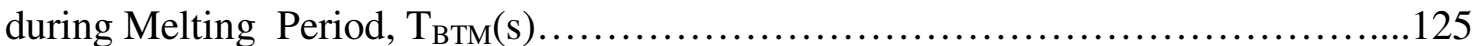

Figure F.8 Simulink Model for Open-Loop Batch Tank Transfer Function

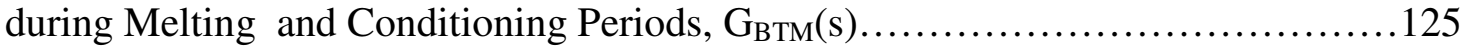

Figure F.9 Simulink Model for Closed-Loop Batch Tank Transfer Function

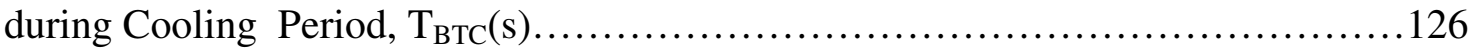

Figure G.1 Front Panel of LabVIEW Application for Acquiring Temperature.........128 
Figure G.2 Block Diagram of LabVIEW Application for Acquiring Temperature .....129

Figure G.3 Block Diagram of LabVIEW for Temperature Conversion................129 


\section{LIST OF TABLES}

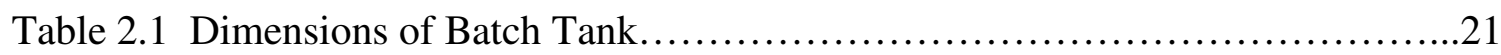

Table 2.2 Specifications for Thermocouple..................................22

Table 3.1 Specifications for Electric-Actuator Parameters...........................29

Table 3.2 Specifications of AC Motor and Gearhead...................................

Table 3.3 Parameters of Output Shaft in Gearhead...............................33

Table 3.4 Calculated Values of Moment of Inertia of Motor and Gearhead..............34

Table 3.5 Specifications of Crank Arm and Connecting Link.........................38

Table 3.6 Response Time and Sensitivity of Type-K Thermocouple.................48

Table 4.1 Comparison of Transient Parameters of Batch Tank.......................54

Table 4.2 Parameters for the Calculation of Heat Transfer Resistance from

Hot Gases to Glass..................................................... 57

Table 4.3 Heat Transfer Conductance and Resistance from Hot Gases to Glass.........57

Table 4.4 Parameters for Capacitance of Products of Combustion.....................57

Table 4.5 Parameters for the Heat Transfer Resistance of the Glass Transfer Function..59

Table 4.6 Heat Transfer Conductance and Resistance from Hot Gases to Glass.........59

Table 4.7 Parameters for Capacitance of Glass Transfer Function....................59

Table 4.8 Transfer Functions for Glass for Different Levels of Glass................65

Table 5.1 Desired Performance of Closed-Loop Model during Working Period ..........76

Table 6.1 Variation of Heat Transfer Parameters with Time........................ 81

Table 6.2 Transfer Function Terms of Glass during Working Period...................82

Table D.1 Variation of Heat Transfer Parameters with Time........................113 
Table D.2 Transfer Function Terms of Glass Element during Working Period..........115

Table F.1 Desired Performance of Closed-Loop Models during Melting and Cooling

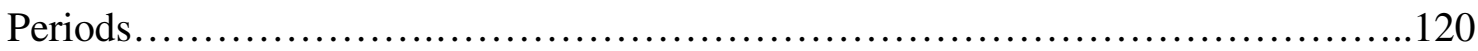




\section{LIST OF SYMBOLS}

$\mathrm{A}_{\mathrm{G}} \quad-\quad$ Surface area of glass

$A_{W G} \quad-\quad$ Area of walls in contact with glass

$\mathrm{C}_{\mathrm{E}} \quad-\quad$ Capacitance of products of combustion

$\mathrm{C}_{\mathrm{G}} \quad-\quad$ Capacitance of glass and refractory

$\left(\mathrm{C}_{\mathrm{V}}\right)_{\mathrm{F}} \quad-\quad$ Calorific value of natural gas

D $\quad-\quad$ Mechanical friction damping factor

E(s) - Laplace transform of input error signal to primary controller

$\Delta \mathrm{E}_{\mathrm{S}}(\mathrm{s}) \quad-\quad$ Laplace transform of error signal within secondary controller

$\mathrm{G}_{\mathrm{B}}(\mathrm{s}) \quad-\quad$ Transfer function for burner

$\mathrm{G}_{\mathrm{BTM}}(\mathrm{s}) \quad-\quad$ Transfer function for batch tank during melting and conditioning periods

$\mathrm{G}_{\mathrm{BTP}}(\mathrm{s}) \quad-\quad$ Transfer function for batch tank during working period

$\mathrm{G}_{\mathrm{CC}}(\mathrm{s}) \quad-\quad$ Transfer function of controller for cooling period

$\mathrm{G}_{\mathrm{CCW}}(\mathrm{s})$ - Transfer function for counter-clockwise motion of motor

$\mathrm{G}_{\mathrm{CM}}(\mathrm{s}) \quad-\quad$ Transfer function of controller for melting period

$\mathrm{G}_{\mathrm{CP}}(\mathrm{s}) \quad-\quad$ Transfer function for current-to-position converter

$\mathrm{G}_{\mathrm{CPU}}(\mathrm{s}) \quad-\quad$ Transfer function of controller for working period

$\mathrm{G}_{\mathrm{CV}}(\mathrm{s}) \quad-\quad$ Transfer function for control valve

$\mathrm{G}_{\mathrm{CW}}(\mathrm{s}) \quad-\quad$ Transfer function for clockwise motion of motor

$\mathrm{G}_{\mathrm{EQ}}(\mathrm{s}) \quad-\quad$ Equivalent transfer function of triac in $\mathrm{AC}$ motor

$\mathrm{G}_{\mathrm{G}}(\mathrm{s}) \quad-$ General transfer function for glass 


\begin{tabular}{|c|c|c|}
\hline $\mathrm{G}_{\mathrm{GM}}(\mathrm{s})$ & - & $\begin{array}{l}\text { Transfer function for glass during melting and } \\
\text { conditioning periods }\end{array}$ \\
\hline $\mathrm{G}_{\mathrm{GP}}(\mathrm{s})$ & - & Transfer function for glass during working period \\
\hline $\mathrm{G}_{\mathrm{I}}(\mathrm{s})$ & - & Transfer function of current-to-voltage converter \\
\hline $\mathrm{G}_{\mathrm{L}}(\mathrm{s})$ & - & Transfer function for parallel-link mechanism \\
\hline $\mathrm{G}_{\mathrm{M}}(\mathrm{s})$ & - & Transfer function of AC motor \\
\hline $\mathrm{G}_{\text {Plant }}(\mathrm{s})$ & - & Transfer function of plant \\
\hline $\mathrm{G}_{\mathrm{PT}}(\mathrm{s})$ & - & Transfer function of pipe train \\
\hline $\mathrm{G}_{\mathrm{TD}}(\mathrm{s})$ & - & Time delay transfer function \\
\hline $\mathrm{G}_{\mathrm{TV}}(\mathrm{s})$ & - & Transfer function for temperature to voltage converter \\
\hline $\mathrm{G}_{\mathrm{V}}(\mathrm{s})$ & - & Transfer function for flow part of control valve for natural gas \\
\hline h & - & Height of batch tank \\
\hline$h_{E}$ & - & Unit thermal conductance for radiant heat from hot gases to glass \\
\hline$h_{W}$ & - & Coefficient of convective heat transfer \\
\hline $\mathrm{H}$ & - & Height of burner above batch tank floor \\
\hline $\mathrm{H}_{\mathrm{T}}(\mathrm{s})$ & - & Transfer function for thermocouple \\
\hline $\mathrm{I}_{\mathrm{F}}(\mathrm{s})$ & - & $\begin{array}{l}\text { Laplace Transform of input current signal from primary controller to } \\
\text { secondary controller }\end{array}$ \\
\hline $\mathrm{J}$ & - & Moment of inertia of rotor and gearhead about output shaft \\
\hline $\mathrm{J}_{\mathrm{G}}$ & - & Moment of inertia of output shaft about its rotational axis \\
\hline $\mathrm{J}_{\mathrm{M}}$ & - & Moment of inertia of rotor about its rotational axis \\
\hline $\mathrm{J}_{\mathrm{M}^{\prime}}$ & - & Moment of inertia of rotor about output shaft \\
\hline $\mathrm{k}_{\mathrm{G}}$ & - & Thermal conductivity of glass \\
\hline
\end{tabular}




\begin{tabular}{|c|c|c|}
\hline $\mathrm{k}_{\mathrm{P}}$ & - & Potentiometer constant \\
\hline $\mathrm{k}_{\mathrm{R}}$ & - & Thermal conductivity of refractory walls \\
\hline $\mathrm{k}_{\mathrm{T}}$ & - & Amplifier gain of thermocouple \\
\hline $\mathrm{K}$ & - & Torsional stiffness \\
\hline $\mathrm{K}_{\mathrm{C}}$ & - & Torque-Voltage constant \\
\hline 1 & - & Length of batch tank \\
\hline $\mathrm{L}_{\mathrm{G}}$ & - & Level of glass inside batch tank \\
\hline $\mathrm{m}_{\mathrm{CO}_{2}}$ & - & Mass of carbon dioxide in exhaust \\
\hline $\mathrm{m}_{\mathrm{G}}$ & - & Mass of glass \\
\hline $\mathrm{m}_{\mathrm{H}_{2} \mathrm{O}}$ & - & Mass of water vapor in exhaust \\
\hline $\mathrm{M}_{\mathrm{G}}$ & - & Mass of output shaft in gearhead \\
\hline $\mathrm{M}_{\mathrm{GP}}$ & - & Pull rate of glass \\
\hline $\mathrm{M}_{\mathrm{M}}$ & - & Mass of rotor \\
\hline $\mathrm{n}$ & - & Gear ratio \\
\hline $\mathrm{Nu}$ & - & Nusselt number \\
\hline $\operatorname{Pr}$ & - & Prandtl number \\
\hline$\dot{Q}_{B}$ & . & $\begin{array}{l}\text { Rate of energy available at burner due to combustion of natural } \\
\text { gas with oxygen }\end{array}$ \\
\hline$r_{\mathrm{G}}$ & - & Radius of output shaft in gearhead \\
\hline$r_{M}$ & - & Radius of rotor \\
\hline $\mathrm{R}$ & - & Input impedance of current-to-position converter \\
\hline $\mathrm{R}_{\mathrm{E}}$ & - & Thermal resistance of products of combustion \\
\hline $\mathrm{R}_{\mathrm{G}}$ & - & Heat transfer resistance of glass and refractory \\
\hline
\end{tabular}




\begin{tabular}{|c|c|c|}
\hline $\operatorname{Re}$ & - & Reynolds number \\
\hline $\mathrm{S}$ & - & Sensitivity of thermocouple \\
\hline $\mathrm{S}_{\mathrm{G}}$ & - & Conduction shape factor referenced to glass level \\
\hline $\mathrm{T}$ & - & Output torque of $\mathrm{AC}$ motor \\
\hline $\mathrm{T}_{\mathrm{A}}$ & - & Sensed temperature in batch tank \\
\hline$\frac{\mathrm{dT}_{\mathrm{A}}}{\mathrm{dt}}$ & - & Time rate of change of sensed temperature in batch tank \\
\hline $\mathrm{T}_{\mathrm{BTC}}(\mathrm{s})$ & - & Transfer function of closed-loop model for batch tank during cooling \\
\hline $\mathrm{T}_{\mathrm{BTM}}(\mathrm{s})$ & - & Closed-Loop transfer function with controller for melting period \\
\hline $\mathrm{T}_{\mathrm{BTP}}(\mathrm{s})$ & - & Transfer function of closed-loop model for batch tank during working \\
\hline $\mathrm{T}_{\mathrm{C}}$ & - & Temperature of combustion \\
\hline $\mathrm{T}_{\mathrm{E}}$ & - & Average temperature of products of combustion \\
\hline $\mathrm{T}_{\mathrm{G}}$ & - & Temperature of glass \\
\hline$\frac{\mathrm{dT}_{\mathrm{G}}}{\mathrm{dt}}$ & - & Time rate of change of glass temperature in batch tank \\
\hline $\mathrm{T}_{\mathrm{P}}$ & - & Ambient temperature of plant \\
\hline $\mathrm{T}_{\mathrm{R}}$ & - & Set-point temperature \\
\hline $\mathrm{T}_{\mathrm{r}}$ & - & Response time of thermocouple \\
\hline $\mathrm{V}_{\mathrm{r}}$ & - & Voltage in reference winding of $\mathrm{AC}$ motor \\
\hline $\mathrm{V}_{\mathrm{c}}$ & - & Voltage in control winding of AC motor \\
\hline $\mathrm{V}_{\mathrm{C}}(\mathrm{s})$ & - & Laplace transform of line voltage \\
\hline$\dot{\mathrm{V}}_{\mathrm{F}}(\mathrm{t})$ & - & Volume flow rate of natural gas through control valve \\
\hline $\mathrm{V}_{\mathrm{G}}$ & - & Volume of output shaft \\
\hline $\mathrm{V}_{\mathrm{T}}(\mathrm{s})$ & - & Laplace transform of output voltage from thermocouple \\
\hline
\end{tabular}


$\mathrm{V}_{1}(\mathrm{~s}) \quad$ - Laplace transform of voltage developed across input impedance

$\mathrm{V}_{2}(\mathrm{~s}) \quad$ - Laplace transform of voltage output from feedback potentiometer

$\Delta \mathrm{V}_{\mathrm{CCW}}(\mathrm{s})$ - Laplace transform of change in output voltage to operate $\mathrm{AC}$ motor when running in counter-clockwise direction

$\Delta \mathrm{V}_{\mathrm{CW}}(\mathrm{s})$ - Laplace transform of change in output voltage to operate $\mathrm{AC}$ motor when running in clockwise direction

$\Delta \mathrm{V}_{\mathrm{X}}(\mathrm{s})$ - Laplace transform of change in output voltage to operate $\mathrm{AC}$ motor

w $\quad-\quad$ Width of batch Tank

$\varepsilon_{\mathrm{E}} \quad-\quad$ Emissivity of products of combustion

$\eta \quad$ - Efficiency of burner

$\theta \quad-\quad$ Angular displacement of output shaft

$\Delta \theta \quad-\quad$ Change in angle output obtained at end of AC motor shaft

$\Delta \theta^{\prime} \quad-\quad$ Change in angular displacement at end of connecting link

$\rho_{g} \quad-\quad$ Density of glass

$\rho_{\mathrm{w}} \quad-\quad$ Density of steel

$\tau \quad$ - Time constant for thermocouple 


\section{Chapter 1. Introduction}

\subsection{Background}

The U.S. glass industry is experiencing competitive pressure from foreign manufacturers and from alternative materials for traditional glass products. The number of glass companies in the United States has dwindled from 232 plants in 1980 to just 166 plants in 2000 [1]. Home to more than 500 handmade glass making companies at the turn of the $20^{\text {th }}$ century, West Virginia is now home to only 21 . The reasons for this downward trend are the intensive capital, higher energy costs, more stringent environmental regulations, competition from low cost regions and cheaper alternative products. Depleting non-renewable sources of energy, increasing global population and rudimentary renewable sources of energy have compounded the situation. This trend can be reduced by making the glass making process more cost-efficient and profitable. The dying glass industry can be saved by developing new products, new sales techniques, improving quality control and at the same time, reducing the cost.

Technology is one key to reducing the burgeoning energy costs. Today's glass industry is constantly trying to reduce costs through improved techniques. By carefully analyzing the design of the batch tank, certain enhancements can be identified and incorporated. The design can also be modified to make the process more productive. Modeling has increasingly become an economical way to test changes designed to increase energy efficiency. One of the major drawbacks of the present operating policies of oxy-fuel fired batch tank is that they are based on the steady-state system behavior. However, the steady state model does not take into account the substantial variations that occur during the working periods and the resulting transients. Thus, the effectiveness of 
using control algorithms based on steady state models for short-term (less than 24 hours) control is largely in question. Owing to the increasing costs of energy, the higher demands on the quality of glass and the need to decrease $\mathrm{NO}_{\mathrm{x}}$ emission, the glass industry needs more detailed information concerning the processes in glass melting tanks. The use of reliable models is necessary for the design and control of these furnaces. Therefore, it is justifiable to study the dynamic control of transient processes in an attempt to increase the efficiency of daily operations for existing batch tank systems.

Also, in recent years, the glass industry has shown a clear trend for the production of glass of higher quality. This is achieved through better control of the processes in glass melting furnaces and batch tanks. Advanced methods to predict accurately the fluid flow, combustion and the heat transfer inside the batch tank will help in developing reliable models.

The Projects with Industry graduate research effort has continued enhancing the controls aspect for the design of oxy-fuel fired batch tank in the hand glass industry of West Virginia. Jim Rhodes' efforts on modeling were based on actual batch tanks in operation in industry [2]. Current research will be to assess the best behavior for the transient behavior of actual batch tanks being planned or now in operation.

\subsection{Industrial Connections}

A clear understanding of the elements in an oxy-fuel fired batch tank is required to accurately model it. Various visits were made to glass plants to obtain the required parameters. The visits also helped in understanding the operation policy and problems faced in existing glass industry companies. 
The first contact was with the L. E. Smith Glass Company, Mt. Pleasant, PA, one of the first glass companies to implement oxy-fuel fired combustion systems in the region. Established in 1907, the L. E. Smith Glass Company is one of only a handful of American hand-glass companies remaining. The glass company has three day-tanks, each with a capacity of three tons, and one continuous tank with a capacity of 60,000 tons. Mr. Harry Fontana, Technical Director of the plant, was the primary contact of this research project. This visit was exclusively made for identifying the elements that form the batch tank. Vital information regarding operating conditions and hardware was obtained during the visit.

The second contact was with Mr. Bob Lynch at the Davis-Lynch Glass Company in Star City, WV. This contact was especially useful because of its proximity to the research team at West Virginia University. Also, the Davis-Lynch Glass Company offered the opportunity to compare computer based control with human control. The company has three day-tanks and is taking giant strides in improving their technology.

The third contact was with Mr. Mike Rhoades at Glassworks WV in Weston, WV. Trips made to the plant helped in understanding the design of pipe trains. Glassworks WV has a single continuous furnace. The visits also helped in understanding glass melting techniques for varied production lines.

Contact with Mr. Bob Jones at Weiss Instrument Inc. in Pittsburgh, PA was helpful in obtaining valuable information on the working of electric-actuated control valves. Conversations with Mr. Jones were beneficial in the development of the transfer function for the electric-actuated control valve. 
Another important contact was Dr. Ron D. Argent, President and CEO of Argent Enterprises Incorporated. This was especially useful for obtaining information regarding furnace design, refractory properties and heat flow characteristics.

Last but not least, through a relationship with the Society of Glass Sciences and Practices, the Projects with Industry Program team was provided with the opportunity to meet with key people from the hand glass industry of the region. This association was helpful in establishing industrial contacts, identifying problems faced in the glass industry and enhancing the potential of the project.

\subsection{Modeling in Glass Industry}

In the field of glass melting, research effort has existed to model the combustion process, as indicated by the number of publications dealing with numerical studies. Experimental investigations of glass furnaces are difficult and prohibitive because of the high temperatures involved. Most of the models are based on experimental data collected in laboratory scale combustors. Joint efforts of experimentalists and theoreticians will contribute to the development of cost-effective tools capable of improving the performance of combustion systems. Experts in the field, both from universities and the industry, have made great contributions in helping to understand the melting process. Mathematical modeling of a glass furnace was developed in the 1980s. The modeling was based on air-fuel combustion systems early on and the emphasis shifted to oxygenfired systems during the 1990s.

L. Post and C. J. Hoogendoorn modeled combustion and the radiative heat transfer in glass furnaces using different models in 1989 [3]. In Europe, oxygen-melting technologies gained momentum earlier than in North America. Researchers like 
Dominique Jouvaud and Jean-Francois l'Huissier at Le Conseil Régional de Concertation et de Développement (CRCD) Research Center in France modeled convective and radiative heat transfer in glass furnaces with pure oxygen melting [4]. They corroborated the practical experience that melting efficiencies improves with oxygen combustion. The use of advanced mathematical simulation models for glass furnaces have also been reported by Gosman, et al [5], Carvalho, et al [6], Ungan and Viskanta [7]. A 3-D glassmelt model has also been reported by Simonis, et al [8]. The interaction between conduction, convection and radiation heat transfer in molten glass has been studied with specific reference to the forehearth of a glass furnace by Roychowdhury and Srinivasan [9].

Experimentally, publications are almost non-existent because of the expense and the difficulty of setting up a measurement system. Farmer, et al [10] and Victor, et al [11] implemented a new-furnace control scheme based on measurements and modeling of the combustion process. Efforts were also undertaken by Newbold, Webb, et al [12] to obtain combustion measurements in industrial gas-fired flat-glass furnace.

\subsection{Chapter Overviews}

Chapter 1 deals with the background of the project and earlier research conducted in the field of modeling in the glass industry. The various industrial connections during the course of this thesis are also discussed here. Chapter 1 also discusses the focus and the six objectives of the transient study of the batch tank.

Chapter 2 describes the glass melting process and the advantages of oxy-fuel firing. It also discusses the development of oxy-fuel combustion systems. Then the 
design specifications of the different components in the oxy-fuel combustion system are explained.

Chapter 3 provides the mathematical models for the batch tank components such as the electric-actuated control valve, the burner and the thermocouple. MATLAB and Simulink programs for the development of the model are illustrated in Appendix A.

Chapter 4 deals with the development of the transfer function model for the glass element in the batch tank. The transfer function of the glass during the working period is considered as an extension of this model with the transient aspects incorporated.

Chapter 5 discusses the development of a controller for the oxy-fuel fired batch tank model using the classical approach. This will include Bode and root locus plots for steady state analysis of the batch tank. Transient responses were also studied for step inputs. A lead-lag controller was designed to provide a reasonable gain margin and phase margin for the batch tank. A Graphical User Interface (GUI) program called SISOTOOL of the Control System Toolbox in MATLAB was used to develop the controller.

Chapter 6 highlights the transient variation of the parameters defining the heat transferred to the glass. This chapter also shows the economic benefits from this venture.

Chapter 7 discusses the methods employed to achieve the results of this endeavor. MATLAB codes employed for obtaining the solutions are explained and validated.

Chapter 8 features the summary and the results of this endeavor. The approach and accomplishments are listed in this chapter.

Chapter 9 summarizes the conclusions of this research project. It also identifies future work that may be extended from this research. 


\subsection{Research Focus}

Earlier research has focused on the development of a controller based on experimental data recorded from batch tanks in operation. During the working period, glass is being pulled out from the tank. Since the glass temperature is to be uniform, there is a potential to cut down on the supply of natural gas to the burner. Currently, the excess energy goes into waste, either as more heat transferred to the walls or as heat transferred up the stack as exhaust. By reducing the burner supply, a reduction in energy consumption is obtained without any compromise on the heat transfer to the glass. The operating procedure for the controller of a batch tank is reviewed in this thesis considering the transient phenomenon that occurs during the working period.

The critical components in the batch tank were identified during visits to glass companies. Specifications were obtained from manufacturers and people from the glass industry.

Specifications of different components are discussed in Chapter 2. The pipe train supplies the specified amount of natural gas and oxygen to the batch tank. The elements in the pipe train, which contribute to the flow rate of gases, are identified here. The electric-actuated valve is the crucial control component for the batch tank. Appendix A shows MATLAB and Simulink programs to simulate the performance of the electricactuated control valve of the natural gas valve.

The heat transfer to the glass during this period was studied using classical theory. Combining two conservation of energy equations, the transfer function for the heat transfer to the glass was developed. Thermal resistances and capacitances were used to define the heat transfers to the glass. The geometry of the batch tank plays a key role in 
the heat transfer to the batch tank. As the glass is pulled out, more refractory walls are exposed and there is a reduction in the heat transfer to the walls from the glass. This will reduce the resistance of the glass transfer function. The mass of the glass inside the tank reduces with time. Thus, the capacitance of the glass also reduces with time during the working period. This information was used for the transient analysis of the batch tank. MATLAB programs for the development of transfer function for the batch tank are illustrated in Appendix A. Based on the closed-loop model developed for the oxy-fuel batch tank, controllers were designed for different operating policies. Appendix B shows the MATLAB and Simulink models used for the development of the controller. Appendix $\mathrm{C}$ shows the mathematical model for the transfer function of the electricactuated valve for oxygen.

Chapter 6 focuses on the heat transferred to the glass by radiation and convection. By studying the geometry of the batch tank, the contributions of various modes of heat transfer were calculated. The economic aspects of this endeavor are also discussed here. Appendix D shows the spreadsheet calculations employed for calculating the variation of heat transfer parameters during the working period. Appendix E features some calculations on the emissivity of the radiant heat from the flame to the glass. Appendix F calculates the amount of dollars saved during an operating cycle as a result of this endeavor. By introducing LabVIEW in the hand glass industry, applications were prepared to measure and log temperatures at glass industry plants. Appendix G illustrates the LabVIEW virtual instruments (VIs) designed for the data acquisition. 


\subsection{Research Objectives}

The six main objectives of this thesis are listed below:

1. Model the key components in a batch tank.

2. Explain the transient behavior of an oxy-fuel fired batch tank during the working period.

3. Define a list of controller equipment specifications.

4. Design an enhanced controller, which incorporates amount of glass pulled.

5. Study the performance of the modeled closed-loop batch tank.

6. Acquire time responses of sample temperatures using LabVIEW. 


\section{Chapter 2. Specifications of an Oxy-Fuel Fired Batch Tank}

\subsection{Glass Melting}

Glass melting has a very long history. One of the most significant changes in the process of glass melting is the use of oxy-fuel combustion. Every conceivable chemical has been used at one time or the other in the melting of glass. Silica is the principal ingredient and is mixed in varying proportions with soda, lime, alumina, magnesia, etc for different applications. The quality of glass depends in part on the purity of the ingredients.

All materials are crushed and granulated to nearly uniform particle size, stored in batch towers, and fed into the melt tank in carefully measured amounts. Recycled glass, called cullet, constitutes a significant percentage of the ingredients. Temperatures up to $1400^{\circ} \mathrm{C}\left(2600^{\circ} \mathrm{F}\right)$ melt the batch and convert it into molten glass. The residence time of glass in a batch tank may be as much as 24 hours. These temperature and time conditions are necessary because glass is a viscous material even at high temperatures. Glass is maintained at a temperature of $2600^{\circ} \mathrm{F}$ for up to 8 hours to rid the glass of small bubbles, seeds from refractory material falling into the molten glass, etc in a period known as the conditioning period.

\subsection{Comparison of Oxy-Fuel and Air-Fuel Combustion}

Combustion can be defined as the rapid chemical reaction of two or more substances with a characteristic liberation of heat and light; it is commonly called burning. In the case of melting of glass, one of the substances is a combustible material, natural gas and the other is an oxidizer. Due to its availability, air is generally used for combustion of natural gas. The composition of air by volume is approximately $79 \%$ 
nitrogen, $20 \%$ oxygen and $1 \%$ moisture and trace gases. The component in air that is significant to combustion is oxygen. Huge amounts of nitrogen, in the range of $1000 \mathrm{ft}^{3}$, enter the batch tank at near room temperature and leaves the batch tank at the exhaust temperature, thus, absorbing and then carrying a significant amount of heat out of the furnace. About $40 \%$ of heat released is lost in the glass melting process due to the moisture and the nitrogen present in the air. Also, nitrogen reacts with oxygen at high temperatures to form hazardous $\mathrm{NO}_{\mathrm{x}}$.

Oxy-fuel firing of glass batch tanks has represented an important recent step forward in the evolution of glass melting. Oxy-fuel combustion refers to the practice of totally replacing air as the source of oxidizer for combustion with industrial grade oxygen. Industrial grade oxygen is defined as liquid oxygen, vaporized to a gas, or oxygen generated on-site. It is a technology that allows increases in energy efficiency while at the same time allows reductions in air pollution. When production increases are needed for an air-fired combustion system, more air is consumed and more $\mathrm{NO}_{\mathrm{x}}$ is produced. The only way to significantly reduce $\mathrm{NO}_{\mathrm{x}}$ before the advent of oxy-fuel firing was to use electric boosting, reduce production, or to post-treat the exhaust with catalytic or non-catalytic methods [13]. Oxy-fuel firing reduces the amount of $\mathrm{NO}_{\mathrm{x}}$ produced by the reduction of nitrogen in the combustion process. Also, the oxy-fuel flame provides better heat penetration into the batch tank because it is more radiative. So less energy is consumed for the same amount of glass melted. The L. E. Smith Glass Company at Mt. Pleasant, PA reports a reduction of up to $66 \%$ in energy consumption for the same amount of melted glass with oxy-fuel technology [14]. By the early 1990s, oxy-fuel burners were developed to physically replace the existing air burners. 
The advantages of oxy-fuel combustion can be attributed to the two aspects of the physical/chemical process. The adiabatic flame temperature increases in the absence of nitrogen. Radiative heat transfer from the flame to the batch also increases due to the higher flame temperatures and the reduced combustion products, which contain only $\mathrm{CO}_{2}$ and $\mathrm{H}_{2} \mathrm{O}$.

The suppression of nitrogen from the combustion process increases the flame temperature and reduces the volume of combustion products. It also increases the vapor pressures of $\mathrm{CO}_{2}$ and $\mathrm{H}_{2} \mathrm{O}$. Since the emissivity of a gas is directly proportional to its vapor pressure, these increased vapor pressures markedly increase the radiative heat transfer of the oxy-fuel flame. The combustion process also does not heat any nitrogen to increase the volume of exhaust gases. The chemical energy release is concentrated into a smaller volume because nitrogen does not dominate the exhaust products. For the same energy input, the volume of the exhaust products for oxy-fuel fired systems takes only $30 \%$ of that for air-fuel fired systems. Heat transfer from a flame to the batch occurs by convection and radiation. Radiation heat transfer is sensitive to the temperature of the flame and composition of the exhaust products. Nitrogen is a poor radiative media in glass batch tanks. Suppression of nitrogen allows the oxy-fuel flame to be an intense and highly efficient source of heat flux to the glass. The velocity profile for an oxy-fuel combustion system is lower than that for an air-fuel fired system [4]. As a result, the heat flux transferred from the oxy-fuel flame is almost entirely radiative. Thus, the design of oxy-fuel combustion systems cannot be considered as an extrapolation of air-fuel combustion systems design. Research has also shown that the design of oxy-fuel batch tanks needs to be modified from that of air-fuel fired batch tank. This is because the 
ambient temperatures and the air require greater furnace lengths to transfer their energies to the glass [4].

The seven main advantages of oxy-fuel combustion are [13]:

1. Increased production per furnace; up to $20 \%$

2. Improved melter efficiency; up to $70 \%$

3. Reduced $\mathrm{NO}_{\mathrm{x}}$ emissions; up to $80 \%$

4. Reduced CO and particulate in exhaust stream; up to $70 \%$

5. Lowered exhaust temperatures, up to $15 \%$

6. Improved homogeneity and quality of melted glass

7. Improved access for furnace maintenance.

Research at the at Le Conseil Régional de Concertation et de Développement (CRCD) Research Center in France has proven that oxy-fuel melting would achieve the following more specific advantages [4]:

1. Reduce fuel consumption

2. Reduce volume of combustion products

3. Increase heat transfer to the batch and melted glass

4. Decrease crown temperatures

5. Increase furnace melting capacity

Oxy-fuel combustion systems improve the glass quality in a number of ways, including [15]:

1. Affect the glass melt flow patterns

2. Reduce superstructure refractory-related defects. 
Oxy-fuel fired furnaces are also by nature more energy-efficient and environmentally clean than air-fuel fired furnaces. Due to the above advantages, oxy-fuel combustion is emerging as a replacement for air-fuel combustion.

Researchers have pursued various methods for melting glass efficiently. Electric

melting is one of the most efficient methods since the energy is released directly in the melt. However, the prohibitive costs of the equipment, such as transformers and the electricity can make this method untenable except for boosting an existing glass melting process. Proper use of oxy-fuel combustion system can deliver many of the benefits of electric boosting while decreasing the melting costs.

\subsection{Oxygen Enhanced Combustion Methods}

Early oxy-fuel firing methods included oxygen-enrichment of the existing combustion air. Oxygen enrichment of combustion air refers to the process where oxygen is pre-mixed with the combustion air before the mixture is combusted with fuel. But there is a practical limit on the level of oxygen enrichment that can be used because of the increased oxidizing nature of the combustion air. Higher levels of oxygen enrichment can cause the burners to wear at an accelerated rate.

Another method was to employ undershot lancing of oxygen to the port of an airfuel burner. Undershot lancing is the practice of strategically injecting oxygen through a lance into the combustion region. The oxygen is injected on the underside of the flame to increase the flame temperature near the glass and thus increase heat transfer to the glass.

In the above two methods, air-fuel flames were augmented through the use of oxygen. All of the oxygen-enhanced combustion methods provide fuel savings to varying degrees. 
While the above has listed two advantages of oxygen combustion systems, there are also disadvantages associated with this system. Selection of materials for the design of pipe trains is crucial because an improper material could catch fire when subjected to high-pressure flowing oxygen. The flames produced by oxygen combustion systems have a very high temperature of about $4200^{\circ} \mathrm{F}$. Though this reduces the fuel consumption, it also can lead to rapid deterioration of the refractories. Higher flame temperatures in the presence of nitrogen increase $\mathrm{NO}_{\mathrm{x}}$ formation. Also, supplemental oxy-fuel boosting flames can overheat the glass locally, leading to glass defects such as cords and seeds. Corrosion of refractory is also increased when oxy-fuel burners are used. The selection of the best refractory technology can minimize potential corrosion problems.

\subsection{Specifications of Pipe Train}

\subsubsection{Introduction}

Pipe trains are used to supply natural gas and oxygen to the burner. Separate pipe trains are used for natural gas and oxygen. The pipe diameter for the oxygen pipe train will be slightly larger than that of natural gas. This is because the ratio of oxygen to natural gas for proper combustion is around 2.10 to 1.0. Since they have different diameters, the valve specifications for the two pipe trains will also be different.

Pipe trains carrying oxygen can pose problems if improperly handled. Oxygen promotes oxidation and care must be taken when transporting oxygen. However, with the right materials and intelligent design, oxygen-handling systems can deliver troublefree, safe performance. It is essential that all components and piping are "compatible" with oxygen. All oxygen contact metals should be stainless steel, copper, brass or bronze 
[16]. Figure 2.1 shows a picture of the pipe trains for a batch tank at the L. E. Smith Glass Company.

The large black box in the center of the picture is the primary controller for the batch tank. The primary controller plays a significant role in maintaining the proper ratio of gases going to the burner. Also, since both natural gas and oxygen are highly combustible, efforts are taken to monitor their flow rates. Thus, the controller serves two purposes: to control the flow rate of natural gas and oxygen to the batch tank burner and to shutdown the gas supply in case of a malfunction in any one of the pipes.

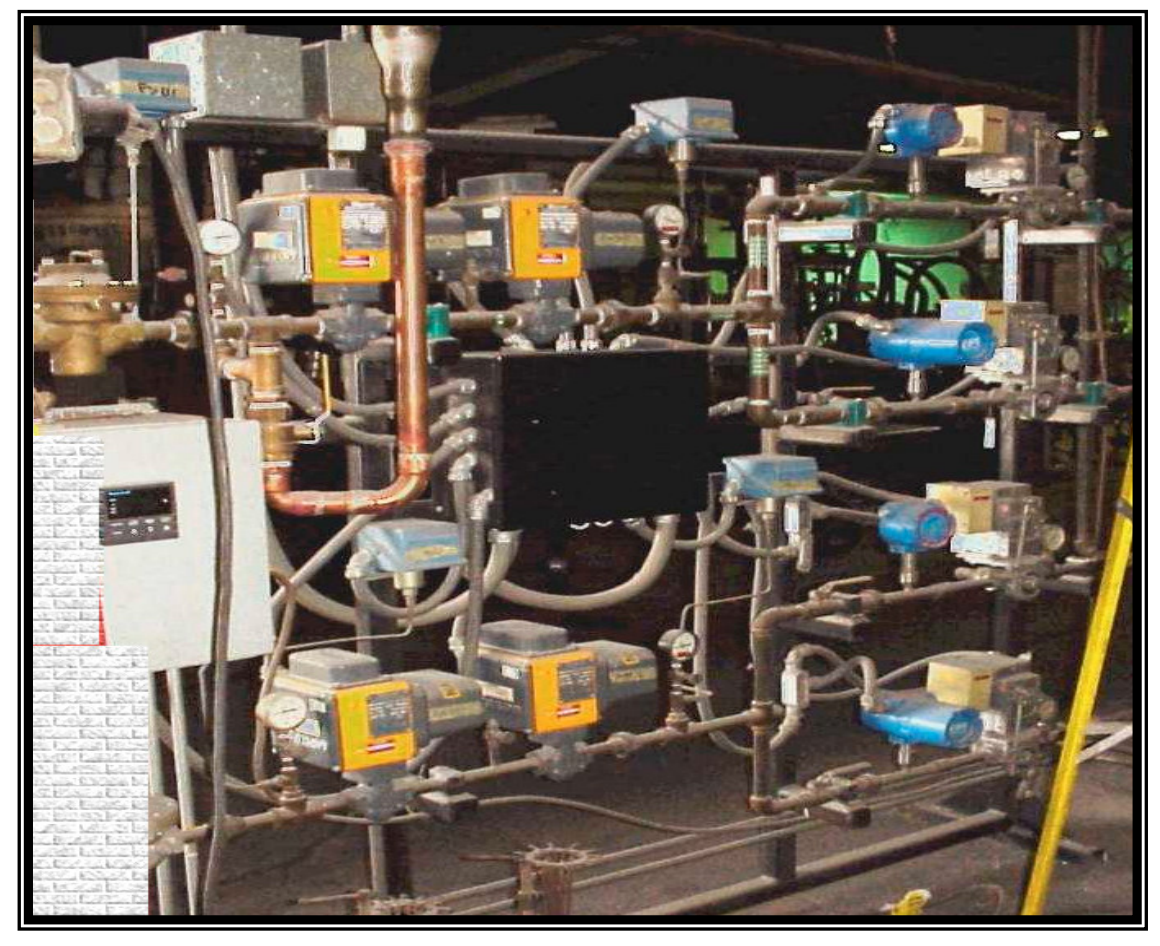

Figure 2.1 Picture of Pipe Trains

The controller maintains the temperature inside the batch tank. A thermocouple is used to obtain a feedback from the batch tank. If the temperature signal from the thermocouple is above or below the set required temperature, the controller sends a signal to the automatic valve to increase or decrease the flows of natural gas and oxygen to the 
burner. For example, AC motors located inside automatic valves open the valves to increase the flows of natural gas and oxygen to the burner, which would then increase the temperature inside the batch tank.

The second purpose of the controller is to ensure safety when a malfunction occurs in one of the two pipe trains. Pressure gauges are used to monitor the pressures of gases inside the pipe. When the controller receives a signal from one of the pressure gauge that the pressure is above or below either of two cut-off points, it sends a signal to the automatic valves on both pipe trains to shutoff the flows through them. This ensures that in the event of flow in one of the pipe trains getting obstructed, the other pipe train will also stop supplying flow to the burner.

\subsubsection{Pipe Train Design}

Figure 2.2 shows a schematic of the pipe trains with different elements, to supply natural gas and oxygen to the burner.

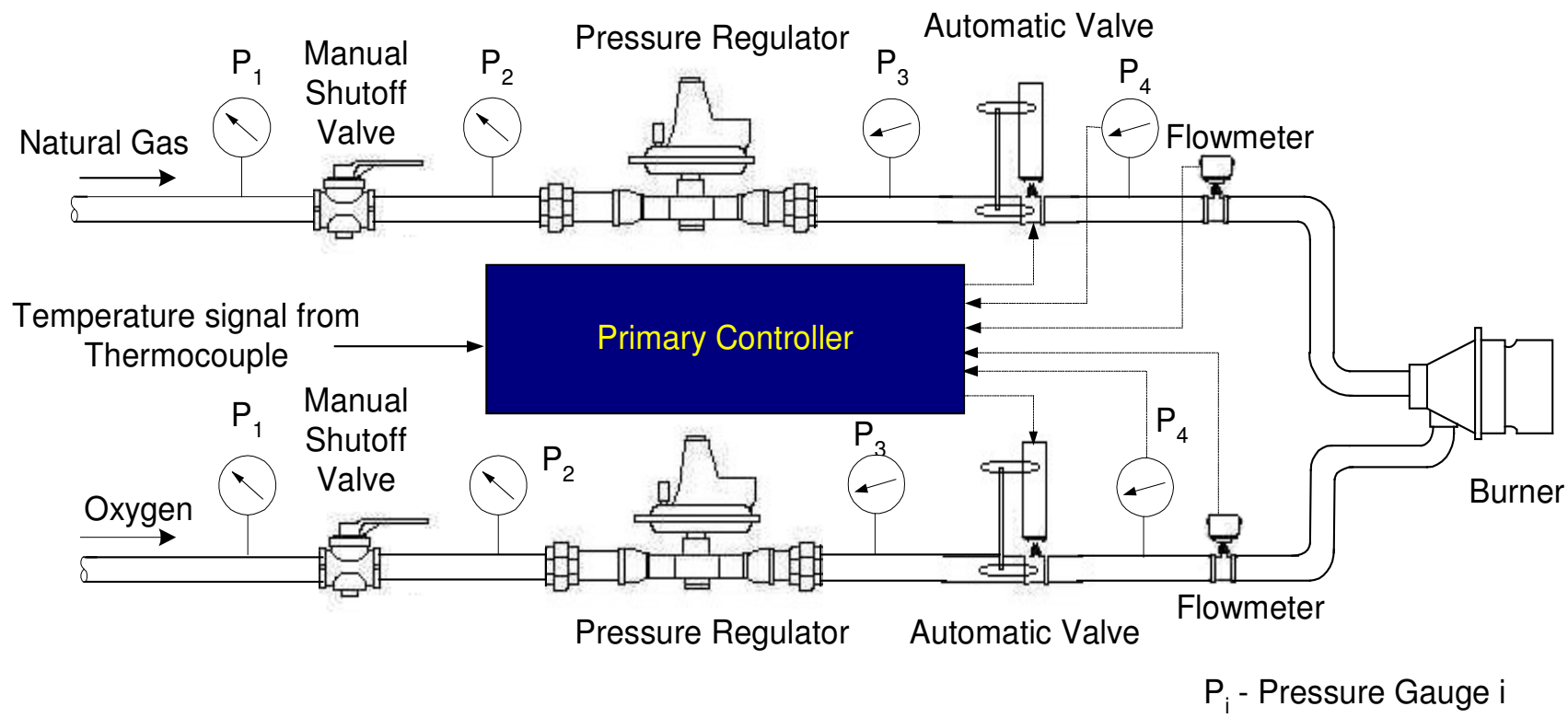

Figure 2.2 Schematic of Pipe Trains showing Different Elements 
The first component to be considered is the manual shutoff valve. It can be used to completely shutoff the flow of natural gas or oxygen. The function of the shutoff valves is to enable the flows to be manually shutoff whenever observed safety conditions are not met, whether pressure, temperature or flow, or when maintenance is required. Pressure gauges are placed before and after the manual shutoff valve to get an indication of its influence on the flow.

Typically, natural gas is supplied at a pressure of $15 \mathrm{psig}$. This has to be brought down to the typical working pressure of 6 psig. Similarly, the supply pressure of oxygen is typically $30 \mathrm{psig}$ and is to be reduced to the typical working pressure of $10 \mathrm{psig}$. This pressure reduction is accomplished using the pressure regulator. The function of the pressure regulator is to decrease and stabilize the delivery pressure that is acceptable at the burners, for proper operation. For example, a burner with a capacity of generating $900,000 \mathrm{BTU} / \mathrm{hr}$ requires the natural gas pressure at the burner inlet to be less than 8 psig to produce its generating capacity [17].

In the earlier days of actuated control valves, the fuel and the oxygen valves were mechanically linked so that the ratio of the flow rates remained a constant. Research has proved that there are inherent inefficiencies with this concept. But with the advent of the latest technology, the ability of the controller to control the fuel and oxygen independently has given users the capability to compensate for process changes that affect the oxy-fuel ratio.

Monitoring the flow inside the pipe train is done either using a turbine meter or using orifice plates. Both of these flow meters use differential pressure to determine the volume flow rate through the pipe train. 
The National Fire Protection Association (NFPA) code for pipe trains stipulates that any pipe train carrying oxygen in excess of $800 \mathrm{ft}^{3} / \mathrm{hr}$ must incorporate a second shut-off valve. This arrangement is known as the double-block arrangement and has not been shown in Figure 2.2. Sometimes a bleed arrangement incorporates the use of a pressure relief valve between the two shut-off valves.

Depending on the applications, there could be additional components on the pipe train. Typical options include thermometers, pressure transmitters and temperature transmitters. Necessity and cost are the two decisive factors in the selection of any other components.

\subsection{Specifications of Burner}

A burner is not only used to combust the natural gas and oxygen provided by the pipe trains, it also performs the following important functions:

1. Provides heat to the glass batch in the batch tank.

2. Controls the inside temperature of the batch tank.

3. Provides a high turndown ratio so that it does not shut off over the full range of the energy requirements for the batch tank.

4. Burns the fuel in the most efficient way possible to keep fuel consumption low.

The turndown ratio is the ratio of the burner's maximum firing capability to its minimum firing capability. Figure 2.3 shows a typical oxy-fuel burner used in the glass industry [17].

Current issues in the manufacture of high energy efficiency burners include the reduction of $\mathrm{NO}_{\mathrm{X}}$ emissions. This is achieved by increasing the luminosity and radiant heat transfer by modifying the fuel prior to combustion. 


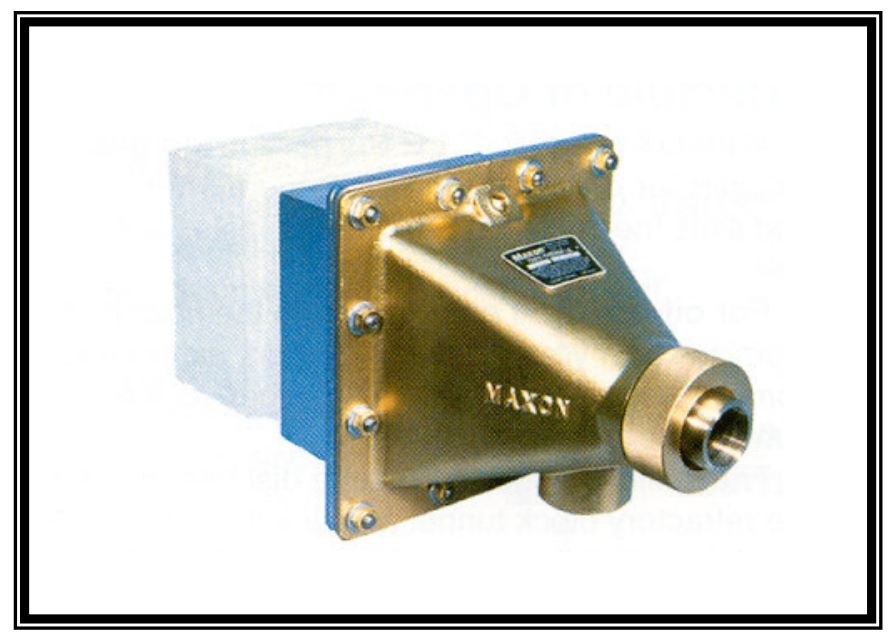

Figure 2.3 Oxy-Fuel Burner (Courtesy: Maxon Corporation)

These burners have two combustion zones. A small portion of the natural gas is burned in the pre-heating zone. The majority of the combustion occurs in the second, fuel-lean combustion zone. Increasing heat transfer rates while decreasing flame temperatures results in increased glass production and energy efficiency.

\subsection{Specifications of Batch Tank}

The typical production capacity of a batch tank is in the range of 1000 to $4000 \mathrm{lb}$ of glass per day. For this research, a batch tank with a daily production capacity of 3000 $\mathrm{lb}$ was chosen. The dimensions for this batch tank were chosen based on actual batch tanks of $3000 \mathrm{lb}$ capacity. Figure 2.4 shows the schematic of a typical $3000 \mathrm{lb}$ batch tank. The initial level of glass in the tank is about 20 inches and glass is pulled out at the end of the conditioning period till it is about 8 inches. A batch tank has a bottom, two side walls, two end walls and a crown. The crown is a curved surface placed directly above the glass. Therefore, it plays a very crucial rule in the heat transfer to the glass. Table 2.1 shows the dimensions of the batch tank in consideration. 


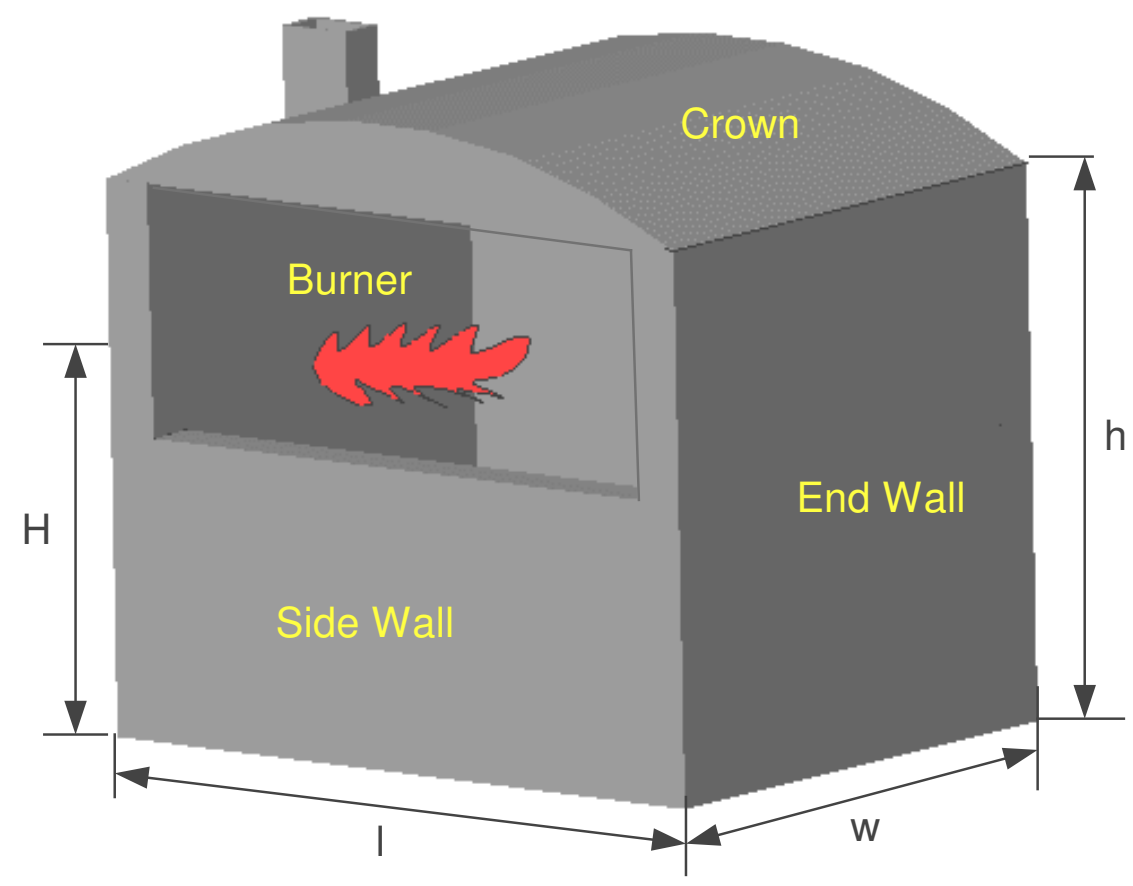

Figure 2.4 Schematic Drawing of an Oxy-Fuel Fired Batch Tank Table 2.1 Dimensions of Batch Tank

\begin{tabular}{|c|c|}
\hline Length, 1 , (ft) & 7.0 \\
\hline Width, w, (ft) & 5.5 \\
\hline Height, h, (ft) & 5.5 \\
\hline Thickness of Walls, $\mathrm{t}(\mathrm{ft})$ & 0.75 \\
\hline $\begin{array}{l}\text { Height of Burner above } \\
\text { Batch Tank Floor, } \mathrm{H}(\mathrm{ft})\end{array}$ & 3.50 \\
\hline $\begin{array}{l}\text { Height of Glass above } \\
\text { Batch Tank Floor, } \mathrm{L}_{\mathrm{G}}(\mathrm{ft})\end{array}$ & 2.00 \\
\hline Side Walls $(\mathrm{ft} x \mathrm{ft})$ & $7.0 \times 5.5$ \\
\hline End Walls (ft $x \mathrm{ft}$ ) & $5.5 \times 5.5$ \\
\hline Crown $(\mathrm{ft} x \mathrm{ft})$ & $7.0 \times 5.5$ \\
\hline Bottom (ft $x$ ft) & $7.0 \times 5.5$ \\
\hline Inner End Walls (ft $x$ ft) & $5.5 \times 4.0$ \\
\hline
\end{tabular}




\subsection{Specifications of Thermocouple Sensor}

A thermocouple is a temperature measurement sensor that consists of two dissimilar metals joined together at a junction that produces a small thermoelectric voltage when the junction is heated or cooled. The change in thermoelectric voltage is interpreted by the thermocouple meter as a change in temperature.

The most important considerations when selecting a thermocouple are the temperature range and the high and the low limits of the temperature to be measured. In a batch tank, the highest temperatures are typically $2500{ }^{\circ} \mathrm{F}$ and the lowest temperatures are typically $1900^{\circ} \mathrm{F}$. The type-K thermocouple was selected as it satisfied all the above requirements for temperature measurement in a batch tank. The type-K thermocouple consists of two metal alloy wires of Chromel (Nickel-Chromium) and Alumel (NickelAluminum) joined together. Table 2.2 lists the specifications of the feedback thermocouple employed.

Table 2.2 Specifications for Thermocouple

\begin{tabular}{|c|c|c|c|c|}
\hline Type & Metals & $\begin{array}{c}\text { Temperature Range } \\
\left({ }^{\circ} \mathrm{F}\right)\end{array}$ & $\begin{array}{c}\text { Voltage } \\
\text { Range }(\mathrm{mV})\end{array}$ & $\begin{array}{c}\text { Wire Diameters } \\
\text { (inches) }\end{array}$ \\
\hline $\mathrm{K}$ & $\begin{array}{c}\text { Nickel-Chromium \& } \\
\text { Nickel-Aluminum }\end{array}$ & -328 to 2600 & -5.89 to 54.9 & 0.032 \\
\hline
\end{tabular}

The set-point temperature is converted to a voltage signal in the controller (See Figure 2.2) and is then compared with the feedback voltage signal from the thermocouple. An error signal is generated if these voltages are different. Instruments to measure such small voltages accurately are very expensive. In order to avoid this, amplifiers are added to magnify the voltage generated by the thermocouple. This will also ensure the accuracy of any error signal. When thermocouples are used in a high 
temperature environment such as the batch tank, the radiant heat from the hot gases inside the tank can affect the readings of the thermocouple. Radiation shields were used so that the radiant heat did not affect the readings. The use of radiation shields ensures the accuracy of the readings at high temperatures.

Based on the specifications defined in Section 2.5, transfer function models were developed in Chapter 3 for the pipe trains, burner, batch tank and the thermocouple for an oxy-fuel fired batch tank. 


\section{Chapter 3. Transfer Function for Batch Tank Components}

This chapter derives the transfer function model of the components required for the proper functioning of the batch tank excluding the batch tank. These are the electricactuated control valve, the burner, and the thermocouple. Section 3.1 derives the transfer function for the electric-actuated control valve. Section 3.2 derives the transfer function for the burner and Section 3.3 derives the transfer function for the thermocouple. Once the transfer functions are derived, these can be combined with the transfer function of the batch tank derived in Chapter 4 to form the closed-loop model for the batch tank.

\subsection{Transfer Function for Electric-Actuated Control Valve}

\subsubsection{Introduction}

The temperature of a batch tank is controlled by comparing the measured temperature, $\mathrm{T}_{\mathrm{A}}$, of the batch tank to the desired temperature, $\mathrm{T}_{\mathrm{R}}$, for the batch tank, as shown in Figure 4.10. The error signal from the comparator, $\mathrm{E}(\mathrm{s})$, is sent to the batch tank controller, $\mathrm{G}_{\mathrm{C}}(\mathrm{s})$. A comparator is used to produce an error signal. The controller output, $\mathrm{I}_{\mathrm{F}}(\mathrm{s})$, is input to the current-to-position converter, which has a secondary controller. The secondary controller adjusts the voltage going to the actuator. A change in current from the controller drives the electric actuator in a direction to modify the burner combustion and return the process controlled to the set-point temperature.

In order to develop the transfer function of the secondary controller, one needs to understand the principle of its working. 


\subsubsection{Principle of Current-to-Position Converter}

The current-to-position converter manufactured by Eurotherm Controls [18] can be considered to be of three parts: the current-to-voltage converter; the secondary controller and the electric actuator. The output of the electric actuator is proportional to the input current from the primary controller. A built-in 100-ohm potentiometer in the electric actuator with wiper arm driven by the output shaft provides a correctional feedback signal to the secondary controller to produce the proportional action [19]. The output from the electric actuator is passed through input impedance of $0.0625 \mathrm{ohms}$. The voltage developed across this impedance is compared with the voltage developed across the potentiometer. Depending on the error signal, the comparator in the secondary controller activates one of two triacs. A triac is a solid state switch, which is activated when a voltage is applied to it. One of the triacs is connected so that activating it makes the AC motor rotate clockwise while activating the other triac makes the motor rotate counter-clockwise. Actuator position is proportionally controlled by the position of the transmitting slidewire.

\subsubsection{Transfer Function of Current-to-Voltage Converter}

The transfer function for the current-to-voltage converter, $\mathrm{G}_{\mathrm{I}}(\mathrm{s})$, is the value of the resistance in the circuit as shown in Equation 3.1.

$$
G_{I}(s)=\frac{V_{1}(s)}{I_{F}(s)}=R=0.0625\left[\frac{\text { volts }}{m A}\right]
$$

where

$V_{1}(s)$ - Laplace transform of voltage developed across input impedance, volts $\mathrm{R} \quad$ - Input impedance, ohms 
$\mathrm{I}_{\mathrm{F}}(\mathrm{s}) \quad$ Laplace transform of input current signal from the primary controller to the secondary controller, amperes.

\subsubsection{Transfer Function Model for Secondary Controller}

Depending on the error signal from the secondary controller, one of two triacs is activated. Activating triac $\mathrm{T}_{1}$ rotates the $\mathrm{AC}$ motor clockwise and activating triac $\mathrm{T}_{2}$ rotates the AC motor counter-clockwise. Assuming clockwise rotation of the shaft as positive, one obtains the transfer function of the current-to-position converter, $\mathrm{G}_{\mathrm{SC}}(\mathrm{s})$, as shown in Equation 3.2.

$$
G_{S C}(s)=\frac{\Delta V_{X}(s)}{\Delta E_{S}(s)}= \pm 1\left[\frac{\text { volts }}{\text { volts }}\right]
$$

where

$\Delta \mathrm{V}_{\mathrm{X}}(\mathrm{s}) \quad$ - $\quad$ Laplace transform of change in output voltage to operate

AC motor, volts.

$\Delta \mathrm{E}_{\mathrm{S}} \quad-\quad$ Laplace transform of change in error signal within secondary controller, volts.

$\mathrm{x} \quad-\quad$ Denotes direction of rotation of AC motor.

$\Delta \mathrm{V}_{\mathrm{CW}}(\mathrm{s}) \quad$ - $\quad$ Laplace transform of change in output voltage to operate AC motor when running in clockwise direction, volts.

$\Delta \mathrm{V}_{\mathrm{CCW}}(\mathrm{s}) \quad$ - $\quad$ Laplace transform of change in output voltage to operate AC motor when running in counter-clockwise direction, volts.

$\mathrm{G}_{\mathrm{SC}}(\mathrm{s})$ will have the error signal, $\Delta \mathrm{E}_{\mathrm{S}}(\mathrm{s})$, as its input. The sign of $\Delta \mathrm{V}_{\mathrm{X}}(\mathrm{s})$ is positive if the error signal $\Delta \mathrm{E}_{\mathrm{S}}(\mathrm{s})$ is positive and will be negative when the error signal is 
negative. In other words, a positive error signal, $\Delta \mathrm{E}_{\mathrm{S}}(\mathrm{s})$, rotates the $\mathrm{AC}$ motor in the clockwise direction and a negative error signal, $\Delta \mathrm{E}_{\mathrm{S}}(\mathrm{s})$, rotates the $\mathrm{AC}$ motor in the counter-clockwise direction.

A block diagram representation of a portion of the pipe train elements, including the controllers, is shown in Figure 3.1.

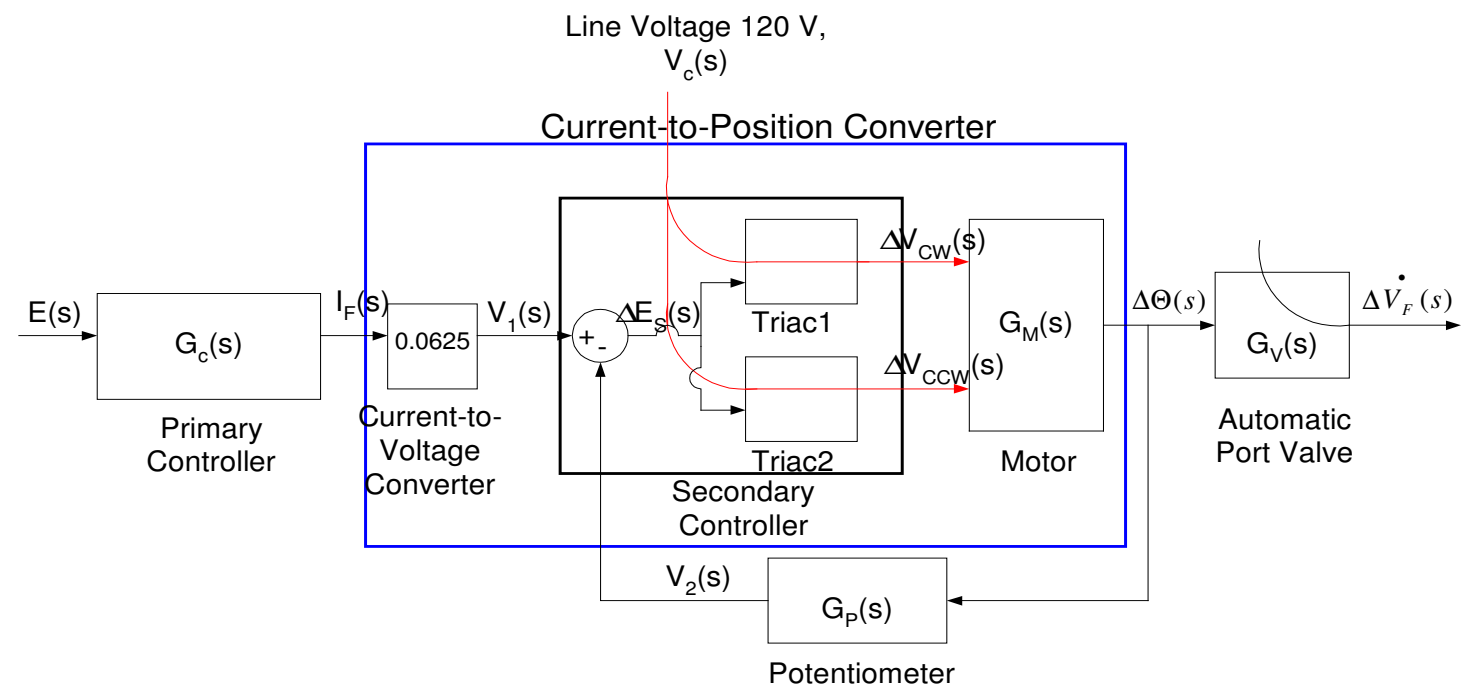

Figure 3.1 Block Diagram of Pipe Train showing Control Valve and Controllers

\subsubsection{Electric-Actuated Control Valve}

The control valve plays a crucial role in the control of modern plants. It varies the fluid flow; in this case the angular position of the valve, to change the process variable, in this case the flow of fuel to the tank burner in order to change the temperature of glass inside the batch tank, to the desired value.

This section derives the transfer function for the electric-actuated control valve. The electric-actuated control valve consists of two parts: the electric actuator part and the control valve part. The electric actuator receives the input voltage signal from the secondary controller and converts this to an equivalent angular displacement of the crank arm. The output torque is transmitted through a system of external crank arm and linkage 
to the control valve. The control valve converts this angular displacement of the crank arm to an equivalent flow of fluid through the pipe train.

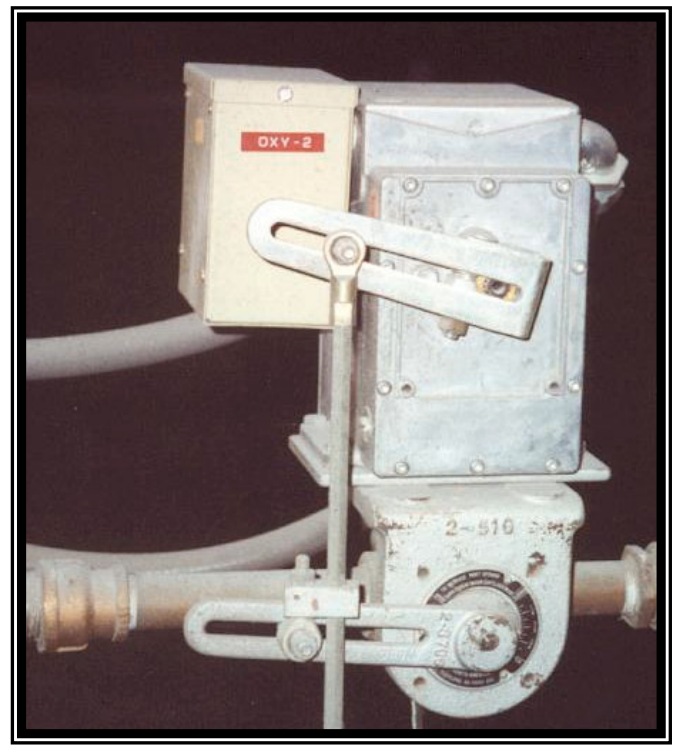

Figure 3.2 Picture of an Electric-Actuated Flow Controlled Valve

Many valve assemblies may be specified with an external crank-arm and linkage. Linkage between motor and valve can be characterized to produce the desired flow curve. Another advantage is that high seating torques required by certain valve types is obtained without over-sizing the drive. Linkages can be adjusted for full or limited valve travel. Figure 3.2 shows a picture of an electric-actuated valve [20].

\subsubsection{Actuator Part of Control Valve}

Actuators with integrated electronics are ideal for proportional positioning of combustion air dampers, valves and similar applications. The electric actuator used in association with the control valve, at the L. E. Smith Glass Company, is manufactured by Eurotherm Controls, Leesburg, VA. The advantage of using this actuator is that it offered flexibility in terms of stroke length. Stroke lengths of $90^{\circ}$ and $180^{\circ}$ are switchselectable. Other stroke lengths can be set using a simple push-button procedure. The microprocessor based integral control circuit accepts current, voltage and resistance input 
signals. Figure 3.3 shows a picture of an electric actuator manufactured by Eurotherm Controls [18].

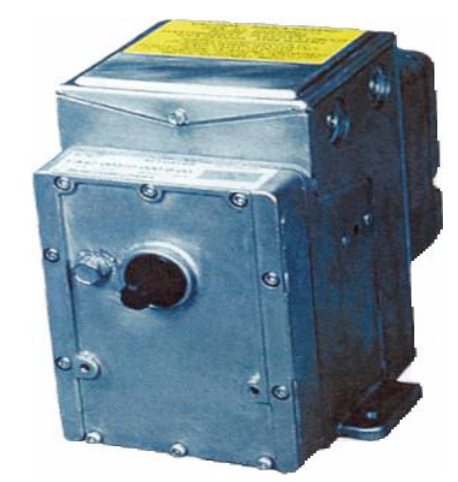

Figure 3.3 Picture of an Electric Actuator

(Courtesy: Eurotherm Controls)

The specifications of the electric actuator manufactured by Eurotherm Controls are shown in Table 3.1 [18].

Table 3.1 Specifications for Electric-Actuator Parameters

\begin{tabular}{|c|c|}
\hline Input Voltage & $120 \mathrm{~V}(\mathrm{ac})$ \\
\hline Rated Torque & $220 \mathrm{lb}-\mathrm{in}$ \\
\hline Allowed Ambient Temperatures & -40 to $136^{\circ} \mathrm{F}$ \\
\hline Physical Dimensions & 7 in. $\mathrm{H} \mathrm{x} \mathrm{5-3/8} \mathrm{in.} \mathrm{w} \mathrm{x} \mathrm{6-5/16} \mathrm{in.} \mathrm{D}$ \\
\hline Maximum Power Consumption & $45 \mathrm{~W}$ \\
\hline Weight & $8 \mathrm{lb}$ \\
\hline
\end{tabular}

The electric actuator employs an AC motor with a gear reducer to produce the output torque. In order to understand the working of the actuator, one needs to appreciate the principle of the $\mathrm{AC}$ motor.

\subsubsection{Principle of AC Motor}

An AC motor consists of two stator windings oriented $90^{\circ}$ apart in space as shown in Figure 3.4 [21]. Voltages of equal rms magnitude are applied to both the reference winding $\mathrm{V}_{\mathrm{r}}$ and the control winding $\mathrm{V}_{\mathrm{c}}$. These voltages however differ in phase by $90^{\circ}$. 


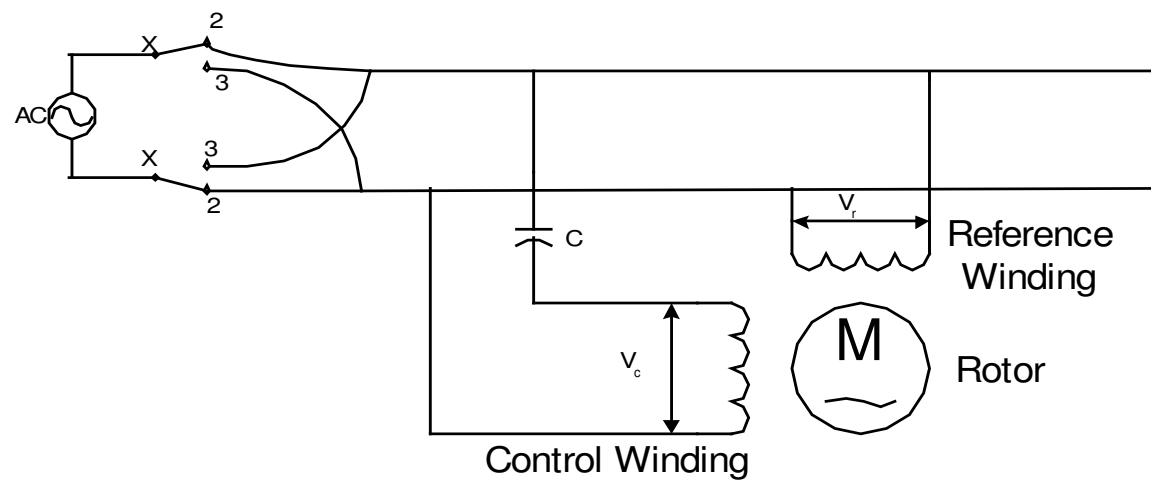

Figure 3.4 Wiring Diagram of AC Motor

In order to bring about this phase difference, a capacitor is inserted to shift the phase of the control voltage approximately $90^{\circ}$ with respect to $\mathrm{V}_{\mathrm{r}}$. Since the fields also differ by $90^{\circ}$ in space, the resultant is a magnetic field of constant magnitude rotating at a constant speed. As the field sweeps over the rotor, voltages are induced, with the resulting rotor currents and the rotating magnetic field interacting to produce a torque on the rotor in the direction of field rotation. The direction of rotation of the rotor depends on the lead or lag phase relation of $\mathrm{V}_{\mathrm{c}}$ to $\mathrm{V}_{\mathrm{r}}$. Switching the terminals changes the direction of rotation of the rotor. Connecting terminal $\mathrm{X}$ to terminal 2 will result in the motor rotating clockwise and connecting $\mathrm{X}$ to terminal 3 will rotate the rotor counterclockwise. The optimum angular position for the valve opening is obtained by switching between the terminals 2 and 3 .

\subsubsection{Transfer Function of AC Motor}

For a rotational system, the general equation of motion for a second-order system is expressed as shown in Equation 3.3.

$$
J \ddot{\theta}+D \dot{\theta}+K \theta=T
$$

where 
J - Moment of inertia of the rotor and gearhead about the output shaft, lb-in-s ${ }^{2} / \mathrm{deg}$.

$\theta \quad-\quad$ Angular displacement of output shaft, degrees.

D - $\quad$ Mechanical friction damping factor, lb-in-s/deg.

K $\quad-\quad$ Torsional stiffness, lb-in/deg.

$\mathrm{T} \quad$ - $\quad$ Applied torque, lb-in.

The applied torque is equal to the retarding wind and friction torques and the inertial torque. The mechanical friction torque is proportional to the angular velocity. In this case, since there is no torsional spring, the effect of the torsional stiffness can be neglected. Therefore, transforming Equation 3.3 into a Laplace transform description yields Equation 3.4 .

$$
T(s)=s^{2} J \Theta(s)+s D \Theta(s)
$$

The relation between output torque and input control voltage can be obtained from linearized characteristics as shown in Equation 3.5 [21].

$$
\Delta T=K_{C} \Delta V_{X}
$$

Substituting the values for torque and voltage from Table 3.1 in Equation 3.5, one obtains the value of $\mathrm{K}_{\mathrm{C}}$ as $1.83 \mathrm{lb}$-in/volt.

The ratio of $\mathrm{D} / \mathrm{J}$ is usually about 5. Using Equation 3.4 and Equation $3.5, \mathrm{G}_{\mathrm{M}}(\mathrm{s})$, the transfer function for the AC motor, is obtained as shown in Equation 3.6.

$$
G_{M}(s)=\frac{\Delta \Theta(s)}{\Delta V_{X}(s)}=\frac{K_{C}}{s^{2} J+s D}\left[\frac{\text { degrees }}{\text { volt }}\right]
$$


Due to the complex nature of its design, the calculation of the moment of inertia of the rotor and the gearhead has been done in Section 3.1.9.

\subsubsection{Calculation of Moment of Inertia of Rotor and Gearhead}

The specifications of the AC motor and the gearhead employed are specified in Table 3.2 [22].

Table 3.2 Specifications of AC Motor and Gearhead

\begin{tabular}{|c|c|c|}
\hline & Rotor & Gearhead \\
\hline Length (in.) & 4.2 & 2.9 (for shaft) \\
\hline Diameter (in.) & 3.54 & 0.5 (for shaft) \\
\hline Weight (lb.) & 4.1 & 2.8 \\
\hline Gear Ratio & - & $50: 1$ \\
\hline
\end{tabular}

The calculation of the moment of inertia can be illustrated using Figure 3.5. The difference in the speed of rotation between the output from the gearhead and the rotor has to be taken into consideration while calculating the equivalent moment of inertia.

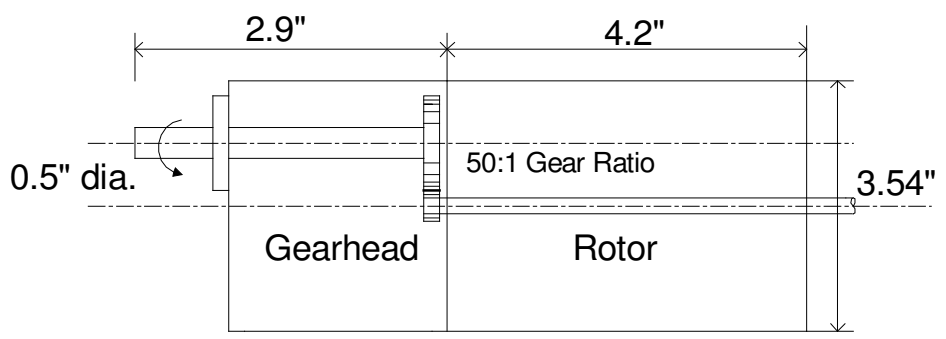

Figure 3.5 Schematic of Rotor and Gearhead

The moment of inertia of the rotor about its rotational axis, $\mathrm{J}_{\mathrm{M}}$, can be calculated using Equation 3.7.

$$
J_{M}=\frac{1}{2} M_{M} r_{M}^{2}
$$

where

$\mathrm{M}_{\mathrm{M}} \quad$ - $\quad$ Mass of the rotor of the motor, slugs.

$\mathrm{r}_{\mathrm{M}} \quad-\quad$ Radius of the rotor, in. 
Similarly the moment of inertia of the output shaft about its rotational axis, $\mathrm{J}_{\mathrm{G}}$, can be calculated using Equation 3.8

$$
J_{G}=\frac{1}{2} M_{G} r_{G}^{2}
$$

where

$\mathrm{M}_{\mathrm{G}} \quad$ - $\quad$ Mass of the output shaft in the gearhead, slugs.

$\mathrm{r}_{\mathrm{G}} \quad$ - $\quad$ Radius of the output shaft in the gearhead, in.

The mass, $\mathrm{M}_{\mathrm{G}}$, of the output shaft in slugs can be calculated using Equation 3.9.

$$
M_{G}=\frac{\rho_{w}}{g} V_{G}
$$

where

$\rho_{\mathrm{w}} \quad-\quad$ Weight density of steel, $0.3 \mathrm{lb} / \mathrm{in}^{3}$.

$\mathrm{V}_{\mathrm{G}} \quad-\quad$ Volume of output shaft, in ${ }^{3}$.

g - $\quad$ Acceleration due to gravity, $386 \mathrm{in} / \mathrm{s}^{2}$.

The two parameters of the output shaft are tabulated in Table 3.3.

Table 3.3 Parameters of Output Shaft in Gearhead

\begin{tabular}{l|c} 
Volume of output shaft, $\mathrm{in}^{3}$. & 0.63 \\
\hline Mass of output shaft, slugs & 0.0059
\end{tabular}

The moment of inertia of the motor about the output shaft, $\mathrm{J}_{\mathrm{M}^{\prime}}$, in $\mathrm{lb}$-in-s ${ }^{2} / \mathrm{deg}$, is obtained as shown in Equation 3.10.

$$
J_{M}^{\prime}=\frac{J_{M}}{n^{2}}
$$

where

$\mathrm{J}_{\mathrm{M}}$ - Moment of inertia of motor about its rotational axis, $1 \mathrm{~b}-\mathrm{in}-\mathrm{s}^{2} / \mathrm{deg}$.

Here the gear ratio, $n$, is $50 / 1$. 
Gears are required to convert the high RPM of the rotor to the lower RPM levels of the output shaft of the gearhead. The mass of the gears employed for this purpose is very small and hence the moment of inertia of the gears can be neglected for this analysis. The equivalent moment of inertia of the rotor of the motor together with the gearhead, $\mathrm{J}$ is obtained as shown in Equation 3.11.

$$
J=J_{G}+J_{M}^{\prime}
$$

The values for the different moments of inertia are tabulated in Table 3.4.

Table 3.4 Calculated Values of Moment of Inertia of Rotor and Gearhead

\begin{tabular}{|c|c|}
\hline Moment of Inertia & Calculated Value (lb-in-s $\left.{ }^{2} / \mathrm{deg}\right)$ \\
\hline $\mathrm{J}_{\mathrm{M}}$ & 0.78 \\
\hline $\mathrm{J}_{\mathrm{G}}$ & 0.00018 \\
\hline $\mathrm{J}_{\mathrm{M}^{\prime}}$ & 0.00032 \\
\hline $\mathrm{J}$ & 0.0005 \\
\hline
\end{tabular}

Substituting Equation 3.11 in Equation 3.6, the transfer function $\mathrm{G}_{\mathrm{M}}(\mathrm{s})$ of the $\mathrm{AC}$ motor is obtained as shown in Equation 3.12.

$$
G_{M}(s)=\frac{\Delta \Theta(s)}{V_{X}(s)}=\frac{3660}{\left(s^{2}+5 s\right)}\left[\frac{\mathrm{degs}}{\text { volt }}\right]
$$

\subsubsection{Transfer Function Model for Current-to-Position Converter}

In order to model the control valve accurately, one needs to understand the operation of the control valve. A few elements of the current-to-position converter in the block diagram shown in Figure 3.1 have the role of deciding when to change the signal from the secondary controller. These are the current-to-voltage converter and the feedback potentiometer. The signals coming from these elements decide the direction of the rotation of the motor. They do not contribute to the overall transfer function of the valve. 
The effect of the current-to-voltage converter, the feedback potentiometer and the secondary controller can be represented by a single transfer function. The final output of all these elements is the same as that of the secondary controller. The value of the equivalent transfer function, $G_{E Q}(s)$, will be +1 when the motor has to run clockwise and it will be -1 when the motor has to run counter-clockwise. Therefore, the equivalent transfer function can be written as shown in Equation 3.13.

$$
G_{E Q}(s)=\frac{\Delta V_{X}(s)}{I_{F}(s)}= \pm 1\left[\frac{\text { volts }}{\mathrm{mA}}\right]
$$

The simplified block diagram model of the current-to-position converter in Figure 3.1 is shown in Figure 3.6.

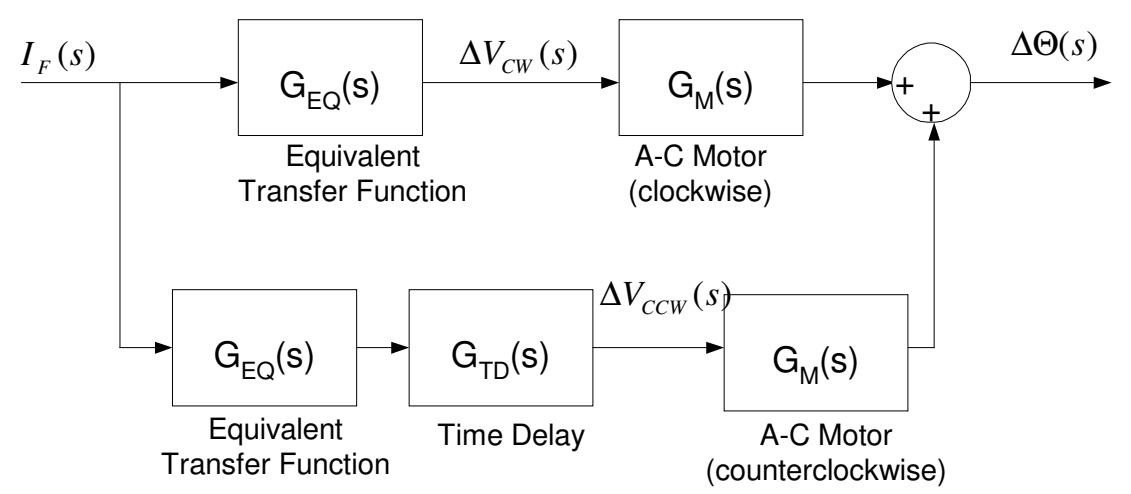

Figure 3.6 Simplified Block Diagram of Current-to-Position Converter

Initially, assume that the voltage developed from the feedback potentiometer is zero. Then the error signal going to the actuator, $\Delta E_{S}(s)$, will be positive and the motor starts rotating in the clockwise direction. The feedback potentiometer starts sending a feedback signal. This reduces the error signal coming from the secondary controller. The motor keeps rotating clockwise till the feedback signal from the potentiometer increases to a value greater than the voltage developed across the input impedance. Then the error signal becomes negative. There is a lag of about 0.005 seconds for this reversal to occur. When the tendency of the motor to go counter-clockwise becomes equal to the 
tendency to go clockwise, the motor is locked in position. This position is translated to the valve through the parallel-link mechanism. The valve sends the equivalent amount of gas to the burner.

The If subsystem in Simulink can be used to model the current-to-position converter because of the conditional nature of the output. The inputs to the If block determine the values of conditions represented as output ports. Each output port is attached to an Action subsystem. The conditions are evaluated top-down starting with the if condition. If a condition is true, its Action subsystem is executed and the If block does not evaluate any remaining conditions. The Simulink model and results for the control valve are shown in Appendix A. MATLAB was also used to validate the results of the Simulink model.

From Figure 3.6, the transfer function for the clockwise motion of the motor, $G_{C W}(s)$, can be obtained as shown in Equation 3.14.

$$
G_{C W}(s)=G_{E Q}(s) \cdot G_{M}(s)=\frac{+3660}{s^{2}+5 s}\left[\frac{\text { degrees }}{\mathrm{mA}}\right]
$$

In this case, the value of the equivalent transfer function will be +1 .

Also, the transfer function for the counter-clockwise motion of the motor, $G_{C C W}(s)$, can be expressed as shown in Equation 3.15.

$$
G_{C C W}(s)=G_{E Q}(s) \cdot G_{T D}(s) \cdot G_{M}(s)
$$

In this case, the value of the equivalent transfer function will be -1 .

The delay in the execution of the counter-clockwise motion of the motor can be expressed by the time delay transfer function, $G_{T D}(s)$. The time delay can be 
approximated as a transfer function by the Padé approximation method as shown in Equation 3.16.

$$
G_{T D}(s)=\frac{1-\left(T_{d} s / 2\right)}{1+\left(T_{d} s / 2\right)}
$$

where

$\mathrm{T}_{\mathrm{d}} \quad-\quad$ Delay in execution of counter-clockwise motion of motor, 0.005 seconds.

Substituting Equations 3.13, 3.16 and 3.12 in Equation 3.15, one obtains the transfer function, $G_{C C W}(s)$, as shown in Equation 3.17.

$$
G_{C C W}(s)=\frac{9.15 s-3660}{0.0025 s^{3}+1.013 s^{2}+5 s}\left[\frac{\text { degrees }}{\mathrm{mA}}\right]
$$

The output of the current-to-position converter is the cumulative effect of the motor running in both directions, as shown in Figure 3.6. Therefore, the transfer function for the current-to-position converter, $G_{C P}(s)$, can be obtained as the sum of the transfer functions $G_{C W}(s)$ and $G_{C C W}(s)$. Adding Equation 3.14 and 3.17, the transfer function for the current-to-position converter is obtained as shown in Equation 3.18. Appendix A illustrates the calculation of these transfer functions.

$$
G_{C P}(s)=\frac{\Delta \Theta(s)}{I_{F}(s)}=\frac{7320}{s^{2}+405 s+2000}\left[\frac{\text { degrees }}{\mathrm{mA}}\right]
$$

\subsubsection{Transfer Function of Parallel Link Mechanism}

The output torque from the AC motor is transmitted through a system of external crank arm and linkage to the control valve. The specifications of the crank arm and the connecting rod are given in Table 3.5 [18]. 
Table 3.5 Specifications of Crank Arm and Connecting Link

\begin{tabular}{|c|c|c|}
\hline Accessory & \multicolumn{2}{|c|}{ Specifications } \\
\hline Crank Arm & Splined Hole 17/64 in. & Adjustable Radius \\
& & $7 / 8$ to 3-1/8 in. \\
\hline Connecting Link & Diameter 5/16 in. & Length 20 in. \\
\hline
\end{tabular}

The effect of the external crank arm and linkage can be compared to a four-bar mechanism. The output torque obtained at the end of the four-bar mechanism will be some factor of the developed torque. This factor depends on where the linkage connectors have been placed along the splined shaft and the actual length of the connecting link used.

The transfer function for the parallel-link mechanism, $\mathrm{G}_{\mathrm{L}}(\mathrm{s})$, can be developed as shown in Equation 3.19.

$$
G_{L}(s)=\frac{\Delta \Theta^{\prime}(s)}{\Delta \Theta(s)}=k_{L}\left[\frac{\mathrm{deg}}{\operatorname{deg}}\right]
$$

where

$\mathrm{k}_{\mathrm{L}} \quad-\quad 0.4$ to 1.2 (using geometry, the value of $\mathrm{k}$ at the time of taking the readings was found to be 1.2)

$\Delta \Theta^{\prime} \quad-\quad$ Angular displacement at end of connecting link, degrees

$\Delta \Theta \quad$ - Angular output obtained at end of AC motor shaft, degrees.

\subsubsection{Position Feedback Potentiometer in Actuated Valve}

The actuator position is proportional to the input current from the primary controller. A built-in potentiometer in the actuator, with wiper arm driven by the output shaft, provides a feedback signal to the converter to produce the proportional action [23]. The error signal from the comparator drives the actuator in the direction to restore 
balance and return the process to the set-point. In order to develop the transfer function for the potentiometer, we need to understand its working.

\subsubsection{Principle of Working of Potentiometer}

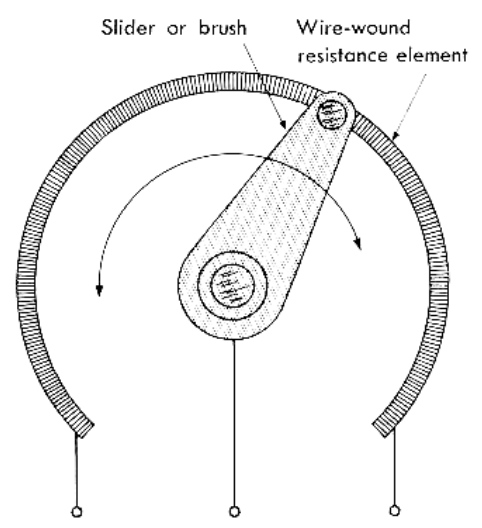

Figure 3.7 Angular-motion Potentiometer

Sliding contact devices convert a mechanical displacement input into an electrical output, either voltage or current. This is accomplished by changing the effective length of an electrical conductor. The resistance element is formed by wrapping a resistance wire around a form. A brush slides across the turns from one turn to the next as shown in Figure 3.7 [23]. This changes the effective resistance existing between either end of the wire and the brush thereby becomes a measure of the mechanical displacement. The resistance changes in finite steps as the contactor moves from turn to turn of the wire. As the resistance increases, the voltage feedback to the comparator decreases. This would send an error signal to one of the triacs to rotate the $\mathrm{AC}$ motor in the appropriate direction. 


\subsubsection{Transfer Function for Potentiometer}

When used as a measurement transducer, a linear potentiometer is normally selected. Use of the term linear assumes that the resistance measured between one of the ends of the element and the contactor is a direct linear function of contactor position to that end. At minimum input, the slidewire wiper is driven to the high end of the slidewire. The linear characteristics of the potentiometer can be represented as shown in Figure 3.8.

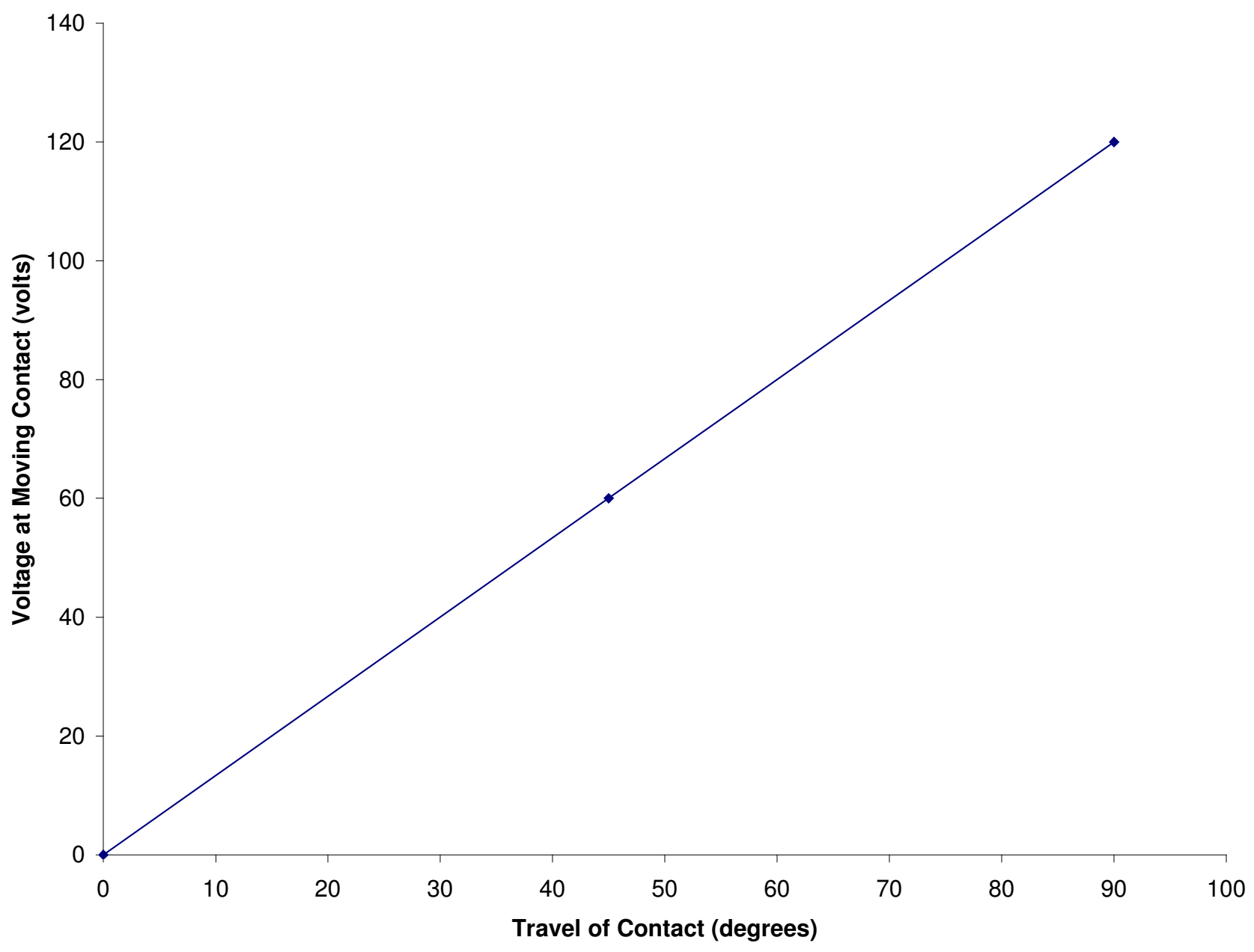

Figure.3.8 Characteristics of Feedback Potentiometer 
From the characteristics of the potentiometer, one can develop its transfer equation, $\mathrm{G}_{\mathrm{P}}(\mathrm{s})$, as shown in Equation 3.20. The slope of the straight line can be represented by a constant $\mathrm{k}_{\mathrm{P}}$.

$$
G_{P}(s)=\frac{V_{2}(s)}{\Delta \Theta^{\prime}(s)}=k_{P} \quad\left[\frac{\text { volts }}{\text { degree }}\right]
$$

where

$\mathrm{V}_{2}(\mathrm{~s})$ - Voltage output from the feedback potentiometer, volts

The value of $k_{P}$ for this potentiometer is around 1.33 volts/degree.

\subsubsection{Principle of Working of Control Valve}

Control valve assemblies operate by double action. The internal view of the valve is shown in Figure 3.9 [24]. The sliding action is set by positioning the core-adjusting knob. The knob can be positioned to keep the core completely closed, completely open or anywhere in between. The core adjustment is strictly manual, but once it is set to establish the flow curve desired, it should not require re-adjustment unless the upstream pressure varies.

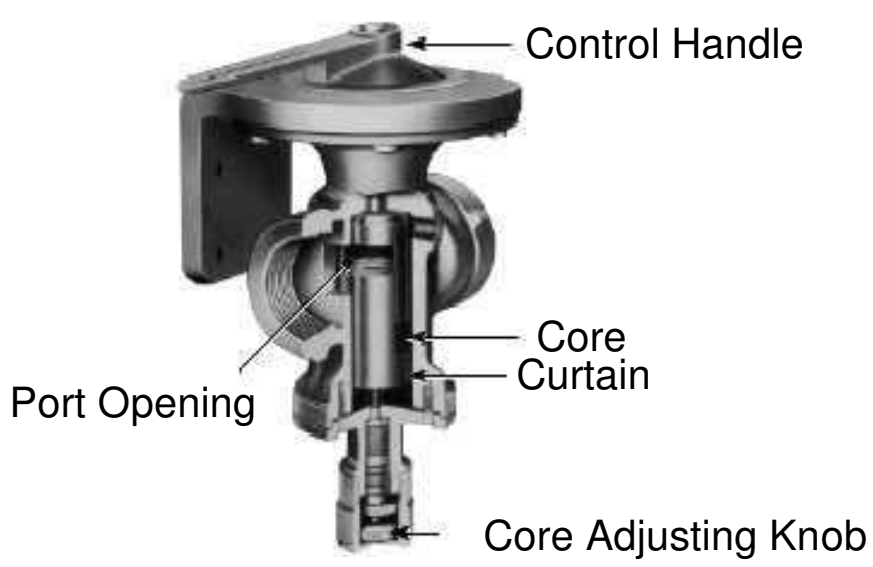

Figure 3.9 Sectional View of Control Valve for Gases 
The second action is obtained by rotating the control handle. The control handle on the top has a rotating plug that moves along a threaded shaft. The core has a curtain surrounding it that covers or uncovers the valve opening, according to the angular position of the curtain. The angular position of the curtain is controlled by rotating the control handle with an AC motor through an external crank arm. The angular displacement at the end of the connecting link is obtained as the angular displacement of the curtain as they lie on the same shaft. Turning the curtain and adjusting the knob changes the valve opening. Figure 3.10 illustrates the two actions behind the working of the control valve. By these two motions, the valve can be sized to cause the desired flow to occur.

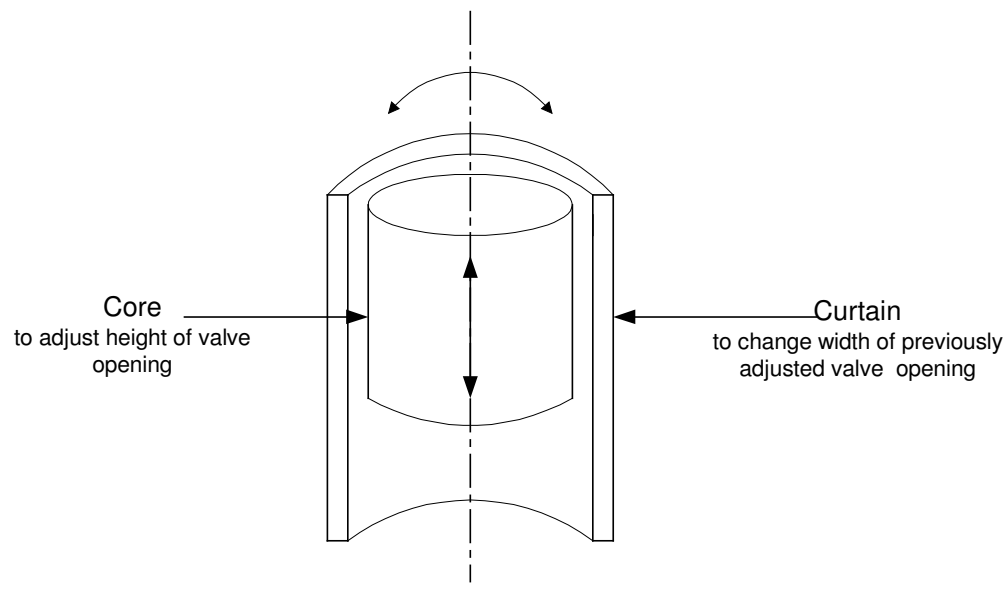

Figure 3.10 Schematic of Control Valve showing Two Motions

The electric actuator influences only the movement of the curtain since not much re-adjustment occurs in the setting of the core once it is set. Various flow configurations can be obtained by manipulating the control handle and the knob as shown in Figure 3.11 [24].

Two or more adjustable control valves can be used in combination to control the flow of oxygen or natural gas. In such combinations, valves can be stacked on a common 
shaft or mounted side-by-side with linked control handles, or both. A side-by-side arrangement also allows additional flexibility [24].

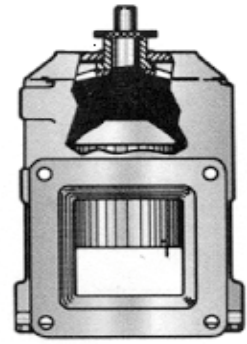

Curtain $1 / 2$ open Core full open

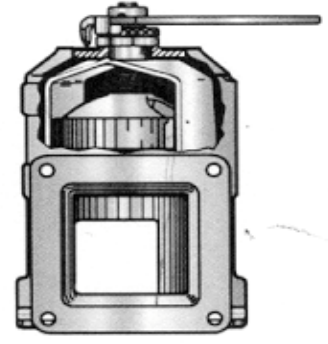

Curtain $3 / 4$ open Core rotated $1 / 4$

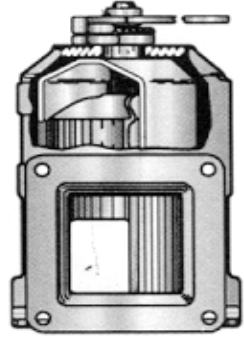

Curtain $3 / 4$ open Core rotated $1 / 2$

Figure 3.11 Various Flow Possibilities Obtainable by Manipulating Control Handle and Core-Adjusting Knob.

\subsubsection{Transfer Function of Flow Part of Control Valve for Natural Gas}

Experimental data collected at the L. E. Smith Glass Company can be used to obtain the transfer function for the flow part of the control valve. The volume flow rate through the pipe train corresponding to different positions of valve opening can be measured.

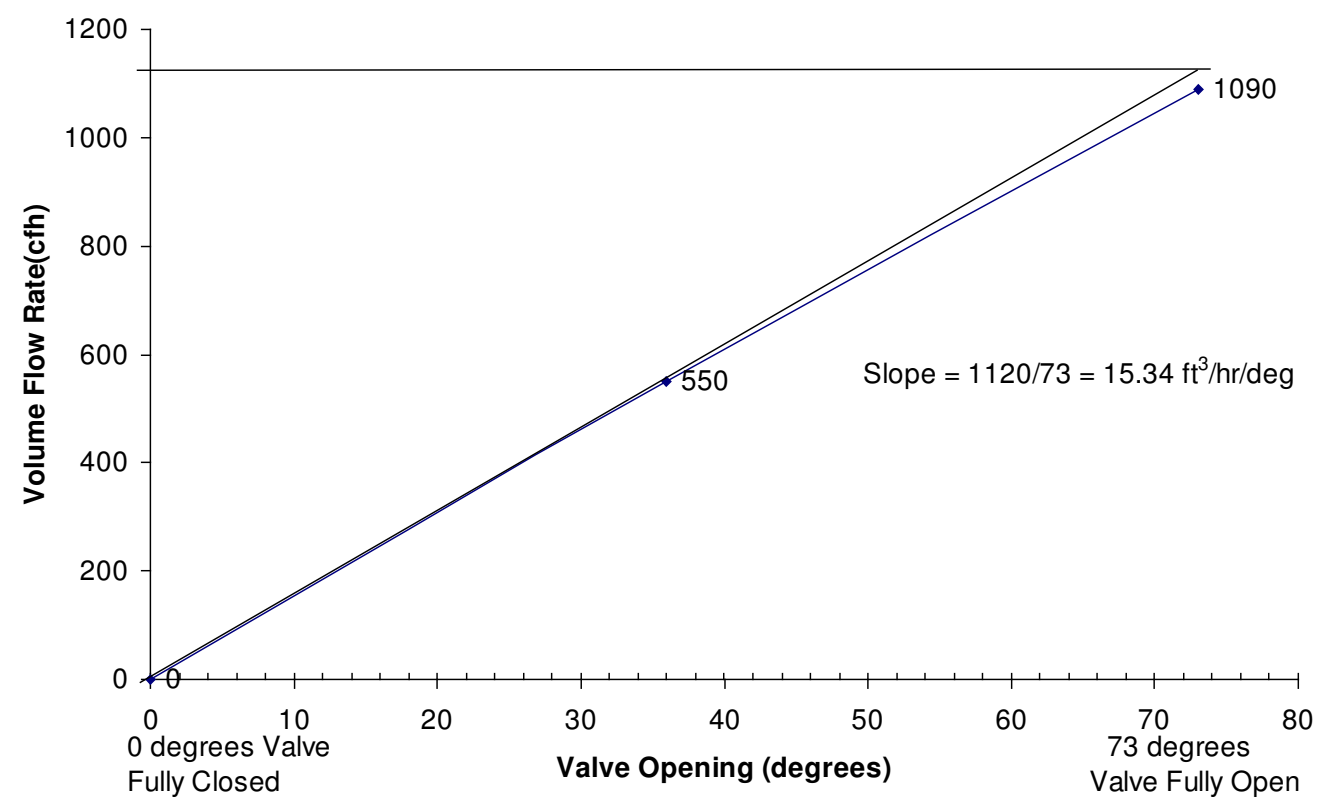

Figure 3.12 Valve Flow Characteristics of Control Valve in

Natural Gas Pipe 
The data collected from the natural gas pipe in the plant has been plotted in Figure 3.12. The volume flow rate for the natural gas pipe is different from that of the oxygen gas pipe.

Linearizing the data, the slope of the above graph is obtained as $15.3 \mathrm{cfh} / \mathrm{deg}$. Based on the experimental data above, one can write the transfer function for flow part of the control valve, $\mathrm{G}_{\mathrm{V}}(\mathrm{s})$, as shown in Equation 3.21.

$$
G_{V}(s)=\frac{s V_{F}(s)}{\Delta \Theta^{\prime}(s)}=15.3\left[\frac{\mathrm{ft}^{3} / \mathrm{hr}}{\text { degrees }}\right]
$$

where

$\dot{V}_{F}(\mathrm{t}) \quad-\quad$ Volume flow rate of natural gas through the control valve, $\mathrm{ft}^{3} / \mathrm{hr}$.

$\Delta \Theta^{\prime}(s)$ - Laplace transform of change in angular opening of the natural gas valve, degrees.

\subsubsection{Transfer Function for Electric-Actuated Control Valve for Natural Gas}

The most important element in the pipe train is the electric-actuated control valve.

Figure 3.13 shows a block diagram representation of the elements in the electric-actuated control valve for Natural Gas.

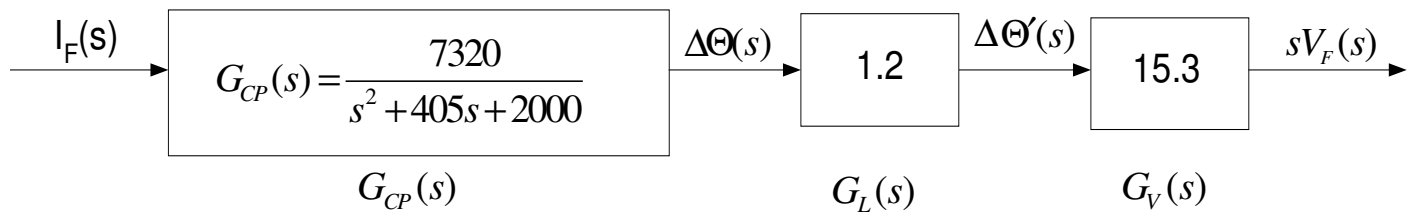

Figure 3.13 Block Diagram Representation of Control Valve

Using the fundamentals of block diagram mathematics, one can obtain the output signal from the valve, $s V_{F}(\mathrm{~s})$, as shown in Equation 3.22

$$
s V_{F}(s)=I_{F}(s) \cdot G_{C P}(s) \cdot G_{L}(s) \cdot G_{V}(s)
$$


Substituting for the values of different transfer functions from Equations 3.18, 3.19 and 3.21, one obtains the transfer function for the control valve, $\mathrm{G}_{\mathrm{CV}}(\mathrm{s})$, as shown in Equation 3.23.

$$
G_{C V}(s)=\frac{s V_{F}(s)}{I_{F}(s)}=\frac{134700}{\left(s^{2}+405 s+2000\right)}\left[\frac{f t^{3} / h r}{m A}\right]
$$

Figure 3.14 shows the unit step input from a controller from a value of $12 \mathrm{~mA}$.

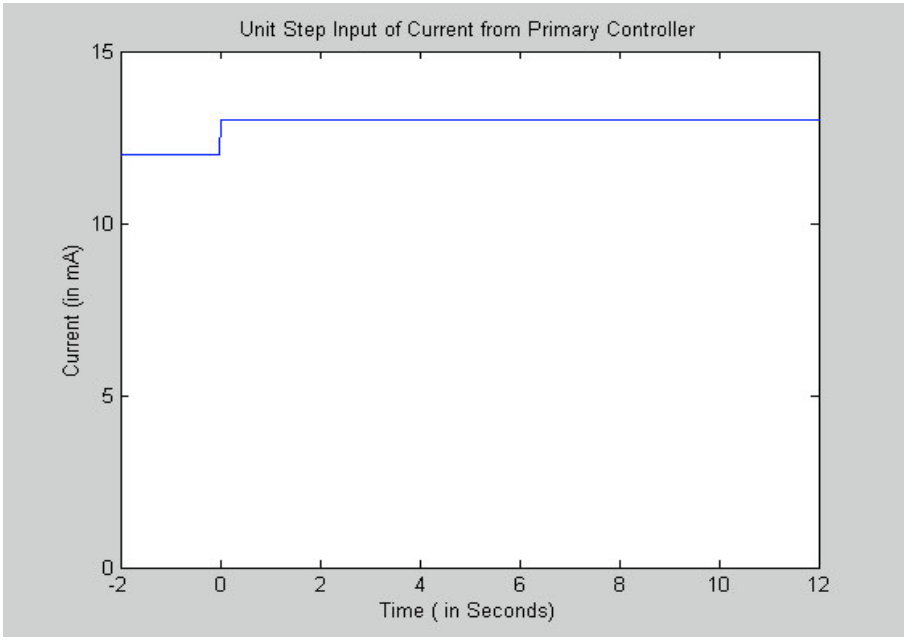

Figure 3.14 Unit Step Input of Current from Primary Controller

Figure 3.15 shows the response of this unit step increase in controller current on the volume flow rate of natural gas.

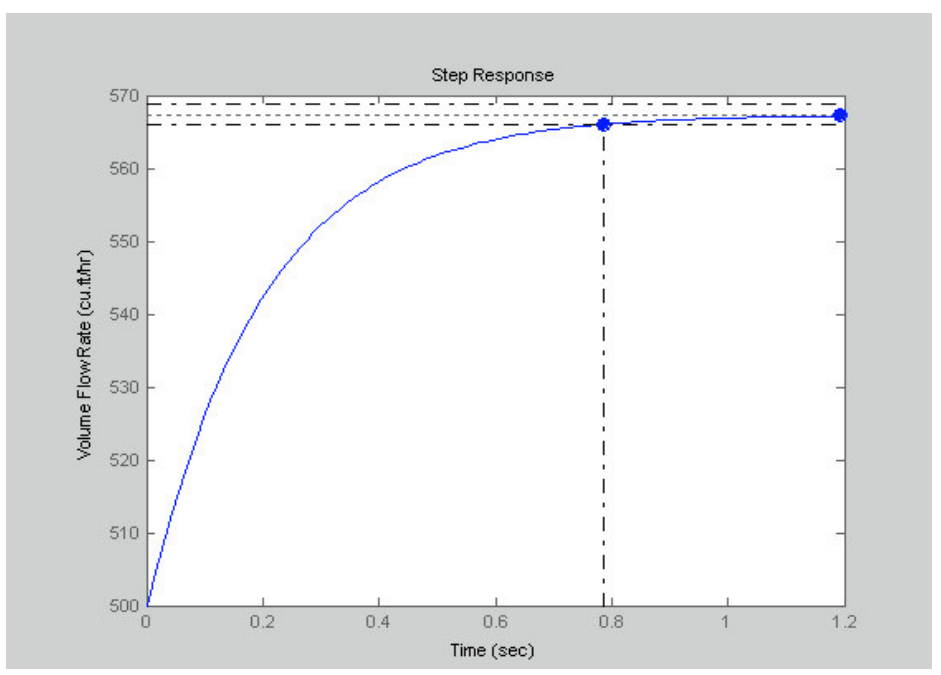

Figure 3.15 Unit Step Response of Electric-Actuated Control Valve 
The result shows that there will be a new flow of $567 \mathrm{ft}^{3} / \mathrm{hr}$ of natural gas. The 67 $\mathrm{ft}^{3} / \mathrm{hr}$ change in flow rate occurs in about 0.785 seconds.

In Section 2.4, the specifications of the pipe train were discussed. The analysis proved that the only element in the pipe train that influences the flow through the pipe train is the electric-actuated control valve. In other words, the transfer function for the pipe train, $G_{P T}(s)$, would be the same as the transfer function for the control valve, $G_{C V}(s)$ as shown in Equation 3.24.

$$
G_{T V}(s)=G_{C V}(s)
$$

\subsection{Transfer Function of Burner}

A burner facilitates the proper combustion of natural gas with oxygen to supply the required energy to the batch tank. For this, natural gas and oxygen are mixed in a ratio of about $2: 1$. The input variable to a burner is the volume flow rate of natural gas, $\dot{V}_{F}$, and the output variable is the energy produced by the combustion of the fuel, $\dot{Q}_{B}$. Oxygen flow rate does not come into the equation because it does not contribute to the energy produced by the burner. Figure 3.16 shows a picture of a typical oxy-fuel burner used in the glass industry.

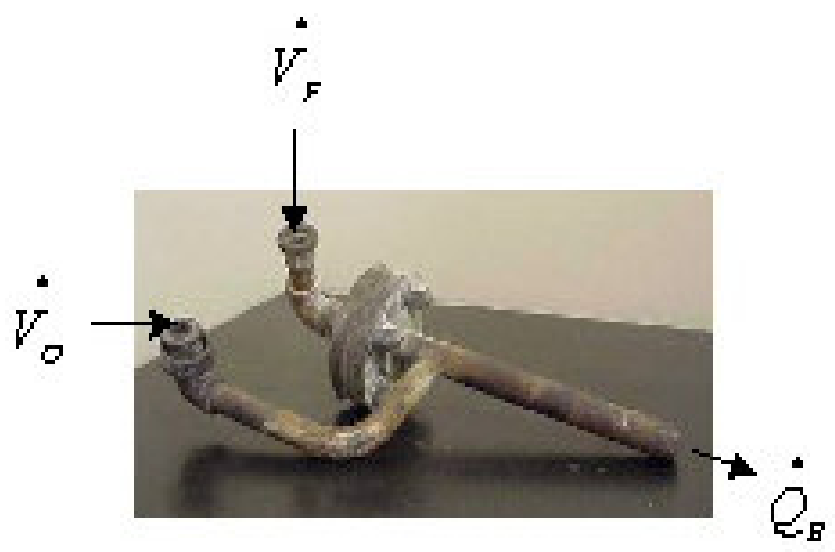

Figure 3.16 Picture of Oxy-Fuel Burner 
The equation for the energy released, $\dot{Q}_{B}$, can be expressed as shown in Equation 3.25 .

$$
\dot{Q}_{B}=\eta\left(C_{V}\right)_{F} \dot{V}_{F}
$$

where

$\dot{Q}_{B} \quad-\quad$ Rate of energy available at burner due to combustion of natural gas with oxygen, Btu/hr.

$\eta \quad$ - $\quad$ Efficiency of Burner

$\left(\mathrm{C}_{\mathrm{V}}\right)_{\mathrm{F}}-\quad$ Calorific value of natural gas, Btu/ft $\mathrm{ft}^{3}$

$\dot{V}_{F} \quad$ - $\quad$ Volume flow rate of natural gas, $\mathrm{ft}^{3} / \mathrm{hr}$.

Taking the Laplace transform of Equation 3.25, one obtains Equation 3.26.

$$
s Q_{B}(s)=\eta\left(C_{V}\right)_{F} s V_{F}(s)
$$

The calorific value of natural gas used at glass industries is about $1000 \mathrm{Btu} / \mathrm{ft}^{3}$. One can assume that the burner has an efficiency of 90\%. Using Equation 3.26, one can write the transfer function for the burner, $G_{B}(s)$, as shown in Equation 3.27.

$$
G_{B}(s)=\frac{s Q_{B}(s)}{s V_{F}(s)}=900\left[\frac{B t u / h r}{f t^{3} / h r}\right]
$$

\subsection{Transfer Function of Thermocouple}

The thermocouple converts the temperature signal to an equivalent voltage and sends it as a feedback signal to the controller. The temperature-voltage relation for a Type-K thermocouple is shown in Figure 3.17. 
The response time of a thermocouple is a function of the medium of submersion, wire diameter, alloy type and the temperature of the alloy. The response time is defined as the time required for the thermocouple to reach $63.2 \%$ of its final temperature when its junction is alternately exposed to two different temperature levels.

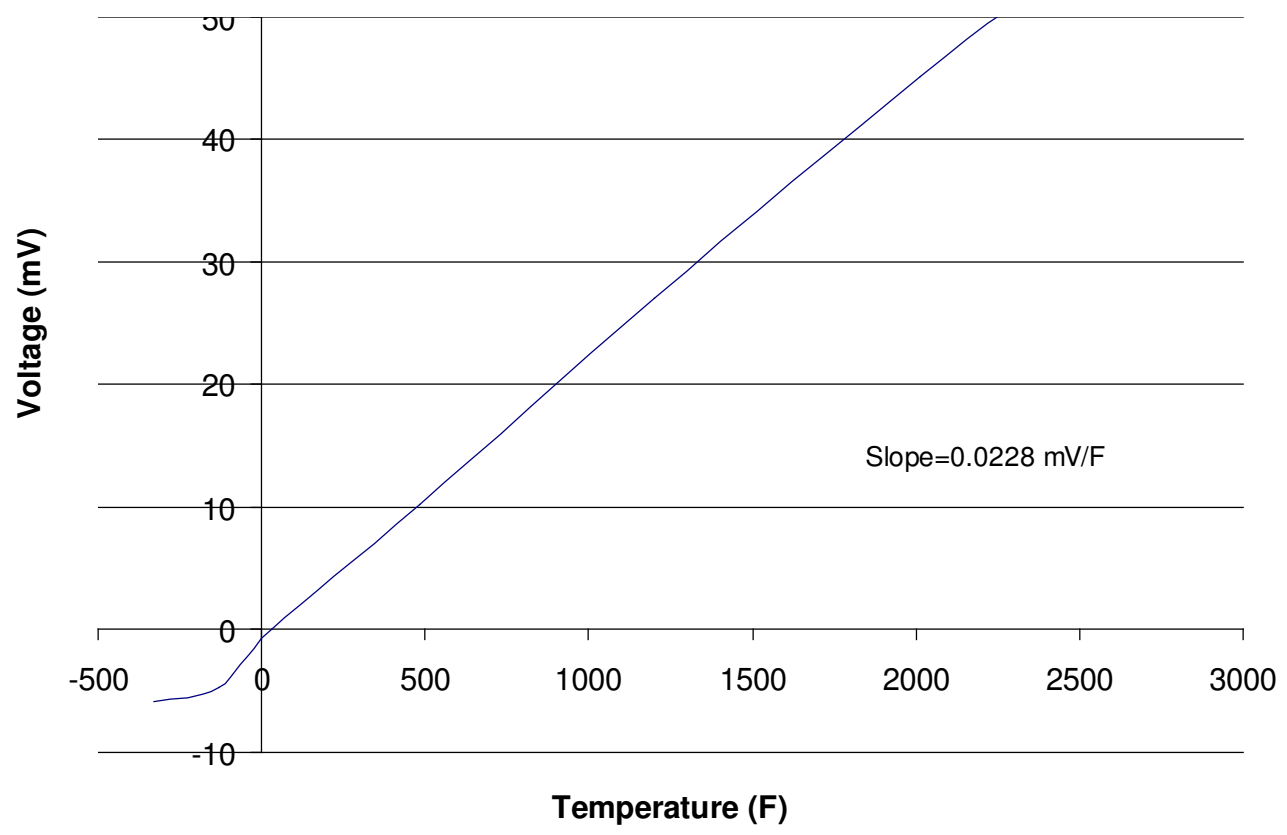

Figure 3.17 Temperature-Voltage Relation for Type-K Thermocouple

Table 3.6 illustrates the response time, $\mathrm{T}_{\mathrm{r}}$, and the sensitivity, $\mathrm{S}$, of the Type-K thermocouple. This can then be used to derive the transfer function for the thermocouple.

Table 3.6 Response Time and Sensitivity of Type-K Thermocouple

\begin{tabular}{|c|c|c|}
\hline Wire Size (inches) & Response Time, $\mathrm{T}_{\mathrm{r}}$ (seconds) & Sensitivity, $\mathrm{S}\left(\mathrm{mV} /{ }^{\circ} \mathrm{F}\right)$ \\
\hline 0.032 & 3.2 & 0.0228 \\
\hline
\end{tabular}

A thermocouple can be modeled as a first-order system. Response theory can be used to find the time constant of a first-order system based on its rise time. Equation 3.28 can be used to calculate the time constant for the thermocouple, $\tau$, in seconds. 


$$
\left.\tau=\frac{T_{r}}{2.2} \text { [seconds }\right]
$$

where

$\mathrm{T}_{\mathrm{r}} \quad-\quad$ Response time, seconds

To avoid errors in measurement when measuring very small voltages, an amplifier is added to the output signal from the thermocouple. An amplifier gain, $\mathrm{k}_{\mathrm{T}}$, of 1000 will satisfy this requirement. The transfer function for the thermocouple, $\mathrm{H}_{\mathrm{T}}(\mathrm{s})$, can be represented as shown in Equation 3.29.

$$
H_{T}(s)=\frac{V_{T}(s)}{T_{A}(s)}=\frac{k_{T} S}{\tau s+1} \quad\left[\frac{m V}{{ }^{\circ} F}\right]
$$

Substituting the values from Table 3.6 in Equation 3.29, one obtains the feedback transfer function for the thermocouple, $\mathrm{H}_{\mathrm{T}}(\mathrm{s})$, as shown in Equation 3.30.

$$
H_{T}(s)=\frac{V_{T}(s)}{T_{A}(s)}=\frac{0.0228}{1.45 s+1}\left[\frac{m V}{{ }^{o} F}\right]
$$

Figure 3.18 shows the step input of $10^{\circ} \mathrm{F}$ temperature inside the batch tank from $2400^{\circ} \mathrm{F}$ to $2410^{\circ} \mathrm{F}$. 


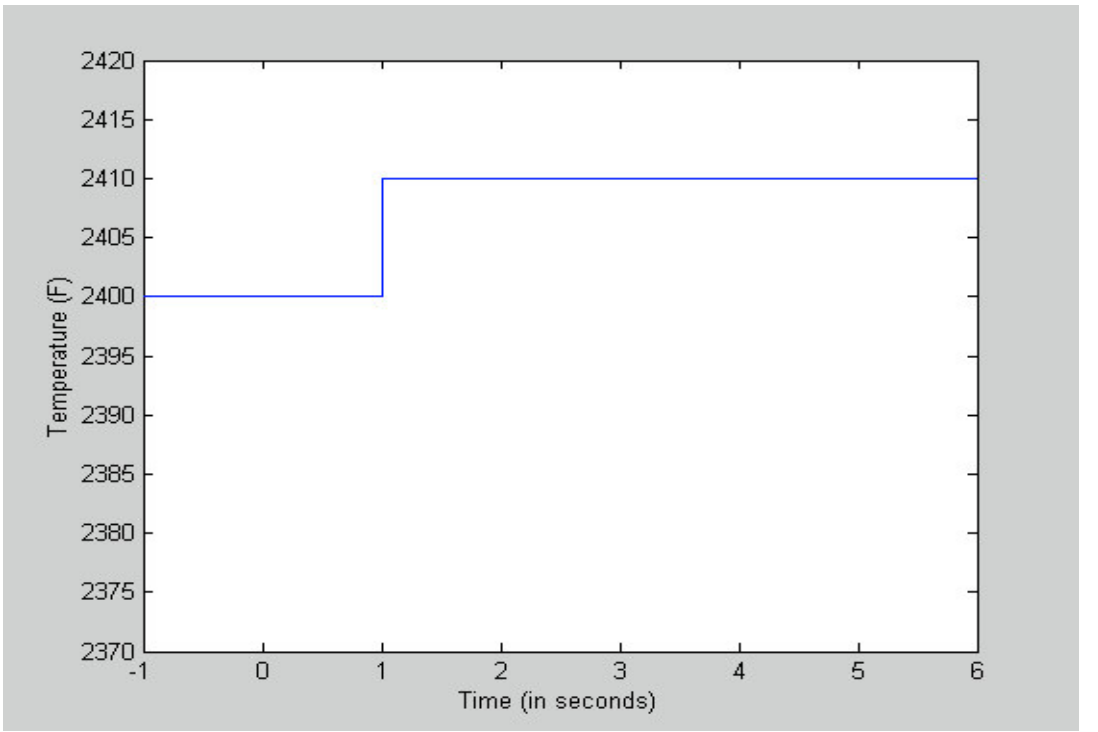

Figure 3.18 Step Increase in Temperature Input to Thermocouple

Figure 3.19 shows the corresponding output voltage from the thermocouple due to this increase in temperature. The results show that the output voltage has a response time of about 3 seconds, which is typical for a K-type thermocouple.

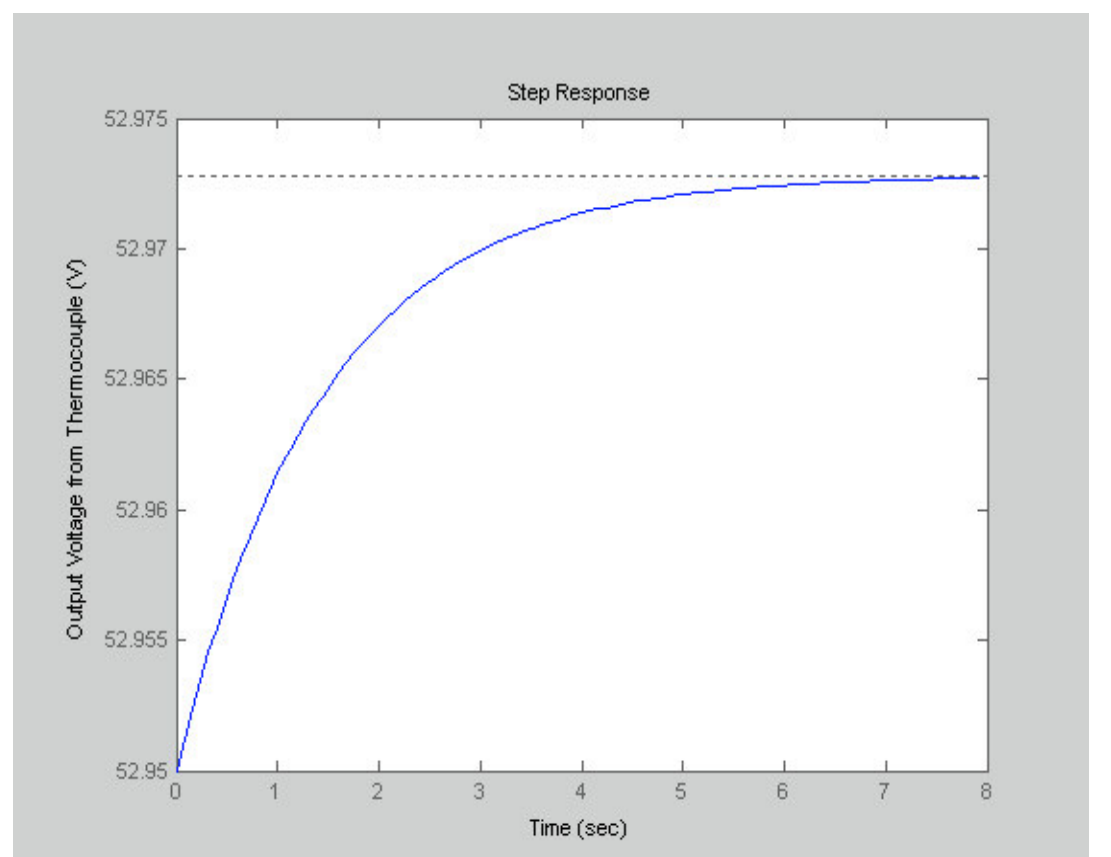

Figure 3.19 Step Response to Temperature Increase of Thermocouple 


\section{Chapter 4. Transfer Function Model for Oxy-Fuel Fired Batch Tank}

\subsection{Introduction}

A clear understanding of the thermal-fluid processes inside a batch tank is required to develop the model of a batch tank. Both for the design and the operation of such furnaces, heat transfer to the glass and the temperatures of different elements such as the glass, the refractory walls and the exhaust gases inside the batch tank should be known.

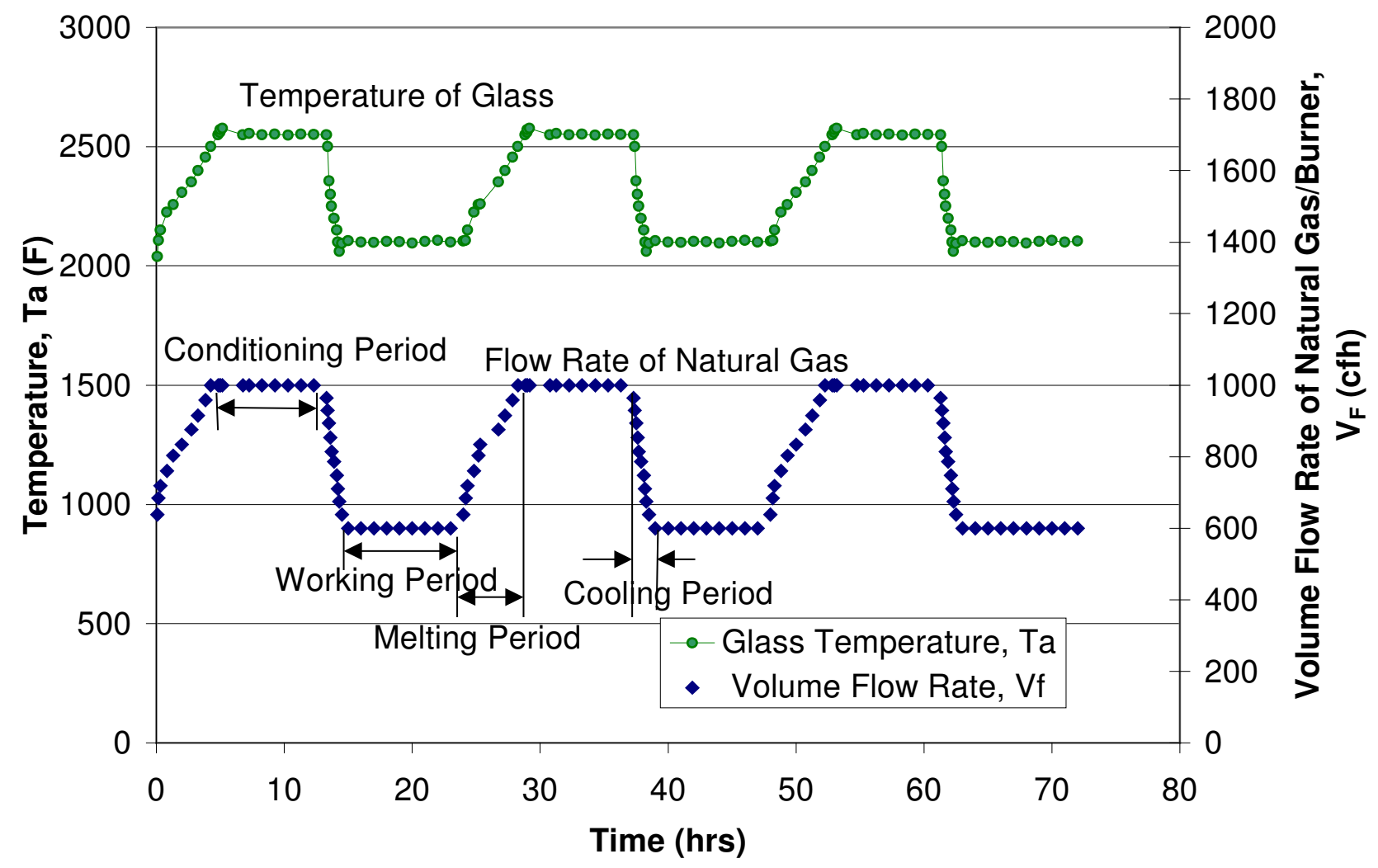

Figure 4.1 Time Profiles of Measured Temperature and Flow Rate of Natural Gas with Present Controller [2] 
Typically, a glass melting process occurs at $2000-2500{ }^{\circ} \mathrm{F}$, whereas the flame temperatures could be as high as $4100-4300^{\circ} \mathrm{F}$. The glass batch process takes place over a 24-hour period. After fresh batch is added, glass is heated to $2500{ }^{\circ} \mathrm{F}$ and held at that temperature for about 8 hours. Then glass is cooled down to a working temperature of about $2100{ }^{\circ} \mathrm{F}$. Glass is pulled out at a constant rate during this working period. At the end of the working period of about 9 hours, fresh batch is added and the cycle is repeated. Figure 4.2 shows the variation of the level of glass $\left(\mathrm{L}_{\mathrm{G}}\right)$ and the weight of the glass over a 72-hour period.

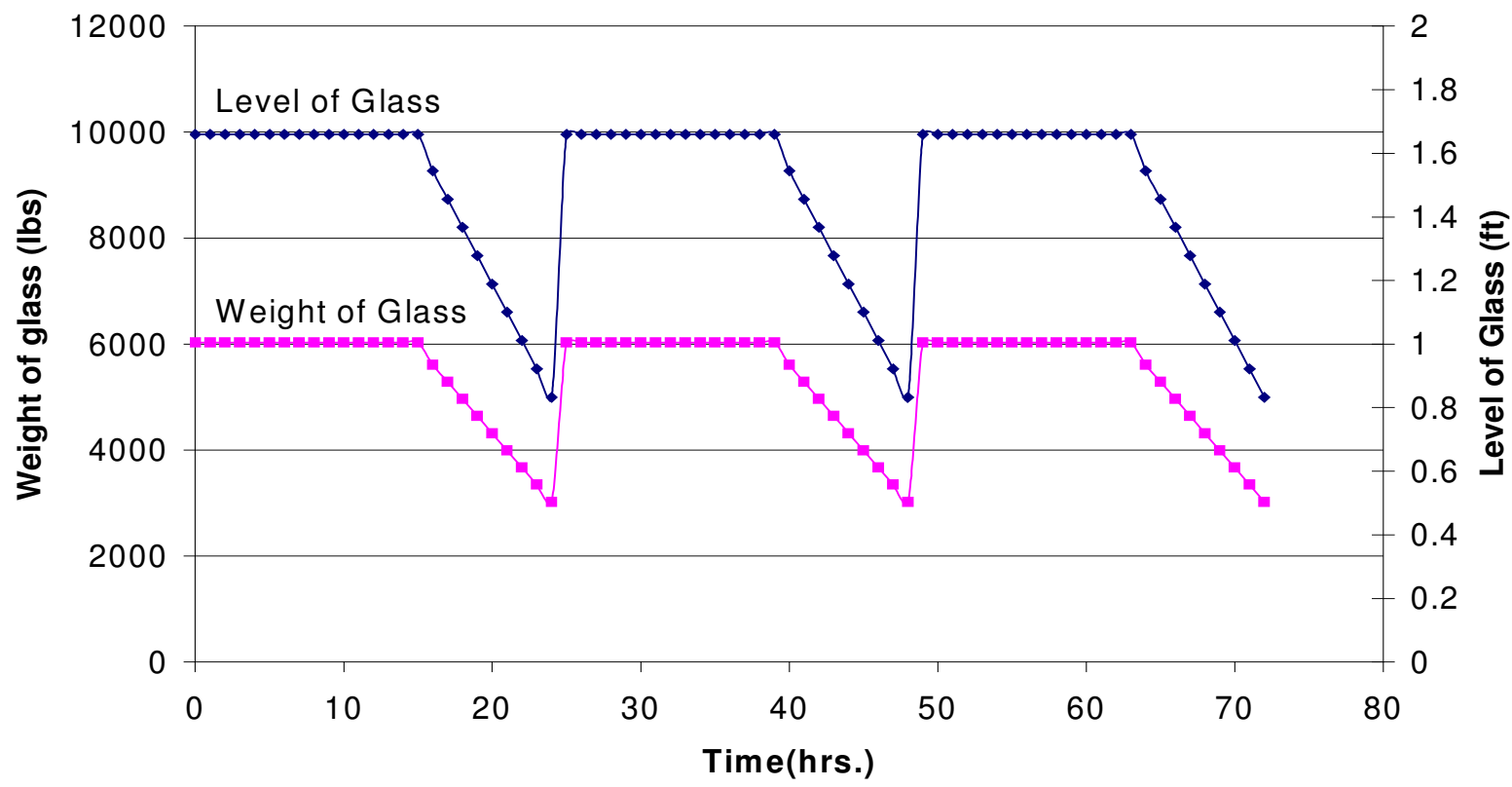

Figure 4.2 Time Profile of Level of Glass and Weight of Glass inside Batch Tank

Figure 4.3 illustrates a batch tank and the different heat transfers to the glass inside the batch tank [25]. The energy from the burner is separated into three forms of output energy. These are the heat going to the glass, the heat going to the refractory walls and the heat going to the exhaust. Among these, the heat going to the glass determines the transfer function for the glass element. 
Research has proved that about $40 \%$ of the total energy from the burner goes into melting the batch material by inducing the glass forming reactions. Roughly, about $30 \%$ of the total combustion is lost through the tank walls, and $30 \%$ is carried away with the exhaust through the stack [26].

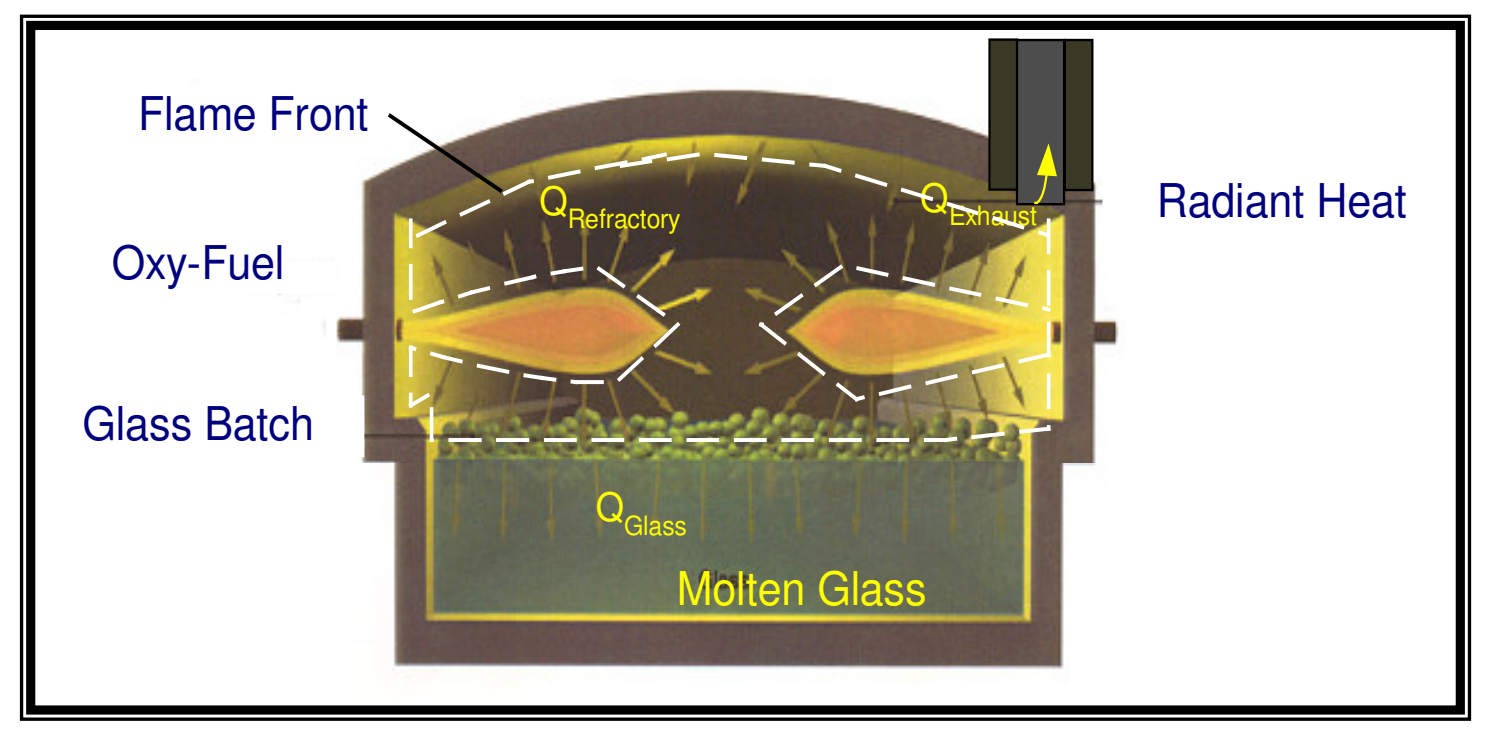

Figure 4.3 Schematic of Oxy-Fuel Fired Batch Tank showing Three Modes of Heat Transfers from Burners

\subsection{Transient Observations for Oxy-Fired Batch Tank}

This analysis is based on the melting of glass in an 3000-lb capacity batch tank with two burners. Glass level is assumed to be about 20 inches at the beginning of melting [27]. At the end of the conditioning period, glass is pulled at a constant rate, $\mathrm{M}_{\mathrm{PG}}$, till the level of glass goes down to 10 inches. Assuming a constant pull rate of 2 $\mathrm{ft}^{3} / \mathrm{hr}$, the volume of glass pulled will be $18 \mathrm{ft}^{3}$. Thus, the amount of molten glass available in the melt period is the volume of molten glass contained in the 10 inches of pulled glass. Based on the dimensions of the batch tank, the volume of glass pulled will be the equivalent of $18 \mathrm{ft}^{3}$. Figure 4.4 shows the effect of the pulling of glass on the volume of glass and the area of walls in contact with the glass, AWG. 


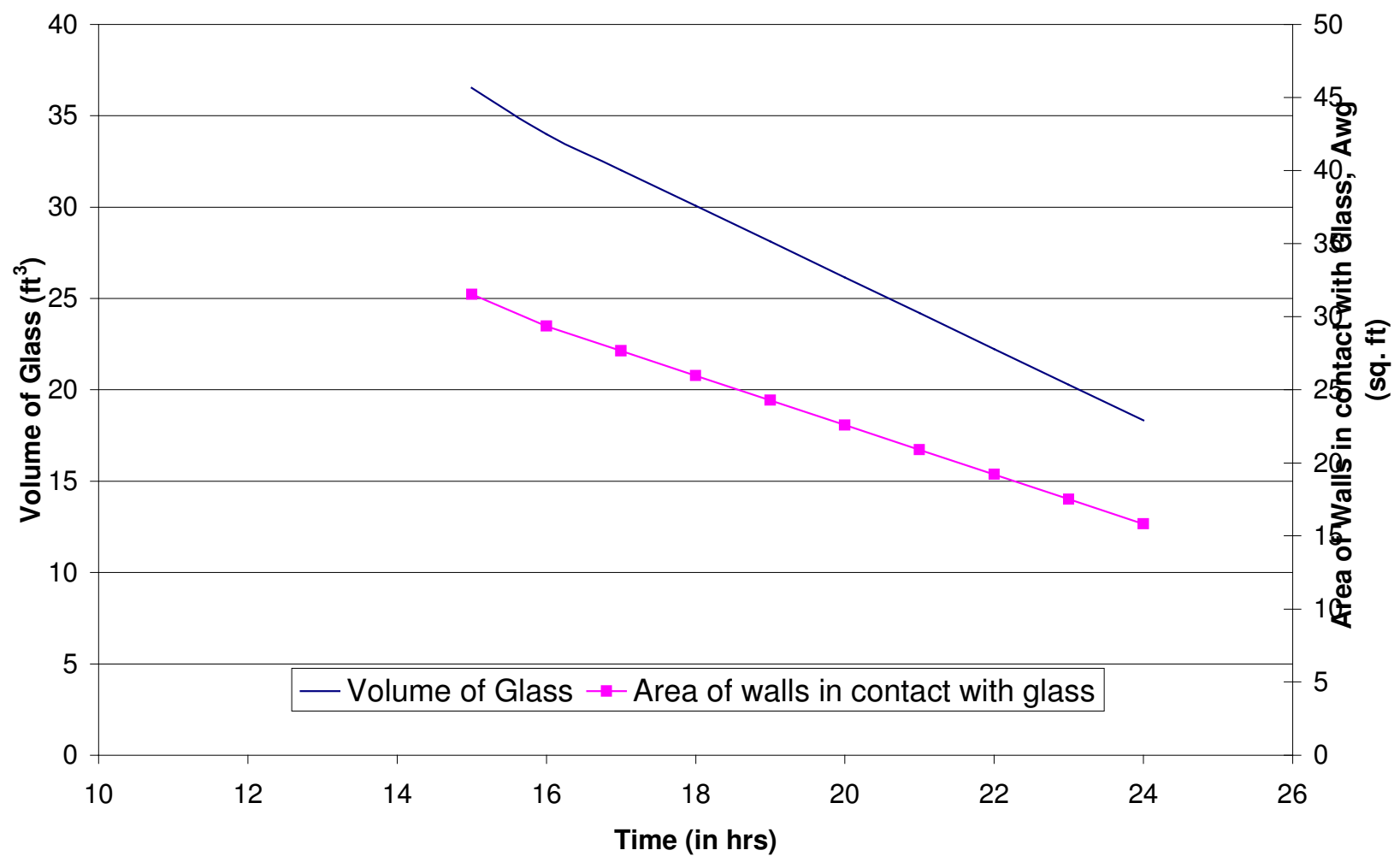

Figure 4.4 Effect of Pulling of Glass on Volume of Glass in Tank and

Area of Walls in Contact with Glass

As the level of glass goes down in the batch tank, more and more area of the walls is exposed. This leads to more heat transfer from the walls to the reduced amount of glass left in the batch tank. This means that one can afford to cut back on the amount of natural gas supplied to the batch tank. Therefore, there is a potential to reduce the amount of natural gas used to heat up the molten glass in the batch tank.

Table 4.1 compares the transient parameters of the batch tank at the beginning and end of the working period.

Table 4.1 Comparison of Transient Parameters of Batch Tank

\begin{tabular}{|c|c|c|}
\hline Parameter & $\begin{array}{c}\text { At the End of Conditioning } \\
\text { (Full) }\end{array}$ & At the End of Working \\
\hline Glass Level (inches) & 20 & 10 \\
\hline Glass Volume $\left(\mathrm{ft}^{3}\right)$ & 36.5 & 18.3 \\
\hline $\begin{array}{c}\text { Area of walls in contact } \\
\text { with Glass, } A_{W G}^{\prime}\left(\mathrm{ft}^{2}\right)\end{array}$ & 31.5 & 15.8 \\
\hline
\end{tabular}


The variation in the batch tank parameters warrants a separate analysis for the heat transfer to the glass during the working period. Thus, the analysis can be divided into two sections: the analysis of the transfer function for the glass during the melting and the conditioning periods, $\mathrm{G}_{\mathrm{GM}}(\mathrm{s})$, and the analysis of the transfer function for the glass during the working period, $\mathrm{G}_{\mathrm{GP}}(\mathrm{s})$.

\subsection{Transfer Function for Glass during Melting and Conditioning Periods}

The most important element in a batch tank is the glass element. Heat is transferred from the hot gas to the glass predominantly by radiation. The analysis of such heat transfers can be described by using thermal resistances and capacitances. The heat transfer to the glass is developed from the two mediums involved, the products of combustion and the glass. Each of these mediums has an associated heat transfer capacitance and resistance. Figure 4.5 shows a schematic of the different heat transfer resistances and capacitances.

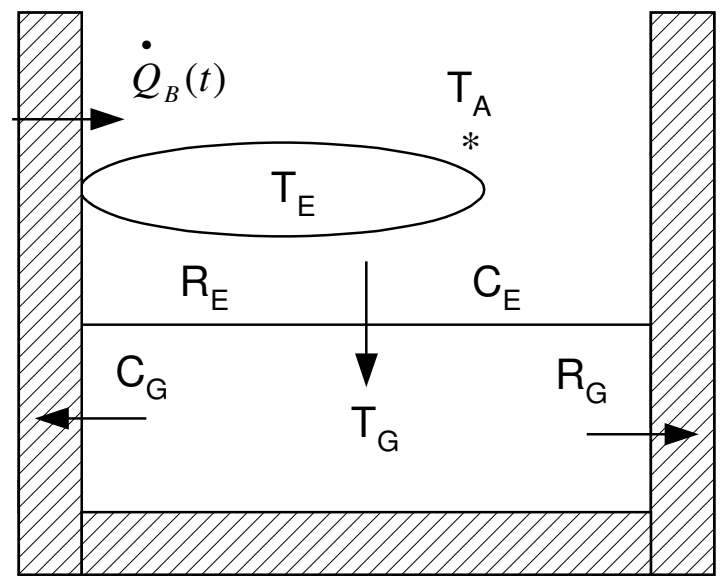

Figure 4.5 Schematic of Different Heat Transfer Resistances and Capacitances 


\subsubsection{Calculation of Thermal Resistance for Radiant Heat Transfer from Hot Gases to Glass}

One needs to calculate the unit thermal conductance for the heat transfer from the hot gases to the glass to obtain its thermal resistance. This can be coupled with the concerned area to get the thermal resistance for the heat transfer. The unit thermal conductance for the radiant heat from hot gases to glass, $h_{E}$, can be approximated using Equation 4.1. This equation does not take into consideration the temperature of the glass, $\mathrm{T}_{\mathrm{G}}$, for calculating the radiant heat transfer. This approximation can be justified due to the small difference in the temperatures of hot gases and the glass.

$$
h_{E}=4 \sigma \varepsilon_{E} T_{A}^{3}\left[\mathrm{~W} / \mathrm{m}^{2}-\mathrm{K}\right]
$$

where

$h_{E} \quad-\quad$ Unit thermal conductance for the radiant heat from hot gases to glass, $W / m^{2}-K$

$\sigma \quad-\quad$ Stefan-Boltzmann constant, $5.67 \times 10^{-8} \mathrm{~W} / \mathrm{m}^{2}-\mathrm{K}$

$\varepsilon_{\mathrm{E}} \quad-\quad$ Emissivity of the products of combustion

$\mathrm{T}_{\mathrm{A}} \quad-\quad$ Average temperature of the hot gases, $\mathrm{K}$

The thermal resistance for the radiant heat from hot gases to glass, $R_{E}$, can be calculated using Equation 4.2.

$$
R_{E}=\frac{1}{h_{E} A_{G}}\left[\frac{h r^{\circ} F}{B t u}\right]
$$

where

$\mathrm{A}_{\mathrm{G}} \quad$ - Surface area of glass, $\mathrm{m}^{2}$.

$R_{E} \quad-\quad$ Thermal resistance of the products of combustion, K/W

Table 4.2 tabulates the parameters for the calculation of the heat transfer resistance from the hot gases to the glass. 
Table 4.2 Parameters for Calculation of Heat Transfer Resistance from Hot Gases to Glass

\begin{tabular}{|c|c|}
\hline Emissivity of products of combustion, $\varepsilon_{\mathrm{E}}$ & 0.39 \\
\hline Average temperature of hot gases, $\mathrm{T}_{\mathrm{A}}(\mathrm{K})$ & 1422 \\
\hline Surface area of glass, $\mathrm{A}_{\mathrm{G}}\left(\mathrm{ft}^{2}\right)$ & 22 \\
\hline
\end{tabular}

Using Table 4.2, one can obtain the values for the heat transfer conductance of the hot gases, $\mathrm{h}_{\mathrm{E}}$, and the heat transfer resistance, $\mathrm{R}_{\mathrm{E}}$, as shown in Table 4.3 for two sets of units.

Table 4.3 Heat Transfer Conductance and Resistance from Hot Gases to Glass

\begin{tabular}{|c|c|c|}
\hline $\mathrm{h}_{\mathrm{E}}$ & $628 \mathrm{~W} / \mathrm{m}^{2}-\mathrm{K}$ & $110.6 \mathrm{BTU} / \mathrm{hr}-\mathrm{ft}^{2}-{ }^{\circ} \mathrm{F}$ \\
\hline $\mathrm{R}_{\mathrm{E}}$ & $7.8 \times 10^{-4} \mathrm{~K} / \mathrm{W}$ & $4.11 \times 10^{-4} \mathrm{hr}^{\circ} \mathrm{F} / \mathrm{BTU}$ \\
\hline
\end{tabular}

\subsubsection{Calculation of Thermal Capacitance for Radiant Heat Transfer from Hot Gases to Glass}

The thermal capacitance of the products of combustion is obtained as the sum of the mass times the specific heats of the products of combustion as shown in Equation 4.3.

$$
C_{E}=\sum m_{i} \cdot c_{P_{i}}\left[\frac{B t u}{{ }^{\circ} F}\right]
$$

where

$\mathrm{C}_{\mathrm{E}} \quad-\quad$ Capacitance of the products of combustion, Btu/ ${ }^{\circ} \mathrm{F}$

$m_{i} \quad$ - Mass of the products of combustion, $1 b_{m}$

$\mathrm{c}_{\mathrm{Pi}} \quad$ Specific heat of the products of combustion, Btu/ $\mathrm{lb}_{\mathrm{m}}-{ }^{\circ} \mathrm{F}$

Appendix D illustrates the calculation of the capacitance associated with the hot products of combustion. The results are shown in Table 4.4.

Table 4.4 Parameters for Capacitance of Products of Combustion

\begin{tabular}{|c|c|}
\hline$m_{\mathrm{CO}_{2}}$ & $0.338 \mathrm{lb}_{\mathrm{m}}$ \\
\hline$m_{\mathrm{H}_{2} \mathrm{O}}$ & $0.276 \mathrm{lb}_{\mathrm{m}}$ \\
\hline$C_{E}$ & $0.2 \mathrm{Btu} /{ }^{\circ} \mathrm{F}$ \\
\hline
\end{tabular}




\subsubsection{Calculation of Thermal Resistance for Glass Transfer Function}

This resistance can be written as a lumped heat transfer because the heat transfer from the glass to the walls takes place by both conduction and convection. The resistance associated with the glass transfer function can be developed as shown in Equation 4.4.

$$
R_{G}=\frac{L_{G}}{k_{G} A_{G}}+\frac{1}{k_{R} S_{G}}+\frac{1}{h_{W} A_{W G}}\left[\frac{h r^{\circ} F}{B t u}\right]
$$

where

$\mathrm{L}_{\mathrm{G}} \quad-\quad$ Level of glass, $\mathrm{ft}$

$\mathrm{k}_{\mathrm{G}} \quad-\quad$ Thermal conductivity of glass, Btu/hr-ft- ${ }^{\circ} \mathrm{F}$

$\mathrm{A}_{\mathrm{G}} \quad-\quad$ Surface area of glass, $\mathrm{ft}^{2}$

$\mathrm{k}_{\mathrm{R}} \quad-\quad$ Thermal conductivity of refractory walls, Btu/hr-ft- ${ }^{\circ} \mathrm{F}$

$\mathrm{S}_{\mathrm{G}} \quad-\quad$ Conduction shape factor referenced to glass level

$\mathrm{h}_{\mathrm{W}} \quad-\quad$ Coefficient of convective heat transfer, Btu/hr- $-\mathrm{ft}^{2}-{ }^{\circ} \mathrm{F}$

$\mathrm{A}_{\mathrm{WG}} \quad-\quad$ Area of the walls in contact with glass, $\mathrm{ft}^{2}$

The calculation for the heat transfer resistance of the glass transfer function, unlike the heat transfer resistance of the products of combustion, depends on the level of glass. But during the melting and conditioning periods since the glass level remains the same, the resistance associated with the glass transfer function, $R_{G}$, remains the same. Table 4.5 illustrates the parameters for the calculation of the resistance associated with the glass transfer function. 
Table 4.5 Parameters for Heat Transfer Resistance of Glass Transfer Function

\begin{tabular}{|c|c|}
\hline $\mathrm{k}_{\mathrm{G}}$ & $1.94 \mathrm{Btu} / \mathrm{hr}-\mathrm{ft}-{ }^{\circ} \mathrm{F}$ \\
\hline $\mathrm{k}_{\mathrm{R}}$ & $1.16 \mathrm{Btu} / \mathrm{hr}-\mathrm{ft}-{ }^{\circ} \mathrm{F}$ \\
\hline $\mathrm{S}_{\mathrm{G}}$ & 46.7 \\
\hline $\mathrm{A}_{\mathrm{WG}}$ & $30.4 \mathrm{ft}^{2}$ \\
\hline
\end{tabular}

Appendix D illustrates the calculation of the resistance associated with glass transfer function. The results are shown in Table 4.6.

Table 4.6 Heat Transfer Conductance and Resistance from Hot Gases to Glass

\begin{tabular}{|c|c|c|}
\hline $\mathrm{h}_{\mathrm{W}}$ & $110.0 \mathrm{~W} / \mathrm{m}^{2}-\mathrm{K}$ & $19.38 \mathrm{Btu} / \mathrm{hr}^{-\mathrm{ft}^{2}-{ }^{\circ} \mathrm{F}}$ \\
\hline $\mathrm{R}_{\mathrm{G}}$ & $0.336 \mathrm{~K} / \mathrm{W}$ & $0.059 \mathrm{hr}-{ }^{\circ} \mathrm{F} / \mathrm{Btu}$ \\
\hline
\end{tabular}

\subsubsection{Calculation of Thermal Capacitance for Glass Transfer Function}

The thermal capacitance of the glass transfer function is obtained as the mass times the specific heats of the mass of glass as shown in Equation 4.5.

$$
C_{G}=m_{G} \cdot c_{P G}\left[\frac{B t u}{{ }^{\circ} F}\right]
$$

where

$\mathrm{C}_{\mathrm{G}} \quad-\quad$ Capacitance of glass, Btu/ ${ }^{\circ} \mathrm{F}$

$\mathrm{m}_{\mathrm{G}} \quad-\quad$ Mass of glass, $\mathrm{lb}_{\mathrm{m}}$

$\mathrm{c}_{\mathrm{PG}} \quad-\quad$ Specific heat of glass, Btu/lb $\mathrm{m}^{-}{ }^{\circ} \mathrm{F}$

Appendix D illustrates the calculation of the capacitance associated with the glass transfer function. The results are shown in Table 4.7.

Table 4.7 Parameters for Capacitance of Glass Transfer Function

\begin{tabular}{|c|c|}
\hline$m_{G}$ & $614 \mathrm{lb}_{\mathrm{m}}$ \\
\hline$c_{P G}$ & $0.2 \mathrm{Btu} / \mathrm{lb}_{\mathrm{m}}{ }^{\circ} \mathrm{F}$ \\
\hline$C_{G}$ & $123 \mathrm{Btu} /{ }^{\circ} \mathrm{F}$ \\
\hline
\end{tabular}


The capacitance associated with the glass transfer function is a function of the level of glass and hence its variation must be considered during the working period. However during the melting period, the mass of glass in the tank remains the same and hence the capacitance for the glass transfer function does not change.

\subsubsection{Development of Transfer Function for Glass}

The transfer function for the glass can be developed by applying equations of the conservation of energy [28]. The Law of Conservation of Energy is applied for the heat transfer from the hot gases to the glass and for the heat transfer from the glass to the walls. These equations are shown in Equations 4.6 and 4.7.

$$
C_{E} \frac{d T_{A}}{d t}=0.4 \dot{Q}_{B}-\left(\frac{T_{A}-T_{G}}{R_{E}}\right)
$$

where

$C_{E} \quad-\quad$ Capacitance of products of combustion

$\frac{d T_{A}}{d t} \quad-\quad$ Time rate of change of sensed temperature in batch tank

$\dot{Q}_{B} \quad-\quad$ Output energy from burner

$T_{A} \quad-\quad$ Sensed temperature in batch tank

$T_{G} \quad-\quad$ Temperature of glass

$R_{E} \quad-\quad$ Heat transfer resistance of products of combustion.

$$
C_{G} \frac{d T_{G}}{d t}=\left(\frac{T_{A}-T_{G}}{R_{E}}\right)-\left(\frac{T_{G}-T_{P}}{R_{G}}\right)
$$

where

$C_{G} \quad-\quad$ Capacitance of glass and refractory 
$\frac{d T_{G}}{d t} \quad$ - Time derivative of glass temperature

$T_{P} \quad-\quad$ Ambient temperature of plant

$R_{G} \quad$ - Heat transfer resistance of glass and refractory.

Laplace transforms of Equations 4.6 and 4.7 are solved for the glass temperature, $\mathrm{T}_{\mathrm{G}}(\mathrm{s})$, in terms of the ambient temperature, $\mathrm{T}_{\mathrm{A}}(\mathrm{s})$, and the plant temperature, $\mathrm{T}_{\mathrm{P}}(\mathrm{s})$, as shown in Equation 4.8. The plant temperature, $\mathrm{T}_{\mathrm{P}}(\mathrm{s})$, is ignored as the effect of the ambient air on the variation of the plant temperature will complicate the analysis.

$$
T_{G}(s)=\frac{2433 s T_{A}(s)}{s\left(2433+\frac{1}{R_{G}}\right)+C_{G}}
$$

Substituting the value of $\mathrm{T}_{\mathrm{G}}(\mathrm{s})$ in the Laplace transform of Equation 4.6, one can develop the transfer function for the glass as shown in Equation 4.9. The heat transfer parameters for the products of combustion, $\mathrm{C}_{\mathrm{E}}$ and $\mathrm{R}_{\mathrm{E}}$, obtained in Tables 4.3 and 4.4, are substituted in Equation 4.8. This enables one to obtain Equation 4.9 for the development of the transfer function when the glass level is changing, for which $R_{G}$ and $C_{G}$ change.

$$
G_{G}(s)=\frac{T_{A}(s)}{s Q_{B}(s)}=\frac{s\left(2433+\frac{1}{R_{G}}\right)+C_{G}}{\frac{2433}{R_{G}} s^{2}+\left(2433 C_{G}+487+\frac{0.2}{R_{G}}\right) s+0.2 C_{G}}\left[\frac{{ }^{\circ} F}{B t u / h r}\right]
$$

Substituting the values of heat transfer resistance and capacitance obtained from Tables 4.6 and 4.7, one obtains the transfer function for the glass element during the melting and conditioning periods as shown in Equation 4.10.

$$
G_{G M}(s)=\frac{T_{A}(s)}{s Q_{B}(s)}=\frac{0.059 s+0.003}{s^{2}+7.26 s+0.0006}\left[\frac{{ }^{\circ} F}{B t u / h r}\right]
$$


In order to obtain results closer to actual batch tanks, the transfer function obtained had to be multiplied by a constant value of $8 \times 10^{-4}$. The revised versions of Equations 4.9 and 4.10 are shown in Equations 4.11 and 4.12, respectively.

$$
G_{G}(s)=\frac{T_{A}(s)}{s Q_{B}(s)}=\frac{8 \times 10^{-4} s\left(2433+\frac{1}{R_{G}}\right)+C_{G}}{\frac{2433}{R_{G}} s^{2}+\left(2433 C_{G}+487+\frac{0.2}{R_{G}}\right) s+0.2 C_{G}}\left[\frac{{ }^{\circ} F}{B t u / h r}\right]
$$

The values of $\mathrm{R}_{\mathrm{G}}$ and $\mathrm{C}_{\mathrm{G}}$ at the beginning of the melting period are obtained from Tables 4.5 and 4.6. Substituting the value of $\mathrm{R}_{\mathrm{G}}=0.059 \mathrm{hr}-{ }^{\circ} \mathrm{F} / \mathrm{Btu}$ and $\mathrm{C}_{\mathrm{G}}=123 \mathrm{Btu} /{ }^{\circ} \mathrm{F}$, the transfer function for the melting and conditioning periods are obtained as shown in Equation 4.12.

$$
G_{G M}(s)=\frac{T_{A}(s)}{s Q_{B}(s)}=\frac{4.72 \times 10^{-5} s+2.4 \times 10^{-6}}{s^{2}+7.26 s+0.0006}\left[\frac{{ }^{\circ} F}{B t u / h r}\right]
$$

The final-value theorem can be used to obtain the response of this transfer function for a step input in energy for a flow rate $900 \mathrm{ft}^{3} / \mathrm{hr}$ of natural gas or 540,000 $\mathrm{Btu} / \mathrm{hr}$. The DC gain is the ratio of the output of a system to its input after all transients have decayed. The final value theorem states that for a stable system such as $\mathrm{G}_{\mathrm{GM}}(\mathrm{s})$, the steady state value for a step input of 540,000 Btu/hr is given by Equation 4.13.

$$
T_{A}(\infty)=\lim _{s \rightarrow 0} s G_{G M}(s) \cdot \frac{540,000}{s}=2160^{\circ} \mathrm{F}
$$

Figure 4.6 shows the response of the model for a step input of $100,000 \mathrm{Btu} / \mathrm{hr}$, assuming an initial temperature of $2160^{\circ} \mathrm{F}$. 


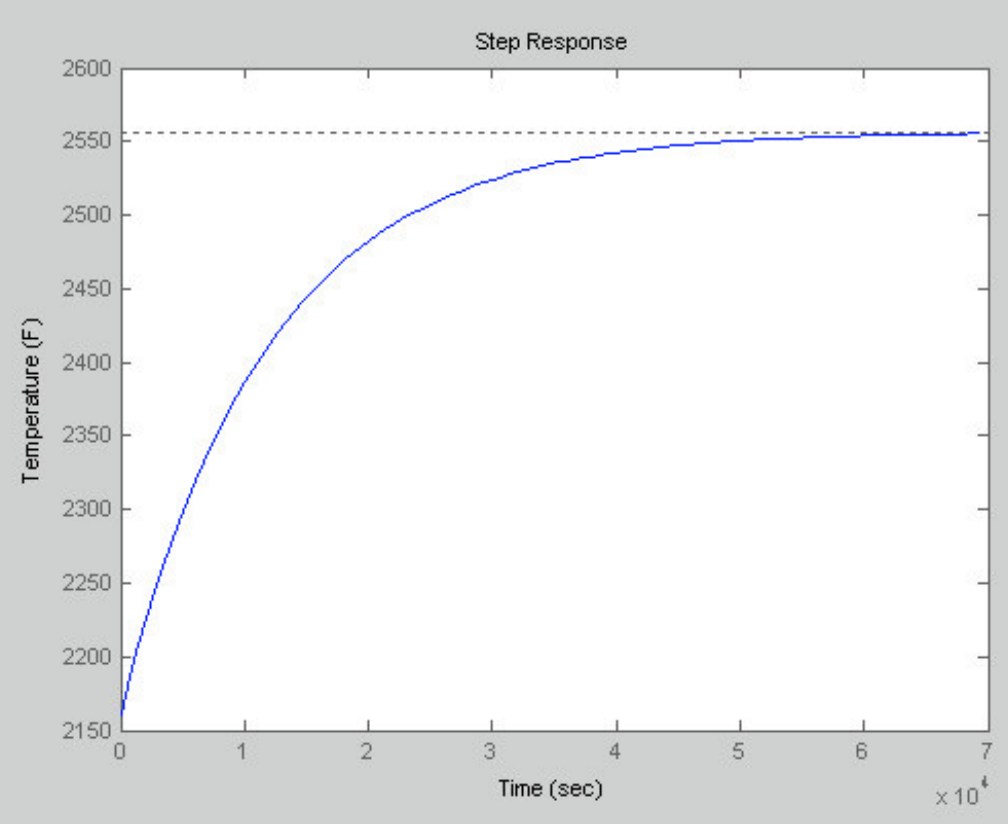

Figure 4.6 Response of Batch Tank Model during Melting and Conditioning Periods for a Step Input in Energy of 100,000 Btu/hr

There is an increase in temperature of about $397^{\circ} \mathrm{F}$ as a result of this additional heat input. These results are acceptable because energy outputs corresponding to the flow rates of natural gas at the beginning and end of melting periods, obtained at the L. E. Smith Glass Company, closely matched these figures.

\subsection{Transfer Functions for Glass during Working Period}

The effect of the heat transfer resistances and capacitances of the products of combustion and the glass element has already been analyzed. MS Excel can be used to develop the variation of the resistance associated with the glass element, $R_{G}$, and the capacitance of the glass element, $\mathrm{C}_{\mathrm{G}}$. These values are calculated as a function of the level of glass and the mass of glass in the tank using Equations 4.4 and 4.5 and are shown in Appendix D. Figure 4.7 shows the variation of the resistance of the glass element with time, as a result of the pulling of glass during glass working period. 


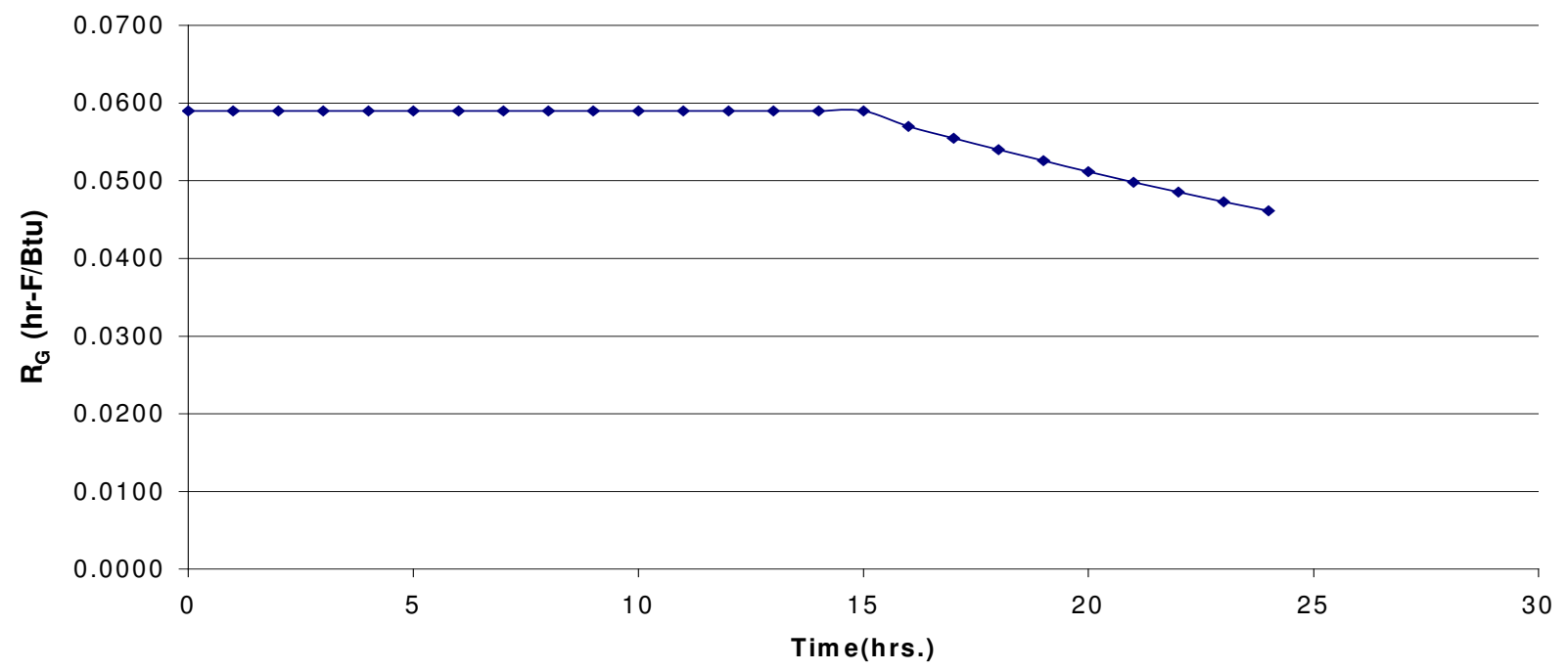

Figure 4.7 Time Profile of Heat Transfer Resistance of Glass $\left(\mathrm{R}_{\mathrm{G}}\right)$

Figure 4.8 shows the time profile of the capacitance of the glass element during glass working period.

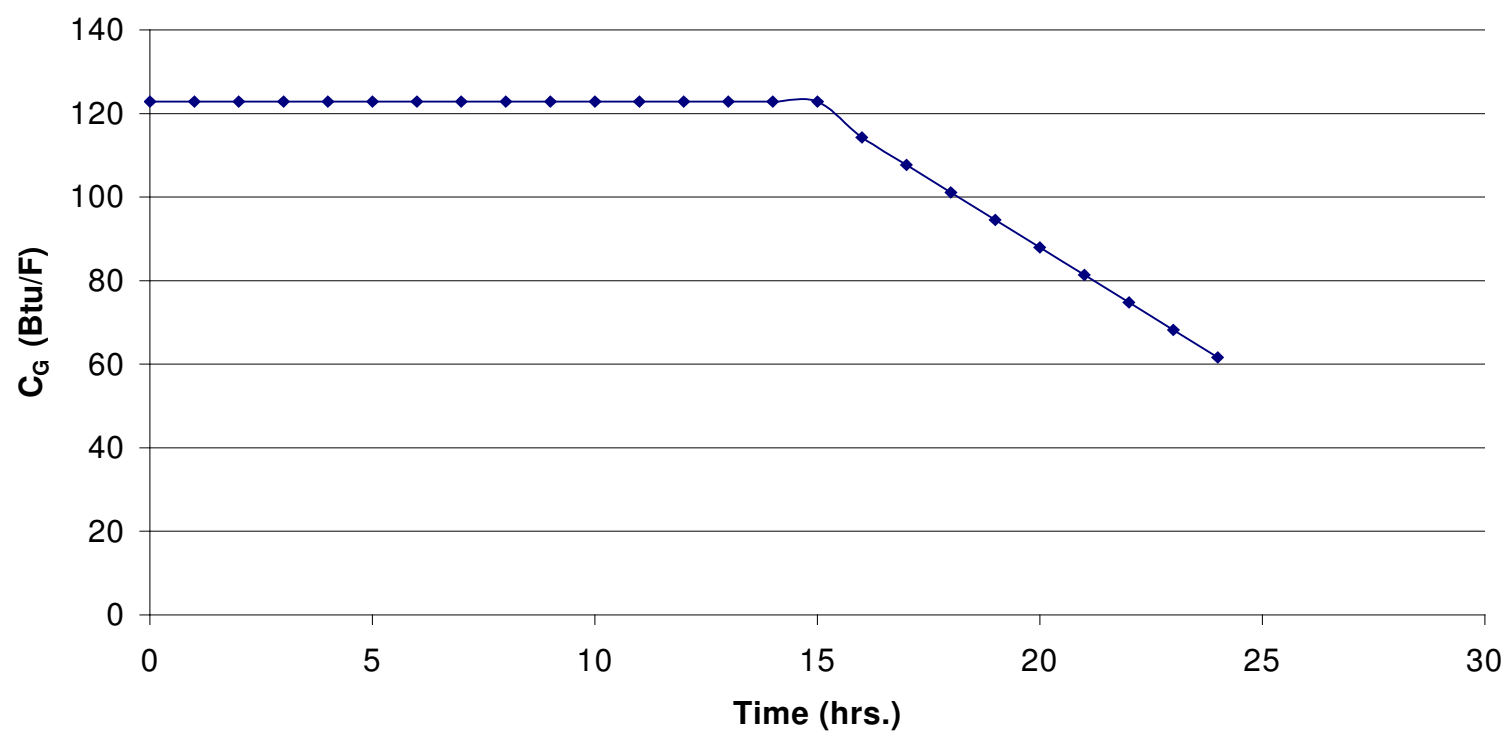

Figure 4.8 Time Profile of Heat Transfer Capacitance of Glass $\left(\mathrm{C}_{\mathrm{G}}\right)$

One can develop transfer functions for the glass element using the values of resistances and capacitances at different levels. These values are substituted in Equation 4.11 to develop the transfer functions for the glass during the working period, $\mathrm{G}_{\mathrm{GP}}(\mathrm{s})$. MS Excel Spreadsheet software was used to develop the transfer functions of the glass 
for various levels when the glass is being pulled (See Table D.1). Table 4.8 features the transfer functions for the glass during the working period for different levels of glass.

Table 4.8 Transfer Functions for Glass for Different Levels of Glass

\begin{tabular}{|c|c|c|}
\hline Time (hrs) & Level of Glass (ft) & Transfer Function for Glass, G $\mathrm{GP}(\mathrm{s})$ \\
\hline 15 & 1.66 & $\frac{4.75 \times 10^{-5} s+2.38 \times 10^{-6}}{s^{2}+7.26 s+0.0006}$ \\
\hline 16 & 1.545 & $\frac{4.59 \times 10^{-5} s+2.14 \times 10^{-6}}{s^{2}+6.53 s+0.00054}$ \\
\hline 17 & 1.456 & $\frac{4.47 \times 10^{-5} s+1.97 \times 10^{-6}}{s^{2}+5.99 s+0.00049}$ \\
\hline 18 & 1.367 & $\frac{4.35 \times 10^{-5} s+1.8 \times 10^{-6}}{s^{2}+5.47 s+0.00045}$ \\
\hline 20 & 1.278 & $\frac{4.24 \times 10^{-5} s+1.63 \times 10^{-6}}{s^{2}+4.98 s+0.00041}$ \\
\hline 21 & 1.189 & $\frac{4.13 \times 10^{-5} s+1.48 \times 10^{-6}}{s^{2}+4.51 s+0.00037}$ \\
\hline 22 & 1.1 & $\frac{4.02 \times 10^{-5} s+1.33 \times 10^{-6}}{s^{2}+4.07 s+0.00033}$ \\
\hline 23 & 1.011 & $\frac{3.91 \times 10^{-5} s+1.19 \times 10^{-6}}{s^{2}+3.64 s+0.0003}$ \\
\hline 24 & 0.922 & $\frac{3.82 \times 10^{-5} s+1.06 \times 10^{-6}}{s^{2}+3.24 s+0.0003}$ \\
\hline & 0.833 & $\frac{3.72 \times 10^{-5} s+9.35 \times 10^{-7}}{s^{2}+2.85 s+0.00022}$ \\
\hline & & \\
\hline
\end{tabular}

The general transfer functions for the glass element, $\mathrm{G}_{\mathrm{G}}(\mathrm{s})$, can be represented as shown in Equation 4.14.

$$
G_{G}(s)=\frac{T_{A}(s)}{s Q_{B}(s)}=\frac{A s+B}{X s^{2}+Y s+Z}\left[\frac{{ }^{\circ} F}{B t u / h r}\right]
$$

where the variables $\mathrm{A}, \mathrm{B}, \mathrm{X}, \mathrm{Y}$ and $\mathrm{Z}$ are determined by various factors such as the surface area of glass $\left(\mathrm{A}_{\mathrm{G}}\right)$, level of glass $\left(\mathrm{L}_{\mathrm{G}}\right)$, etc.

The relations between each variable and batch tank parameters are expressed in Equations 4.15, 4.16, 4.17, 4.18 and 4.19. 


$$
\begin{gathered}
A=f\left(A_{G}, \frac{L_{G}}{A_{G}}, S_{G}\right) \\
B=f\left(M_{G}\right) \\
X=f\left(A_{G}, \frac{A_{G}}{L_{G}}, \frac{1}{S_{G}}\right) \\
Y=f\left(M_{G}, A_{G}\right) \\
Z=f\left(M_{G}\right)
\end{gathered}
$$

where

$\mathrm{A}_{\mathrm{G}} \quad-\quad$ Surface area of glass, $\mathrm{ft}^{2}$

$\mathrm{L}_{\mathrm{G}} \quad-\quad$ Level of glass, $\mathrm{ft}$

$\mathrm{S}_{\mathrm{G}} \quad-\quad$ Conduction shape factor referenced to glass level

$\mathrm{M}_{\mathrm{G}} \quad-\quad$ Mass of glass, $\mathrm{lb}_{\mathrm{m}}$

The surface area of glass, $\mathrm{A}_{\mathrm{G}}$, remains constant throughout the working period while the rest of the properties change. From Equations 4.14 and 4.18, one can conclude that the damping for the batch tank depends on the mass of the glass in the tank, $\mathrm{M}_{\mathrm{G}}$, and the surface area of glass, $A_{G}$. Also, the natural frequency of the tank depends on the mass of the glass, $\mathrm{M}_{\mathrm{G}}$, in the tank. Any changes in these parameters will directly influence the performance of the batch tank model.

The operating practices of batch tanks require that a constant temperature of around $2100^{\circ} \mathrm{F}$ be maintained even when glass is pulled. The final value theorem can be used to prove that with a reduction in energy input to the burner, the same temperature can be obtained. In Section 4.3.5, one noticed that a step input of 540,000 Btu/hr was required to maintain a temperature of $2160^{\circ} \mathrm{F}$. The lowest level of the glass in the tank is $0.833 \mathrm{ft}$ (10 inches) and the corresponding transfer function for the glass element is 
shown in Table 4.8. The final value theorem is applied for the transfer function for the glass element corresponding to the lowest level of glass and is shown in Equation 4.20.

$$
T_{A}(\infty)=\lim _{s \rightarrow 0} s \cdot \frac{3.72 \times 10^{-5} s+9.35 \times 10^{-7}}{s^{2}+2.85 s+0.00022} \cdot \frac{508200}{s}=2160^{\circ} \mathrm{F}
$$

In this case, an input energy of 508,200 Btu/hr was enough to maintain the same temperature. This is equivalent to a reduction of about $3 \%$ during the working period. This proves that the reduction in energy during the working period is valid. The economic aspects of this reduction in input energy are discussed in Section 4.5.

\subsection{Overall Transfer Function for Batch Tank}

The overall transfer function for the batch tank can be developed from the models of the electric-actuated control valve, burner and the glass element. Again the variation of heat transfer parameters necessitates a different overall transfer function for the working period.

\subsubsection{Overall Transfer Function for Batch Tank during the Working Period}

From Table 4.8, one can notice that it would be a daunting task to develop controllers for each of the transfer functions during the working period. One way of obtaining an approximation will be to assume the transfer function corresponding to 14.5 inches of glass $(1.189 \mathrm{ft})$ as the transfer function that defines the sensed temperature of the batch tank during the entire working period. This argument permits one to use a single controller to maintain the temperature as closely as possible during the working period.

The transfer function for the glass during the working period, $\mathrm{G}_{\mathrm{GP}}(\mathrm{s})$, can be defined as shown in Equation 4.21.

$$
G_{G P}(s)=\frac{T_{A}(s)}{s Q_{B}(s)}=\frac{4.13 \times 10^{-5} s+1.48 \times 10^{-6}}{s^{2}+4.51 s+0.00037}\left[\frac{{ }^{\circ} F}{B t u / h r}\right]
$$


Figure 4.9 shows the open-loop block diagram representation of the transfer function for the batch tank.

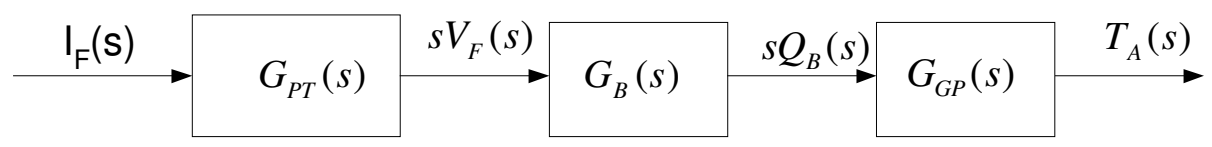

Figure 4.9 Block Diagram of Batch Tank Transfer Function during Glass

Working Period

The transfer function for the batch tank during the working period, $\mathrm{G}_{\mathrm{BTP}}(\mathrm{s})$, can be obtained as shown in Equation 4.22.

$$
G_{B T P}(s)=\frac{T_{A}(s)}{I_{F}(s)}=G_{P T}(s) \cdot G_{B}(s) \cdot G_{G P}(s)\left[\frac{{ }^{\circ} F}{m A}\right]
$$

Substituting the values for different transfer functions from Equations 3.23, 3.24, 3.27 and 4.21 in Equation 4.22, one obtains the transfer function for the batch tank during the working period, $\mathrm{G}_{\mathrm{BTP}}(\mathrm{s})$ as shown in Equation 4.23.

$$
G_{B T P}(s)=\frac{T_{A}(s)}{I_{F}(s)}=\frac{5007 s+179}{s^{4}+409 s^{3}+3827 s^{2}+9020 s+0.74} \quad\left[\frac{{ }^{\circ} F}{m A}\right]
$$

\subsection{Closed-Loop Model for Oxy-Fuel Fired Batch Tank}

Based on the transfer functions for the batch tanks, a controller can be designed for the working period. The closed-loop transfer function models can be developed based on Figure 4.10.

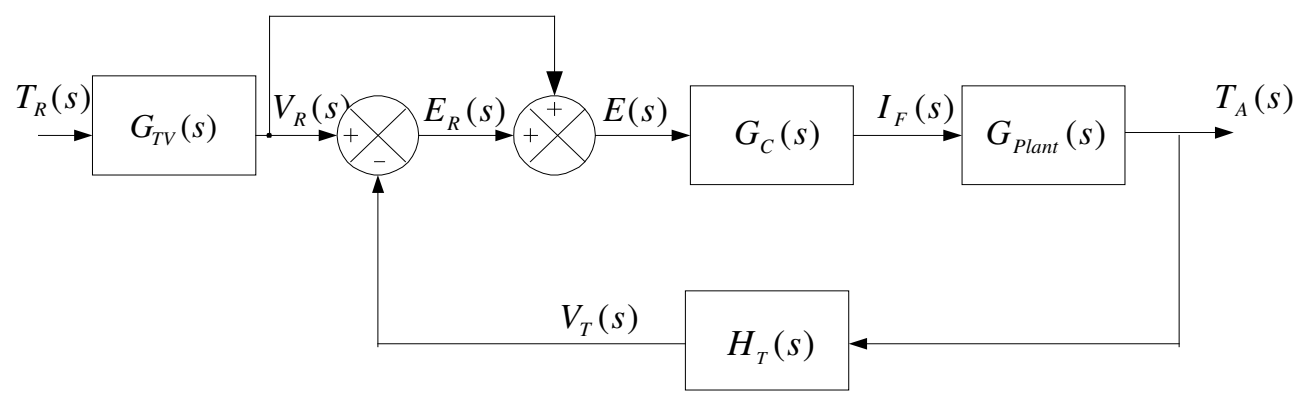

Figure 4.10 Closed-Loop Model for Oxy-Fired Batch Tank 
The transfer function for the plant, $\mathrm{G}_{\text {Plant }}(\mathrm{s})$, shown in Figure 4.10, depends on the glass making cycle. During the working period, the transfer function for the plant is represented by the transfer function, $\mathrm{G}_{\mathrm{BTP}}(\mathrm{s})$, shown in Equation 4.23.

The working of the closed-loop model can be explained as follows. A set-point temperature, $\mathrm{T}_{\mathrm{R}}(\mathrm{s})$, is passed through a temperature-to-voltage converter. This converter has the same calibration as the transfer function for the thermocouple, $G_{T}(s)$. But since in this case, there is no delay in the response to the input, the transfer function for the temperature to voltage converter, $\mathrm{G}_{\mathrm{TV}}(\mathrm{s})$, can be represented from Section 3.3 as shown in Equation 4.24.

$$
G_{T V}(s)=\frac{V_{R}(s)}{T_{R}(s)}=0.0228 \quad\left[\frac{V}{{ }^{\circ} F}\right]
$$

The output signal from the temperature to voltage converter is compared with the output signal from the feedback thermocouple to generate the error signal, $\mathrm{E}_{\mathrm{R}}(\mathrm{s})$. A feedforward arrangement is made so that the closed-loop model continues to function when the error signal, $\mathrm{E}_{\mathrm{R}}(\mathrm{s})$, becomes zero. The controller sends an output signal to the plant as determined by the transfer function, $\mathrm{G}_{\mathrm{C}}(\mathrm{s})$. The controller parameters depend on the glass making cycle of the plant and hence on the transfer function for the plant, $\mathrm{G}_{\text {Plant }}(\mathrm{s})$. The resultant output temperature is measured and sent back to the comparator.

\subsubsection{Closed-Loop Model of Batch Tank during Working Process}

One has already discussed that the transfer function for the plant, $G_{\text {Plant }}(s)$, during the working period can be represented by the batch transfer function for $\mathrm{G}_{\mathrm{BTP}}(\mathrm{s})$ in Section 4.5.1. The controller design for the working period is shown in Section 5.3.2. The closed-loop transfer function with the transfer function for the working period can be developed from Figure 4.10 as shown in Equation 4.25. 


$$
T_{B T P}(s)=\frac{T_{A}(s)}{T_{R}(s)}=G_{T V}(s) \cdot \frac{G_{C P U}(s) \cdot G_{B T P}(s)}{1+G_{C P U}(s) \cdot G_{B T P}(s) \cdot H_{T}(s)}\left[\frac{{ }^{\circ} F}{{ }^{\circ} F}\right]
$$

where

$\mathrm{G}_{\mathrm{CPU}}(\mathrm{s})$ - Transfer function of controller for working period

$\mathrm{T}_{\mathrm{BTP}}(\mathrm{s}) \quad$ - Transfer function of closed-loop model for batch tank during working period

Substituting Equation 4.24, Equation 4.23, Equation 3.30, and Equation 5.3 in Equation 4.25 one obtains the closed-loop batch tank transfer function with the controller for the working period, $\mathrm{T}_{\mathrm{BTP}}(\mathrm{s})$, as shown in Equation 4.26 .

$$
T_{B T P}(s)=\frac{0.86 s^{3}+5.4 s^{2}+3.5 s+0.11}{s^{6}+410 s^{5}+4110 s^{4}+1.16 \times 10^{4} s^{3}+6280 s^{2}+35 s+0.12}\left[\frac{{ }^{\circ} F}{{ }^{\circ} F}\right] 4.26
$$

The MATLAB and Simulink programs for the development of the closed-loop batch tank model are shown in Appendix A.

\subsection{Economic Aspects of Transient Controls for Oxy-Fired Batch Tank}

Figure 4.11 shows a typical glass manufacturing cost breakdown [29].

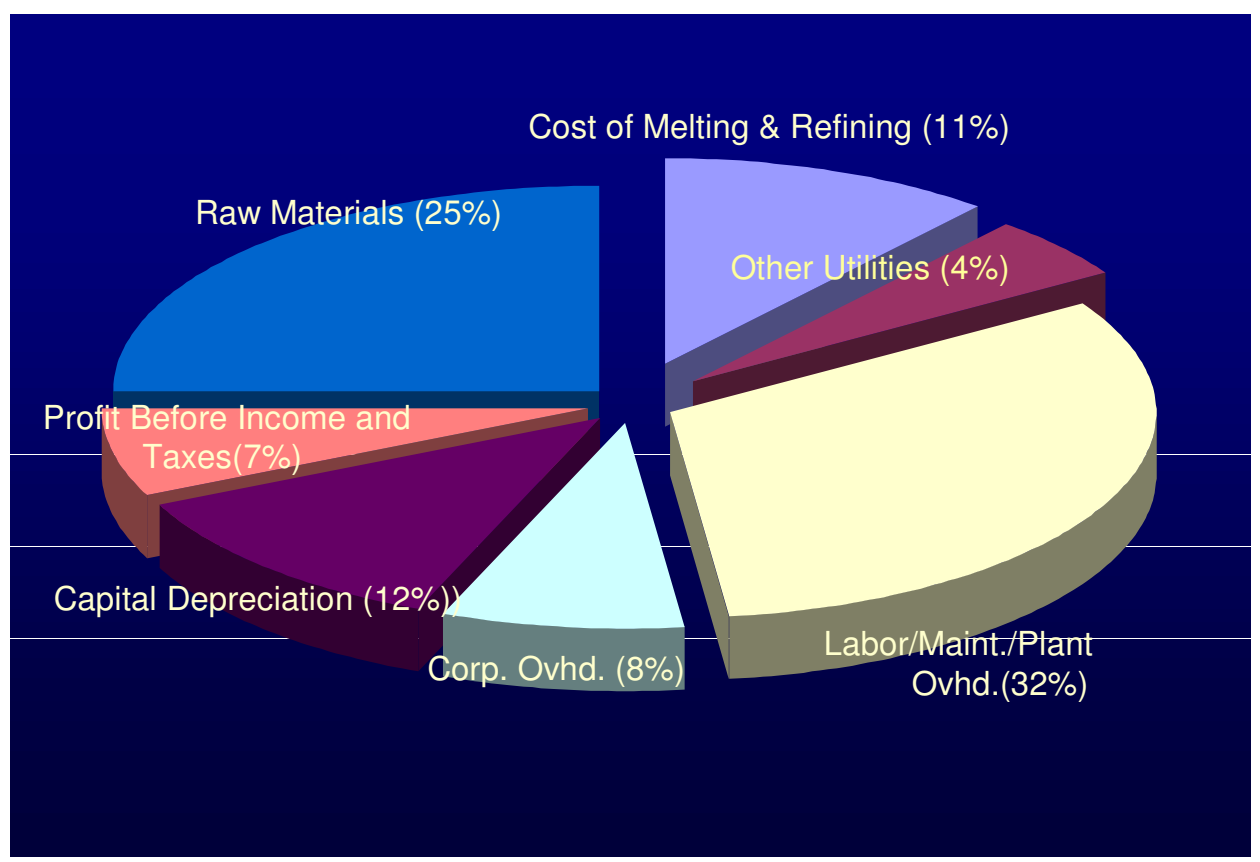

Figure 4.11 Typical Glass Manufacturer's Cost Breakdown 
The figure shows that $11 \%$ of the cost is spent on energy requirements. By the design of the enhanced controller, efforts were taken to reduce the contribution of energy expenses to the total cost for a glass manufacturer.

Based on the analysis of the heat going to the glass, the reduction in energy supplied to the tank had been recommended. In Section 4.4, analysis of the model dynamics confirmed that the reduction in energy could be achieved without any compromise on the temperature of the glass in the tank. Controllers were designed in Section 5.3 taking into consideration the average rate at which glass is pulled. This section will look at the economic benefits from the implementation of the enhanced design for the controllers. The improved design reduced the amount of energy spent during the working period. Figure 4.12 shows the temperature profile and the natural gas flow variation with the present and improved design.

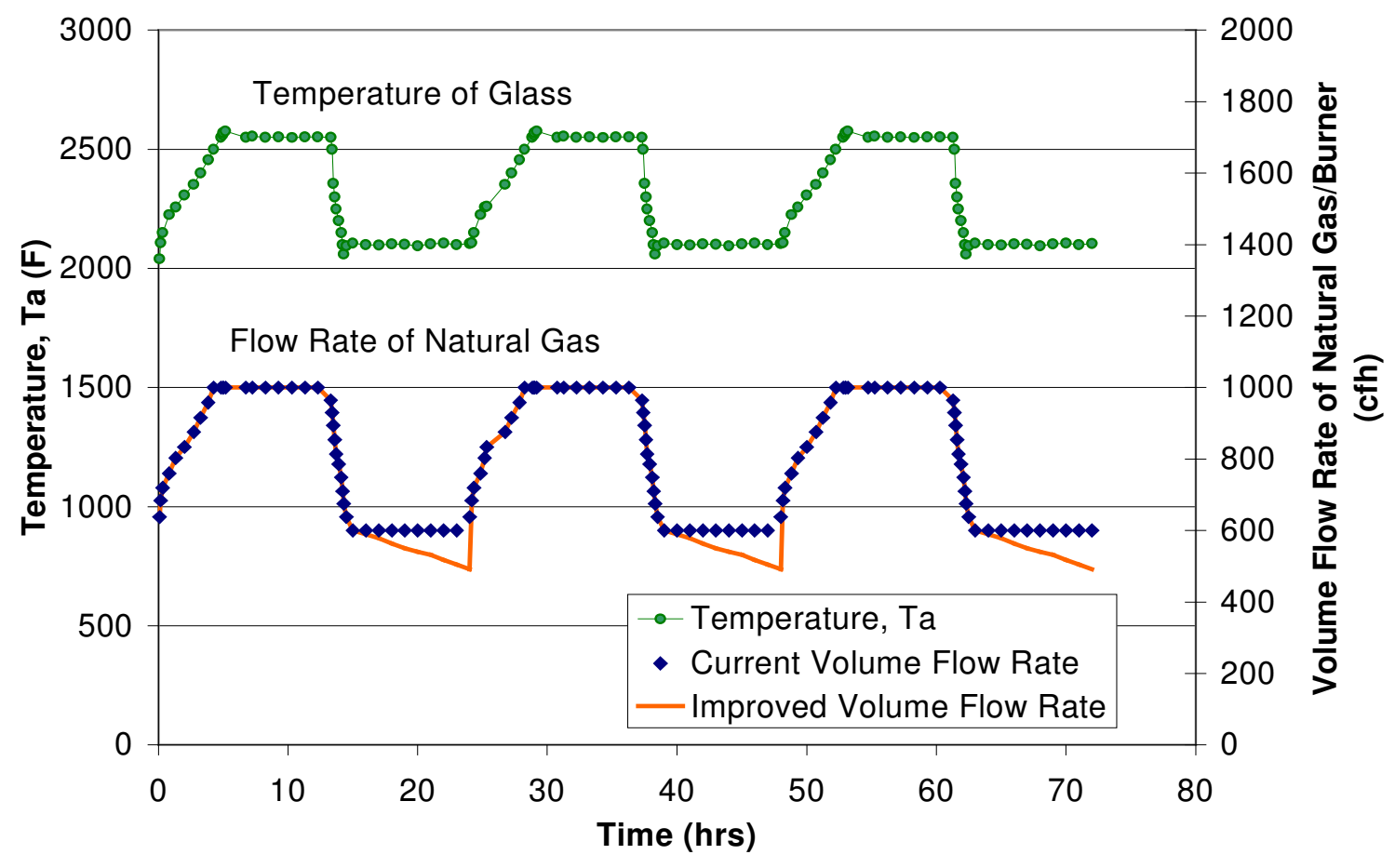

Figure 4.12 Time Profiles of Measured Temperature and Flow Rate of Natural Gas with Present and Enhanced Controllers [2] 
A similar graph can be plotted for the variation of oxygen flow during the 72-hour period as shown in Figure 4.13.

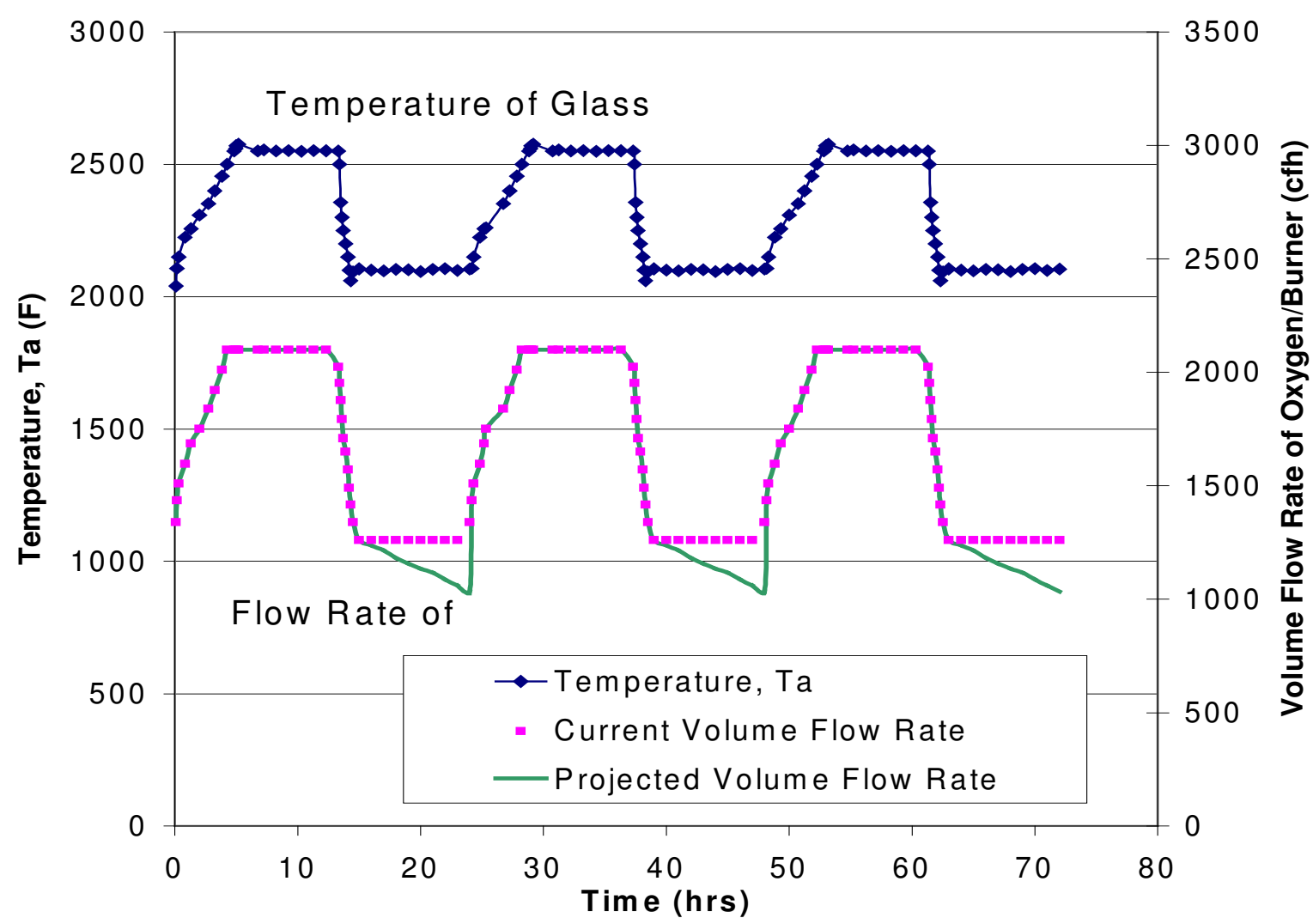

Figure 4.13 Time Profiles of Measured Temperature and Flow Rate of Oxygen with Present and Enhanced Controllers [2]

Section 4.3 discussed that an input energy of 540,000 Btu/hr was required at the beginning of the working period to maintain $2160^{\circ} \mathrm{F}$. Moreover, for maintaining a temperature of $2160^{\circ} \mathrm{F}$, an input energy of $508,200 \mathrm{Btu} / \mathrm{hr}$ was required at the end of the working period. This means that the natural gas supply can be reduced by about $4 \mathrm{ft}^{3} / \mathrm{hr}$ for every hour during the working period. Under present operating practices, this energy is being expended to the walls and to the exhaust. By cutting down on the natural gas supply, savings of $143,100 \mathrm{Btu}$ is achieved during a 9-hr working period. The total energy consumption for the glass making cycle is about $18700 \mathrm{MJ} /$ ton of glass melted. 
Research has proved that the amount of energy spent during the working period can be brought down from about $6800 \mathrm{MJ} / \mathrm{ton}$ of glass melted to about $6600 \mathrm{MJ} / \mathrm{ton}$ of glass melted. This amounts to savings of about 3\%. Figure 4.14 compares the energy consumption with present and enhanced methods for controlling the temperature inside the batch tank.

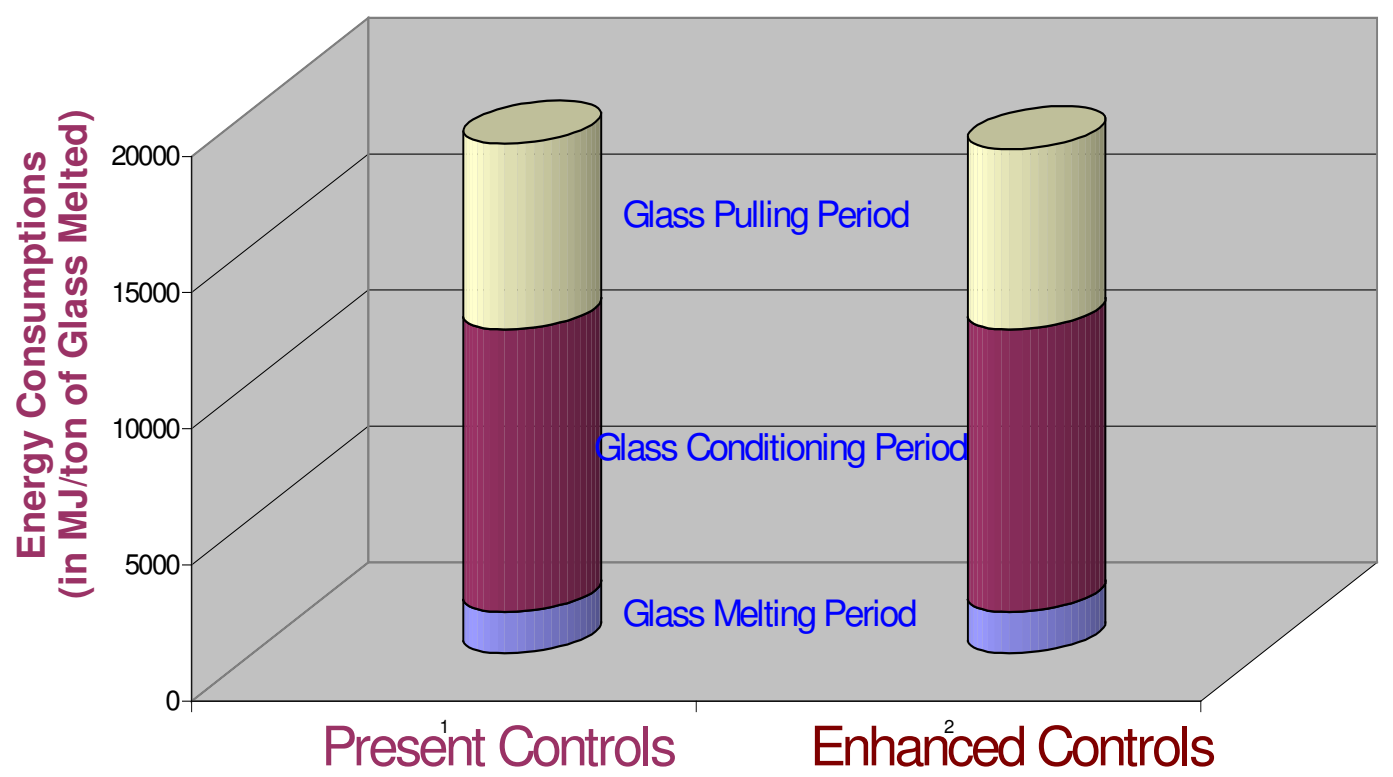

\section{$3 \%$ Reduction}

Figure 4.14 Comparison of Energy Consumptions with Present and Enhanced Controls

Since the oxygen flow rate depends on the natural gas supply, this also means there is additional savings from the reduced supply of oxygen. Appendix F shows the calculation of energy savings. 


\section{Chapter 5. Controller Design for Oxy-Fuel Fired Batch Tank}

\subsection{Introduction}

In this chapter, a controller will be designed for the working period of the glass making cycle. The closed-loop model of the batch tank will then be analyzed to maintain desired behavior.

A majority of the industries use PID (Proportional-Integral-Derivative) controllers or lead-lag controllers for their control applications. This is because of their cost and effectiveness for a variety of applications. Besides these advantages, the simple tuning techniques in these controllers make them best suited for the control applications in the glass industry. For the working period, a lead-lag controller will be designed.

\subsection{Discussion of Responses}

In this section, the performance of the overall batch tank transfer function will be analyzed. The performance of the batch tank during the working period can be obtained by doing root locus analysis and Bode plot analysis for the transfer function shown in Equation 4.25.

Figure 5.1 shows the root locus plot of the overall batch tank transfer function during the working period with a proportional controller with a gain of 1 . The SISOTOOL function of MATLAB was used for this purpose. Once the performance of the batch tank with a constant gain controller was analyzed, this could then be used to specify the parameters of the lead-lag controller to satisfy design constraints. The design of the controller is discussed in Section 5.3. 


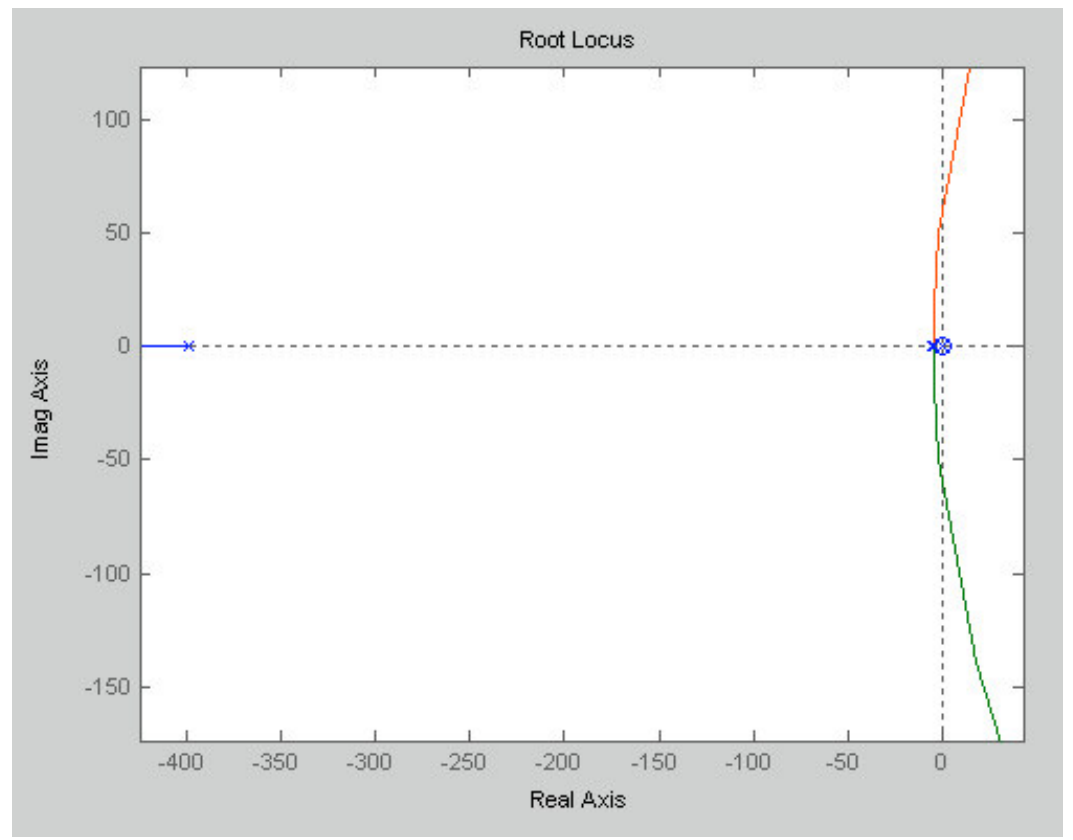

Figure 5.1 Root Locus Plot of Overall Batch Tank Transfer Function during Working Period

The root locus indicates that the system is not stable for values of $\mathrm{K}>1.2 \times 10^{4}$.

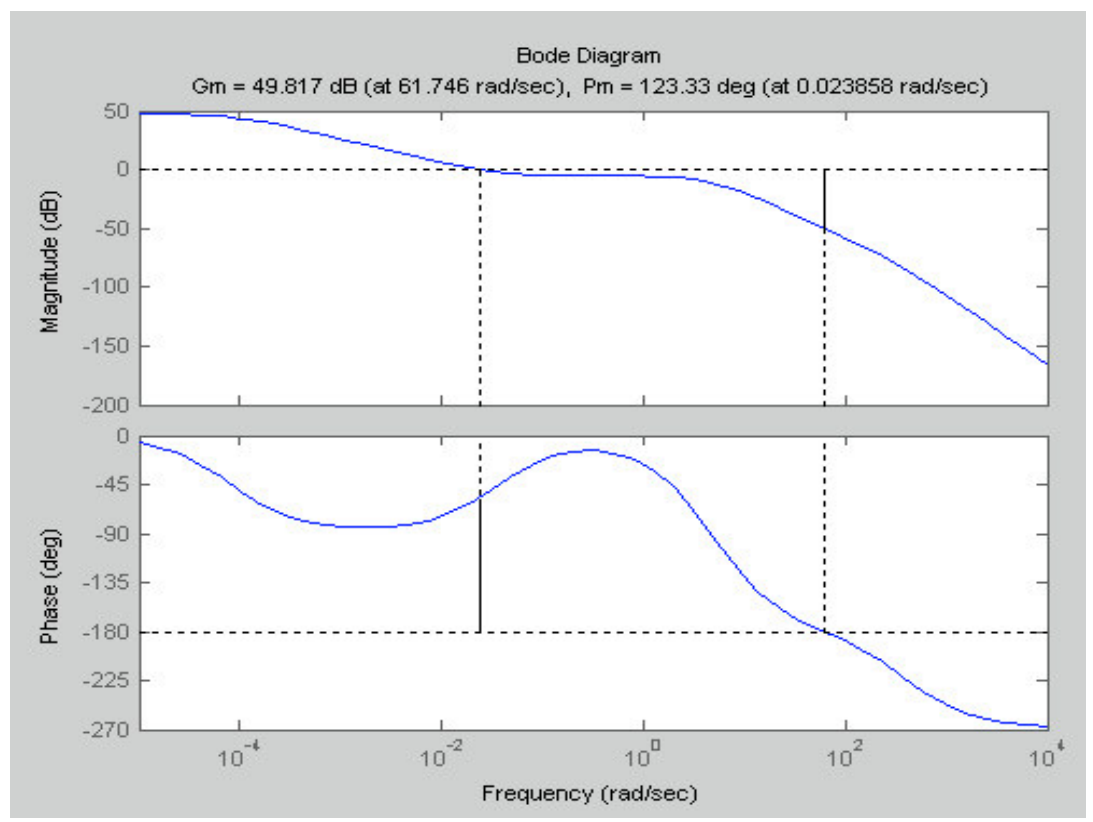

Figure 5.2 Bode Plot of Overall Batch Tank Transfer Function during Working Period

The Bode plot indicates that the transfer function for the batch tank has a Gain Margin of $50 \mathrm{~dB}$ and a Phase Margin of $124^{\circ}$. These stability margins are acceptable values for the batch tank. 
The desired behavior of the batch tank during the working period is featured in Table 5.1.

Table 5.1 Desired Performance of Closed-Loop Model during Working Period

\begin{tabular}{|c|c|c|c|}
\hline Period & Gain Margin, dB & Phase Margin, deg & Settling Time, $\mathrm{hr}$ \\
\hline Working & INF & 90 & 2 \\
\hline
\end{tabular}

\subsection{Design of Controller during Working Period}

The next step is determining the values for the controller to achieve the desired performance. The SISOTOOL function of the Control System Toolbox in MATLAB was used to develop the controller for the glass making cycles. This enables a user to modify the controller parameters and view the results instantaneously.

The selection of the parameters for the controller design is based on design constraints relevant to the working period. During the working period, glass temperature within the melt should not vary more than $4^{\circ} \mathrm{F}$. Table 5.2 shows some of the transient design requirements for the working period.

Table 5.2 Design Constraints for Working Period

\begin{tabular}{|c|c|}
\hline Maximum Overshoot & $<10 \%$ \\
\hline Rise Time & $<10$ minutes \\
\hline Settling Time & $<30$ minutes \\
\hline Steady State Error & $>60^{\circ}$ \\
\hline Phase Margin & \\
\hline
\end{tabular}

These design constraints are useful in the selection of the poles of the controller. The rise time of a system can be related to the natural frequency and the settling time can be related to the real part of the poles of the system. Similarly, the maximum overshoot can be related to the damping of the system. By selection of appropriate damping and natural frequency, the design conditions are satisfied. 
A pole was placed at -0.005 , in accordance with the design constraint for the steady state error. This reduced the rise time from 1.15 hours to 53 seconds. This modification reduced the steady state error from $15 \%$ to $0.1 \%$. But this change increased the maximum overshoot from $0 \%$ (over-damped) to $31 \%$. By placing a zero at -5.6 , the overshoot can be brought down to $19 \%$. The rise time in this case was 15 seconds, which is too fast. In order to reduce the maximum overshoot further and to slow down the response, the damping has to be increased. Reducing the gain to 0.0075 reduced the maximum overshoot to $7 \%$ and also increased the rise time to 7 minutes.

\subsubsection{Controller Design for Working Period}

The transfer function for the overall batch tank during the working period was found to be different from the one for the melting and conditioning period (See Appendix F). The transfer function for analysis during the working period was obtained in Equation 4.23.

Equation 5.1 shows the transfer function for the controller during the working period.

$$
G_{C P U}(s)=\frac{I_{F}(s)}{E(s)}=\frac{0.0075(s+5.6)}{(s+0.005)}\left[\frac{m A}{V}\right]
$$

Table 5.3 shows the transient features of the closed-loop model of the batch tank with the controller. Comparing the values of transient parameters in Table 5.3 with the design constraints specified in Table 5.2, one can conclude that the controller satisfies the design requirements. Also, one should consider that this is an open-ended design problem. This performance can be achieved through a set of totally different parameters for the lead-lag controller. 
Table 5.3 Transient Parameter of Closed-Loop Batch Tank

During Working Period

\begin{tabular}{|c|c|}
\hline Maximum Overshoot & $7 \%$ \\
\hline Rise Time & 7 minutes \\
\hline Settling Time & 22 minutes \\
\hline Steady State Error & $2 \%$ \\
\hline
\end{tabular}

Figure 5.3 shows the step response for the controller for a step decrease of $1{ }^{\circ} \mathrm{F}$ in the set-point from $2100{ }^{\circ} \mathrm{F}$ to $2099^{\circ} \mathrm{F}$.

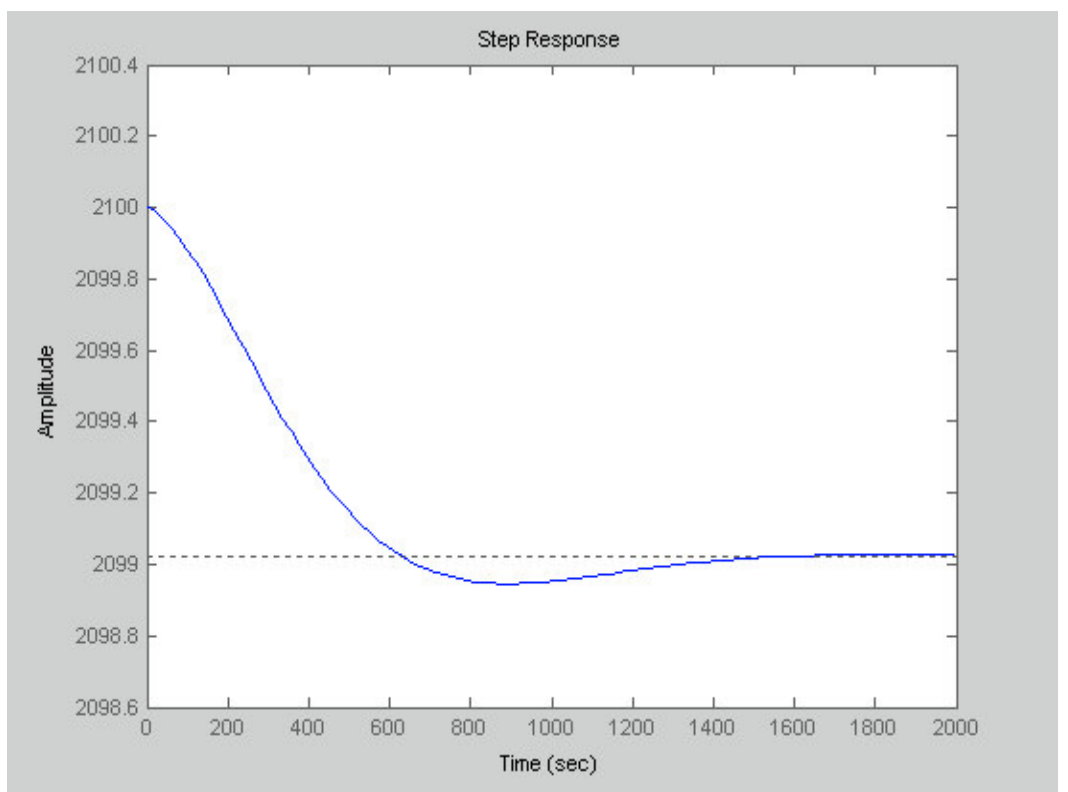

Figure 5.3 Response of Closed-Loop Transfer Function during Working Period for a Step Decrease in Set-Point of $1^{\circ} \mathrm{F}$.

Figure 5.4 shows the root locus of the closed-loop model for the working period with the controller. In this case, the system is not stable for all values of $\mathrm{K}>5.87 \times 10^{5}$. The range of $\mathrm{K}$ for which the system is stable has increased by the enhanced design. 
Figure 5.5 indicates that the closed-loop transfer function has a Gain Margin of about $117 \mathrm{~dB}$ and a Phase Margin of infinity. These values satisfy the requirements for stability of the system.

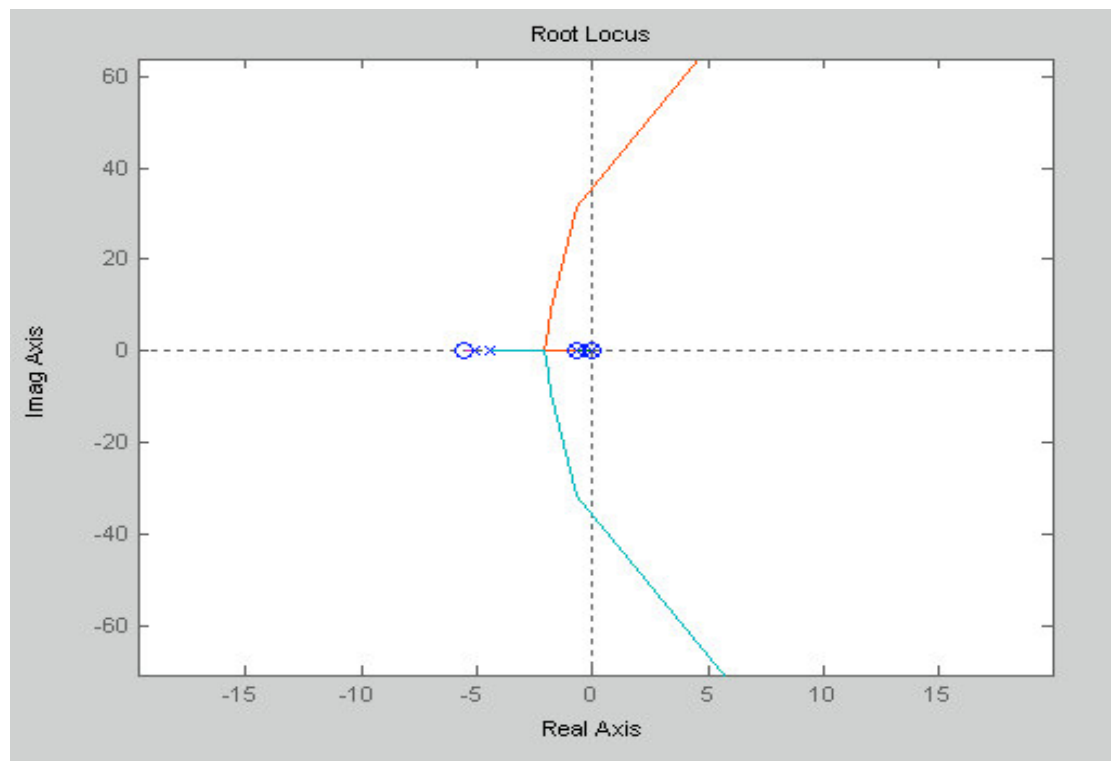

Figure 5.4 Root Locus Plot of Closed-Loop Transfer Function during Working Period

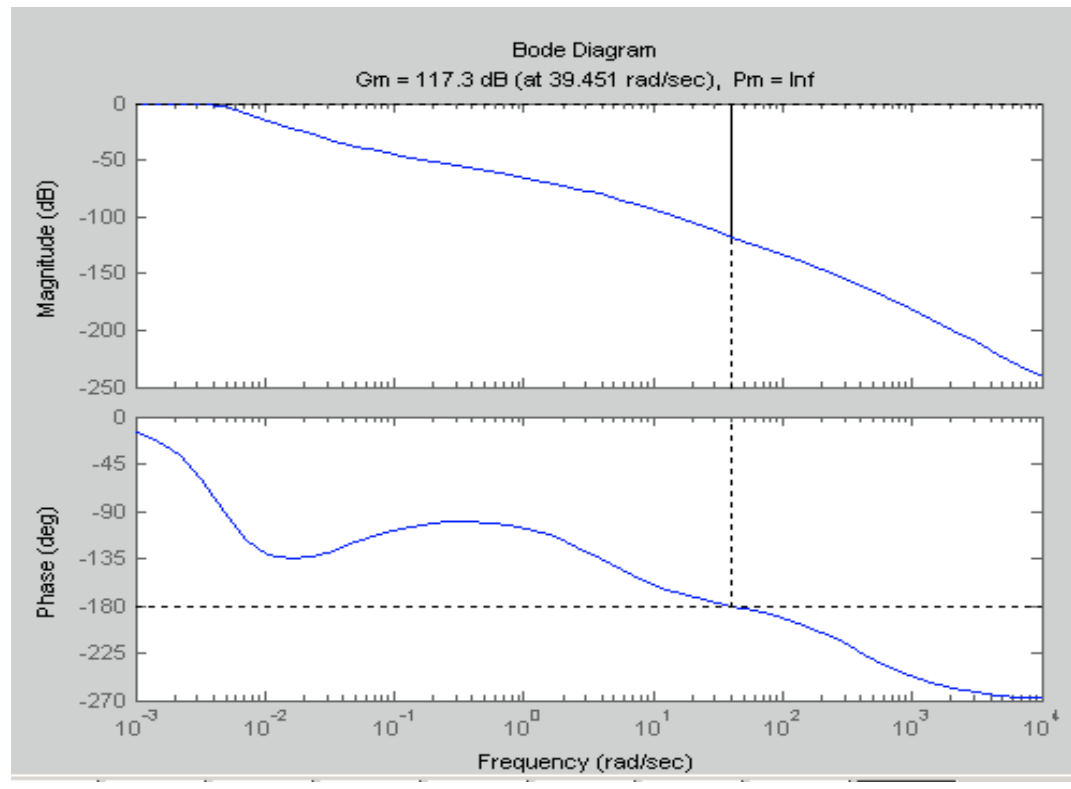

Figure 5.5 Bode Plot of Closed-Loop Transfer Function during Working Period 


\section{Chapter 6. Approach to Results}

The classical approach was used in Chapters 3 and 4 to achieve models of the various components of the batch tank, such as electric-actuated valves, burners, thermocouple, and batch tank. The transfer function approach was based on applied knowledge of mechanics, electronics, combustion, fluid flow, heat transfer, and control theory. This chapter discusses the methods selected to achieve the results for the closedloop model for the oxy-fuel fired batch tank shown in Chapter 7.

\subsection{Analysis using MS Excel}

In Section 4.3.5, the effect of the heat transfer resistance, $\mathrm{R}_{\mathrm{G}}$, and heat transfer capacitance of glass, $\mathrm{C}_{\mathrm{G}}$, on the transfer function for the glass was discussed. The variation of the heat transfer parameters during the working period could be analyzed with a spreadsheet application like MS Excel. Table 6.1 shows the spreadsheet program to determine the variation of these parameters during a glass making cycle. The first row in Table D. 1 corresponds to the beginning of the melting period. Similarly, the row corresponding to the sixteenth hour represents the condition in the batch tank at the beginning of the working period. The level of glass starts decreasing from this point till fresh batch is added at the end of the working period. Appendix D shows the calculations required for the determination of the transient parameters.

Once the values of the heat transfer parameters are obtained, these values can be substituted in Equation 4.11 to obtain the transfer functions at various stages of the working period. 
Table 6.1 Variation of Heat Transfer Parameters with Time

\begin{tabular}{|c|c|c|c|c|c|c|c|}
\hline $\begin{array}{c}\text { Time } \\
\text { (in hrs.) }\end{array}$ & $\begin{array}{l}L_{G} \text {, Level } \\
\text { of Glass(ft) }\end{array}$ & $\begin{array}{c}h_{\mathrm{W}} \\
\left(\mathrm{Btu} / \mathrm{hr}^{2}-\mathrm{ft}^{2}-{ }^{\circ} \mathrm{F}\right)\end{array}$ & $\begin{array}{l}A_{W G} \\
\text { (sq. ft) }\end{array}$ & $S_{G}$ & $\begin{array}{c}\mathrm{R}_{\mathrm{G}} \\
\left(\mathrm{hr}-{ }^{\circ} \mathrm{F} / \mathrm{Btu}\right)\end{array}$ & $\begin{array}{l}\text { Weight of } \\
\text { Glass } \\
\text { (lb) }\end{array}$ & $\begin{array}{l}\mathrm{C}_{\mathrm{G}} \\
(\mathrm{B})\end{array}$ \\
\hline 0 & 1.66 & 19.38 & 31.54 & 46.69 & 0.0590 & 6025 & 123 \\
\hline 1 & 1.66 & 19.38 & 31.54 & 46.69 & 0.0590 & 6025 & 123 \\
\hline 2 & 1.66 & 19.38 & 31.54 & 46.69 & 0.0590 & 6025 & 123 \\
\hline 3 & 1.66 & 19.38 & 31.54 & 46.69 & 0.0590 & 6025 & 123 \\
\hline 4 & 1.66 & 19.38 & 31.54 & 46.69 & 0.0590 & 6025 & 123 \\
\hline 5 & 1.66 & 19.38 & 31.54 & 46.69 & 0.0590 & 6025 & 123 \\
\hline 6 & 1.66 & 19.38 & 31.54 & 46.69 & 0.0590 & 6025 & 123 \\
\hline 7 & 1.66 & 19.38 & 31.54 & 46.69 & 0.0590 & 6025 & 123 \\
\hline$\varepsilon$ & 1.66 & 19.38 & 31.54 & 46.69 & 0.0590 & 6025 & 123 \\
\hline g & 1.66 & 19.38 & 31.54 & 46.69 & 0.0590 & 6025 & 123 \\
\hline 10 & 1.66 & 19.38 & 31.54 & 46.69 & 0.0590 & 6025 & 123 \\
\hline 11 & 1.66 & 19.38 & 31.54 & 46.69 & 0.0590 & 6025 & 123 \\
\hline 12 & 1.66 & 19.38 & 31.54 & 46.69 & 0.0590 & 6025 & 123 \\
\hline 13 & 1.66 & 19.38 & 31.54 & 46.69 & 0.0590 & 6025 & 123 \\
\hline 14 & 1.66 & 19.38 & 31.54 & 46.69 & 0.0590 & 6025 & 123 \\
\hline 15 & 1.66 & 19.38 & 31.54 & 46.69 & 0.0590 & 6025 & 123 \\
\hline 16 & 1.545 & 19.65 & 29.36 & 45.23 & 0.0570 & 5608 & 114 \\
\hline 17 & 1.456 & 19.88 & 27.66 & 44.10 & 0.0555 & 5285 & 108 \\
\hline 18 & 1.367 & 20.13 & 25.97 & 42.98 & 0.0540 & 4962 & 101 \\
\hline 19 & 1.278 & 20.41 & 24.28 & 41.85 & 0.0526 & 4639 & 95 \\
\hline 20 & 1.189 & 20.71 & 22.59 & 40.72 & 0.0512 & 4316 & 88 \\
\hline 21 & 1.100 & 21.05 & 20.90 & 39.60 & 0.0498 & 3993 & 81 \\
\hline 22 & 1.011 & 21.42 & 19.21 & 38.47 & 0.0485 & 3670 & 75 \\
\hline 23 & 0.922 & 21.84 & 17.52 & 37.34 & 0.0473 & 3347 & 68 \\
\hline 24 & 0.833 & 22.33 & 15.83 & 36.22 & 0.0461 & 3023 & 62 \\
\hline
\end{tabular}

The general transfer functions for the glass element, $\mathrm{G}_{\mathrm{G}}(\mathrm{s})$, can be represented as shown in Equation 6.1. This is a repeat of Equation 4.14.

$$
G_{G}(s)=\frac{T_{A}(s)}{s Q_{B}(s)}=\frac{A s+B}{X s^{2}+Y s+Z}\left[\frac{{ }^{\circ} F}{B t u / h r}\right]
$$

MATLAB code to determine the terms of the transfer function during the working stage is listed below.

$\mathrm{s}$ term in numerator $(\mathrm{A})$

ns $=2433+(1 / \operatorname{Rg})$;

constant term in numerator (B) 
$\mathrm{nc}=\mathrm{Cg}$;

$\mathrm{s}^{\wedge} 2$ term in denominator $(\mathrm{X})$

$\mathrm{ds} 2=2433 / \mathrm{Rg}$;

$\mathrm{s}$ term in denominator $(\mathrm{Y})$

$\mathrm{ds}=2433 * \mathrm{Cg}+487+0.2 / \mathrm{Rg}$;

constant term in denominator $(\mathrm{Z})$

$\mathrm{dc}=0.2 * \mathrm{Cg}$

corrected $\mathrm{s}$ term in numerator

ns1 = ns $* 8 \mathrm{e}-4$

corrected constant in numerator

$\mathrm{nc} 1=\mathrm{nc} * 8 \mathrm{e}-4$

corrected $\mathrm{s}^{\wedge} 2$ term in denominator

$\mathrm{ds} 21=\mathrm{ds} 2 / \mathrm{ds} 2=1$;

corrected $\mathrm{s}$ term in denominator

$\mathrm{ds} 1=\mathrm{ds} / \mathrm{ds} 2$;

corrected constant term in denominator

$\mathrm{dc} 1=\mathrm{dc} / \mathrm{ds} 2 ;$

Table 6.2 shows the spreadsheet for the development of the terms of the transfer function of glass during the working period, $\mathrm{G}_{\mathrm{GP}}(\mathrm{s})$.

Table 6.2 Transfer Function Terms of Glass during Working Period

\begin{tabular}{|r|r|r|r|r|r|r|r|r|}
\hline $\begin{array}{r}\text { Time } \\
(\mathrm{hrs})\end{array}$ & $\begin{array}{c}\mathrm{s} \\
\text { term } \\
\text { in } \\
\mathrm{Nr} . \\
(\mathrm{A})\end{array}$ & $\begin{array}{c}\mathrm{s}^{\wedge} 2 \\
\text { term } \\
\text { in } \mathrm{Dr} . \\
(\mathrm{X})\end{array}$ & $\begin{array}{c}\mathrm{s} \text { term } \\
\text { in } \mathrm{Dr} \\
(\mathrm{Y}) .\end{array}$ & $\begin{array}{c}\text { Constant } \\
\text { term in } \\
\text { Dr. } \\
(\mathrm{Z})\end{array}$ & $\begin{array}{c}\text { Corrected } \\
\text { s term } \\
\text { in Nr. }\end{array}$ & $\begin{array}{c}\text { Corrected } \\
\text { Constant } \\
\text { in Nr. }\end{array}$ & $\begin{array}{r}\text { Corrected } \\
\text { s term } \\
\text { In Dr }\end{array}$ & $\begin{array}{c}\text { Corrected } \\
\text { Constant } \\
\text { in Dr. }\end{array}$ \\
\hline 15 & 2450 & 41240 & 299400 & 25 & $4.75 \mathrm{E}-05$ & $2.38 \mathrm{E}-06$ & 7.26 & 0.0006 \\
\hline 16 & 2451 & 42690 & 278700 & 23 & $4.59 \mathrm{E}-05$ & $2.14 \mathrm{E}-06$ & 6.53 & 0.00054 \\
\hline 17 & 2451 & 43850 & 262700 & 22 & $4.47 \mathrm{E}-05$ & $1.97 \mathrm{E}-06$ & 5.99 & 0.00049 \\
\hline 18 & 2452 & 45060 & 246600 & 20 & $4.35 \mathrm{E}-05$ & $1.8 \mathrm{E}-06$ & 5.47 & 0.00045 \\
\hline 19 & 2452 & 46290 & 230600 & 19 & $4.24 \mathrm{E}-05$ & $1.63 \mathrm{E}-06$ & 4.98 & 0.00041 \\
\hline 20 & 2453 & 47550 & 214600 & 18 & $4.13 \mathrm{E}-05$ & $1.48 \mathrm{E}-06$ & 4.51 & 0.00037 \\
\hline 21 & 2453 & 48840 & 198500 & 16 & $4.02 \mathrm{E}-05$ & $1.33 \mathrm{E}-06$ & 4.07 & 0.00033 \\
\hline 22 & 2454 & 50140 & 182500 & 15 & $3.91 \mathrm{E}-05$ & $1.19 \mathrm{E}-06$ & 3.64 & 0.0003 \\
\hline 23 & 2454 & 51440 & 166500 & 14 & $3.82 \mathrm{E}-05$ & $1.06 \mathrm{E}-06$ & 3.24 & 0.00027 \\
\hline 24 & 2455 & 52720 & 150500 & 12 & $3.72 \mathrm{E}-05$ & $9.35 \mathrm{E}-07$ & 2.85 & 0.00022 \\
\hline
\end{tabular}




\subsection{Analysis using MATLAB}

MATLAB and Simulink were used to obtain the dynamic response of each subsystem of the batch tank. MATLAB provides the ability to represent the models and then appreciate the transient step responses and the steady state Bode plots of these subsystems. Simulink code was also used to represent the models and to generate results. These results were then compared with the MATLAB results for consistency.

The control system toolbox in MATLAB offers tools to manipulate and analyze Linear Time Invariant (LTI) models. This toolbox provides customized data structures, which encapsulate the model data. The object-oriented programming capability of MATLAB allows one to include properties like model data, sample time, delay times, input or output names [30].

The use of MATLAB in producing the results can be illustrated by solving the model for the batch tank developed in Section 4.3.5. The transfer function model for the batch tank during the working period was obtained as shown in Equation 6.2.

$$
G_{G P}(s)=\frac{T_{G}(s)}{s Q_{B}(s)}=\frac{4.13 \times 10^{-5} s+1.48 \times 10^{-6}}{s^{2}+4.51 s+0.00037} \quad\left[\frac{{ }^{\circ} F}{B t u / h r}\right]
$$

The continuous-time Single Input Single Output (SISO) transfer function above is characterized by its numerator, $\mathrm{n}(\mathrm{s})$ and denominator, $\mathrm{d}(\mathrm{s})$, both polynomials of the Laplace variable, s. In the code below, $\mathrm{n}$ and $\mathrm{d}$ are row vectors listing the coefficients of the polynomials, $\mathrm{n}(\mathrm{s})$ and $\mathrm{d}(\mathrm{s})$ respectively, when these polynomials are ordered in descending powers of $\mathrm{s}$.

$$
\begin{aligned}
& \mathrm{n}=\left[\begin{array}{lll}
4.13 \mathrm{e}-5 & 1.48 \mathrm{e}-6
\end{array}\right] ; \\
& \mathrm{d}=\left[\begin{array}{lll}
1 & 4.51 & 0.00037
\end{array}\right]
\end{aligned}
$$


One can use the 'tf' command to develop the transfer function model in MATLAB. The ' $\mathrm{tf}$ ' command is one of many ways that MATLAB offers to represent model data. The 'zpk' command is used for zero-pole-gain representation of the model. $\mathrm{g}=\mathrm{tf}(\mathrm{n}, \mathrm{d})$

The control system toolbox builds this transfer function Transfer function:

$$
g=\frac{4.13 e-5 s+1.48 e-6}{s^{\wedge} 2+4.51 s+0.00037}
$$

Based on actual appreciation of the batch tank performance, certain modifications need to be made to the developed model. To modify the design, the model obtained had to be multiplied by $8 \times 10^{-4}$. The modified transfer function is entered in MATLAB code using row vectors for numerators and denominators as illustrated earlier.

$$
\begin{aligned}
& \operatorname{ngp}=8 \mathrm{e}-4 *\left[\begin{array}{ll}
4.13 \mathrm{e}-5 & 1.48 \mathrm{e}-6
\end{array}\right] \\
& \operatorname{dgp}=\left[\begin{array}{lll}
1 & 4.51 & 0.00037
\end{array}\right] \\
& \operatorname{ggp}=\operatorname{tf}(\operatorname{ngp}, \operatorname{dgp})
\end{aligned}
$$

The Control System Toolbox also provides a set of functions that provide the basic time and frequency domain analysis plots used in control system engineering. Time responses investigate the time-domain transient behavior of linear models for particular inputs and disturbances. The toolbox provides functions for step response, impulse response, and general linear simulations. Frequency-domain analysis can be performed with Bode plots, Nichols plots and Nyquist plots. The function 'step' automatically generates a simulation horizon for the time response plot for the model. These time response functions also allow one to customize the plots obtained. When the natural gas 
flow rate is $600 \mathrm{ft}^{3} / \mathrm{hr}$, the amount of energy output from the burner is about 540,000 $\mathrm{Btu} / \mathrm{hr}$. One has seen in Section 4.3 that the output temperature for this energy is about $2160^{\circ} \mathrm{F}$. This can be verified in MATLAB by the following code:

$$
\text { step }(540000 * \text { ggp) }
$$

The steady state value of this response is the output temperature for a step input in energy of 540,000 Btu/hr.

An initial value can be set for the output response. The temperature at the beginning of the melting period is about $2100{ }^{\circ} \mathrm{F}$. The response of the batch tank model when the input energy is increased by $100,000 \mathrm{Btu} / \mathrm{hr}$ can be obtained by multiplying the transfer function by 100,000 . The step response of the model for the batch tank during the melting period is obtained by typing the code written below.

$$
\text { step }(100000 * \text { ggp }+2160)
$$

The Control System Toolbox also offers the SISO Design Tool, which is a graphical user interface (GUI) that facilitates the design of compensators for single-input, single-output feedback loops. It offers the control system engineer, the ability to manipulate closed-loop dynamics using root locus techniques, shape open-loop Bode responses, adjust phase and gain margins and add compensator poles and zeros, if required. The SISOTOOL function was used to design the controller in Section 5.3. The gains and pole placements of the controller were based on understanding of control system engineering.

\subsection{Temperature Acquisition using LabVIEW}

LabVIEW was used to develop an application to monitor temperatures acquired using a thermocouple, inside the batch tank for potential use in the future. LabVIEW is a 
graphical programming language which has language code written in a flow chart manner. Measured temperatures are shown on graphs on the front panel. The flow chart code is represented on the diagram window of the LabVIEW program. This program was created to acquire the temperatures in either degree Celsius or degree Fahrenheit. The data acquisition card used for this application was a DAQ 6024E card, manufactured by National Instruments. This card has a maximum sampling rate of 200,000 samples/second and a 12-bit resolution. Practice temperatures were acquired at 1000 samples/second in a refrigerator and the mean was calculated to reduce errors in the measurement. Also, the program offers the user the choice of saving the acquired temperature. The measured temperature and time of measurement is saved in a MS Excel program, which can then be analyzed to observe performance of the batch tank. Appendix $G$ features the LabVIEW application for acquiring the temperatures from a batch tank. 


\section{Chapter 7. Summary and Results}

This chapter is a summary of all the results and conclusions obtained in this endeavor. A comprehensive description of these results and conclusions are available in previous chapters.

\subsection{Summary}

\subsubsection{Main Objectives}

The six main objectives of this research were: (1) Identification and modeling of the key elements in a batch tank; (2) Explanation of the transient behavior of batch tank during the working period; (3) Development of enhanced controller which incorporates the amount of glass pulled; (4) Definition of new controller equipment specifications; (5) Study of the performance of the closed-loop model for the batch tank; and (6) Analyze actual time responses using LabVIEW for potential use in batch tanks.

\subsubsection{Main Approach}

Classical approach was used to perform modeling and analysis of batch tank related subsystems such as electric actuated valves, burners, thermocouple, and the batch tank. The research was based on the applied knowledge of mechanics, electronics, combustion, fluid flow, heat transfer and control theory.

\subsubsection{Results}

Glass melting was assumed to take place over a 24-hour period. After fresh batch is added, the glass is heated to $2500^{\circ} \mathrm{F}$ in about 6 hours and held at that temperature for about 8 hours. Then glass is cooled down to a working temperature of about $2100^{\circ} \mathrm{F}$ in about an hour. Glass is generally pulled out at a constant rate during the nine-hour working period. At the end of the working period of 9 hours, fresh batch is added and the 
cycle is repeated. Figure 7.1 shows the variation of the level of glass $\left(\mathrm{L}_{\mathrm{G}}\right)$ and the weight of the glass over a 72-hour period.

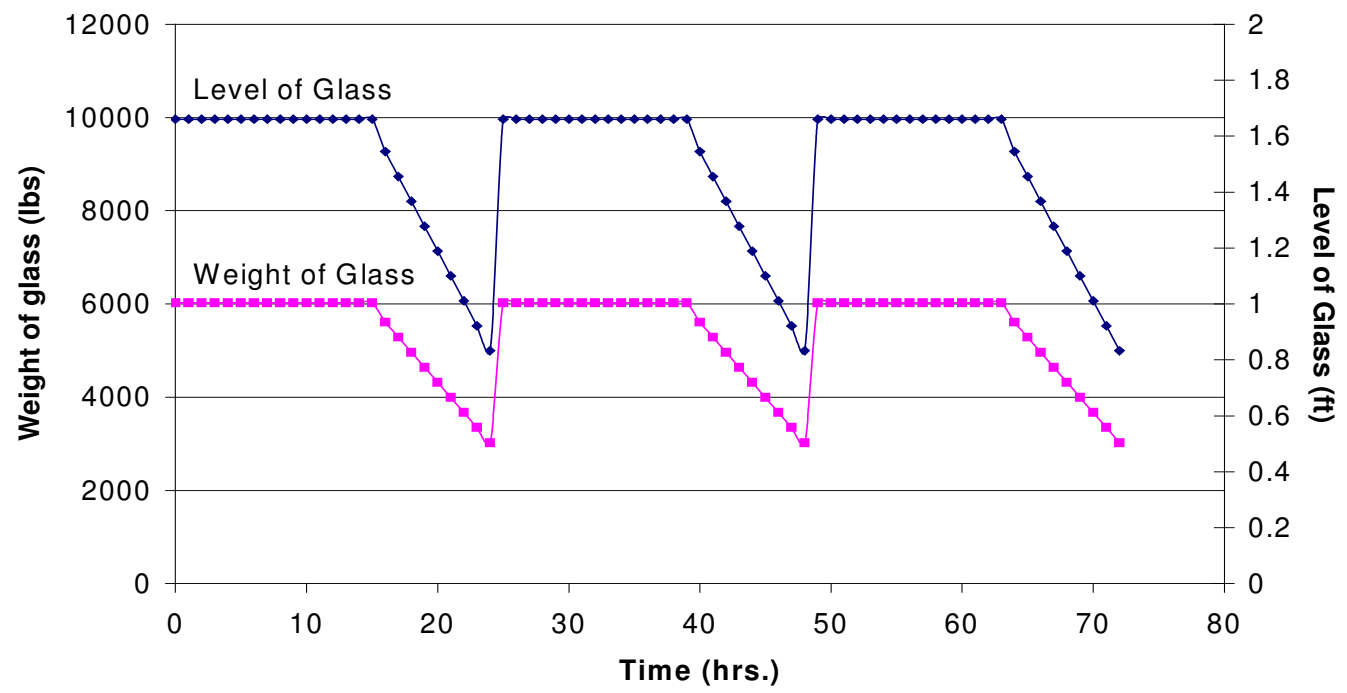

Figure 7.1 Time Profile of Level of Glass and Weight of Glass inside Batch Tank As the level of glass $\left(\mathrm{L}_{\mathrm{G}}\right)$ and the mass of the glass $\left(\mathrm{M}_{\mathrm{G}}\right)$ in the tank decreases, the resistance of heat transfer to glass $\left(\mathrm{R}_{\mathrm{G}}\right)$ and the capacitance of heat transfer to glass $\left(\mathrm{C}_{\mathrm{G}}\right)$ also decreases. Figure 7.2, a repeat of Figure 4.7, shows the variation of the heat transfer resistance of the glass $\left(\mathrm{R}_{\mathrm{G}}\right)$ during the working period and Figure 7.3, a repeat of Figure 4.8, shows the variation of the heat transfer capacitance of the glass $\left(\mathrm{C}_{\mathrm{G}}\right)$.

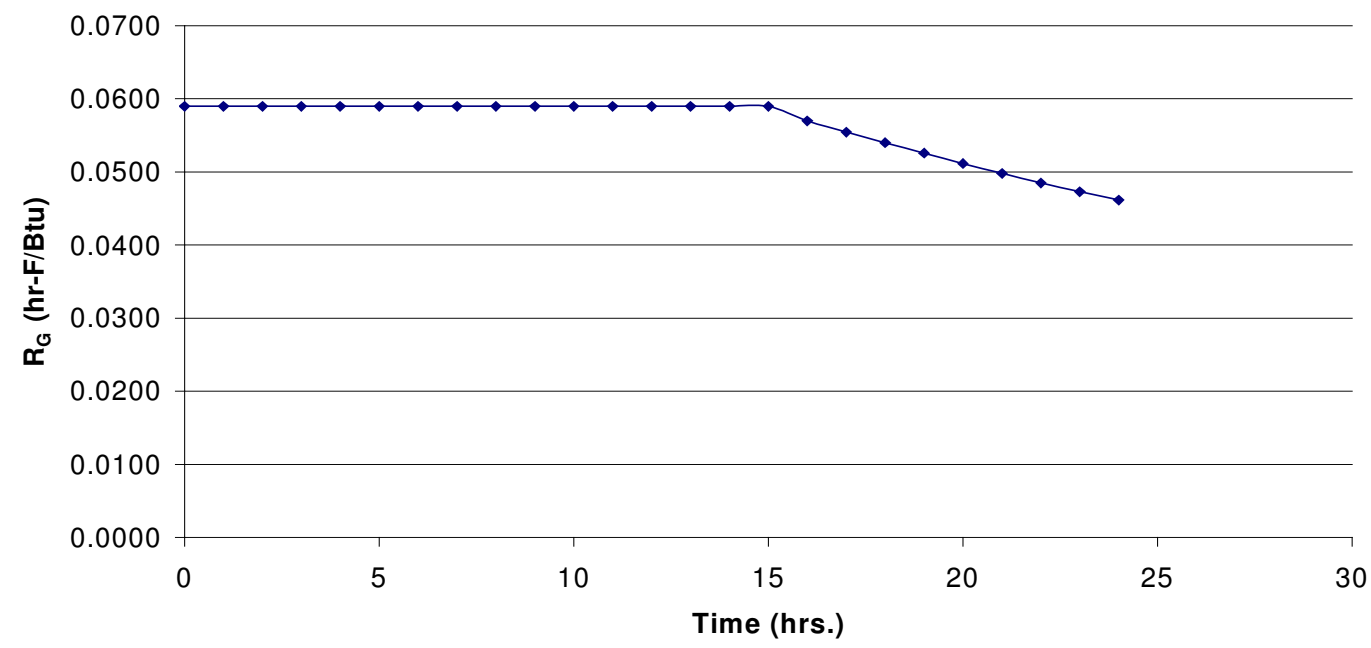

Figure 7.2 Time Profile of Heat Transfer Resistance of Glass $\left(\mathrm{R}_{\mathrm{G}}\right)$ 


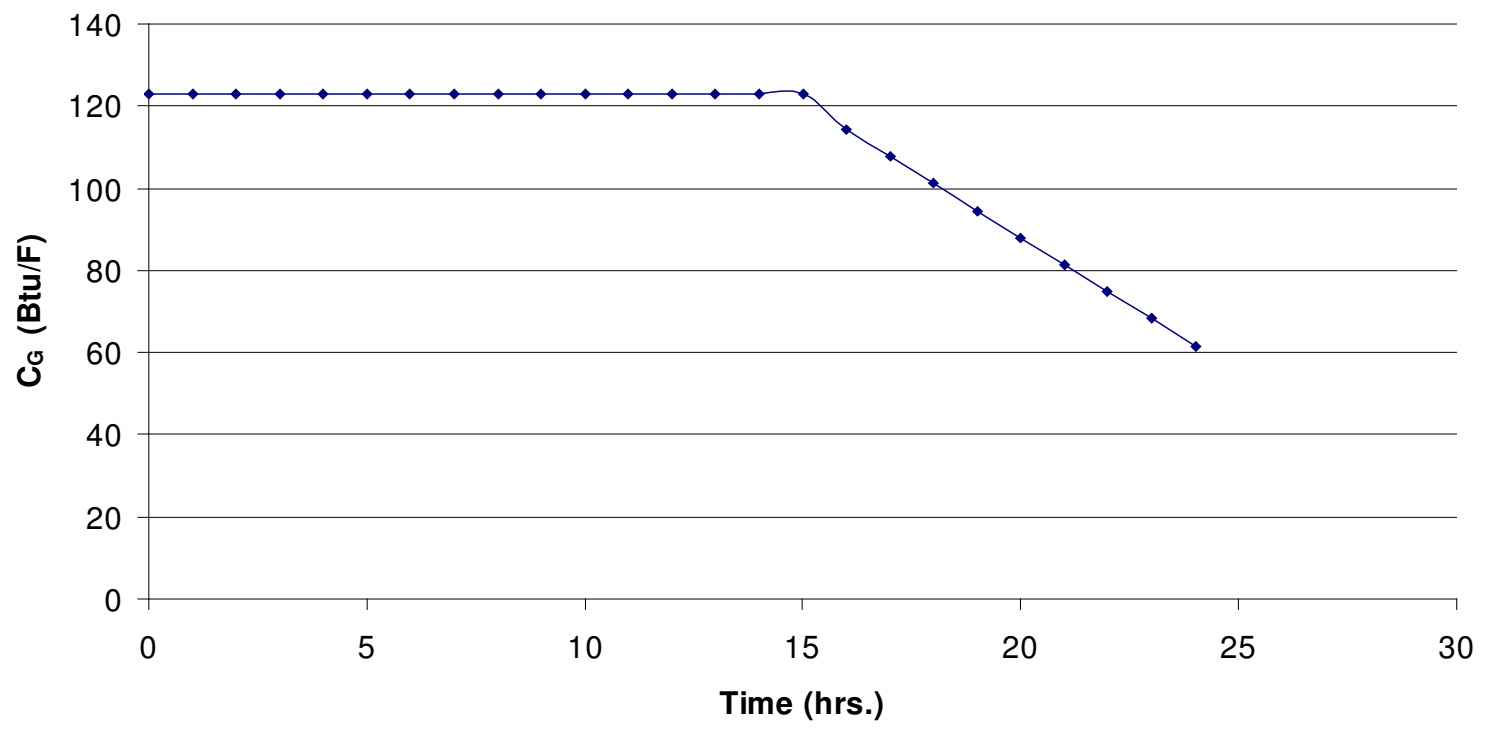

Figure 7.3 Time Profile of Heat Transfer Capacitance of Glass $\left(\mathrm{C}_{\mathrm{G}}\right)$

The transfer functions for the glass element can be represented as shown in Equation 7.1.

$$
G_{G}(s)=\frac{T_{A}(s)}{s Q_{B}(s)}=\frac{A s+B}{X s^{2}+Y s+Z}\left[\frac{{ }^{\circ} F}{B t u / h r}\right]
$$

where the variables $\mathrm{A}, \mathrm{B}, \mathrm{X}, \mathrm{Y}$ and $\mathrm{Z}$ are determined by various factors such as the surface area of glass $\left(\mathrm{A}_{\mathrm{G}}\right)$, Level of glass $\left(\mathrm{L}_{\mathrm{G}}\right)$, etc.

The relations between each variable and batch tank parameters are expressed in Equations 7.2, 7.3, 7.4, 7.5, and 7.6.

$$
\begin{gathered}
A=f\left(A_{G}, \frac{L_{G}}{A_{G}}, S_{G}\right) \\
B=f\left(M_{G}\right) \\
X=f\left(A_{G}, \frac{A_{G}}{L_{G}}, \frac{1}{S_{G}}\right) \\
Y=f\left(M_{G}, A_{G}\right) \\
Z=f\left(M_{G}\right)
\end{gathered}
$$


where

$\mathrm{A}_{\mathrm{G}} \quad-\quad$ Surface area of glass, $\mathrm{ft}^{2}$

$\mathrm{L}_{\mathrm{G}} \quad-\quad$ Level of glass, $\mathrm{ft}$

$\mathrm{S}_{\mathrm{G}} \quad-\quad$ Conduction shape factor referenced to the glass level

$\mathrm{M}_{\mathrm{G}} \quad-\quad$ Mass of glass, $\mathrm{lb}_{\mathrm{m}}$

The surface area of glass, $\mathrm{A}_{\mathrm{G}}$, remains constant throughout the working period while the rest of the properties change. From Equations 7.1 and 7.5, one can conclude that the damping for the batch tank depends only on the mass of the glass in the tank, $\mathrm{M}_{\mathrm{GP}}$, as the surface area of the glass is a constant. Also, the natural frequency of the tank depends on the mass of the glass in the tank. Any changes in these parameters will directly influence the performance of the batch tank model.

Figure 7.4 shows the step response for the controller for a decrease of $1^{\circ} \mathrm{F}$ in the set-point. This figure is a repeat of Figure 5.10.

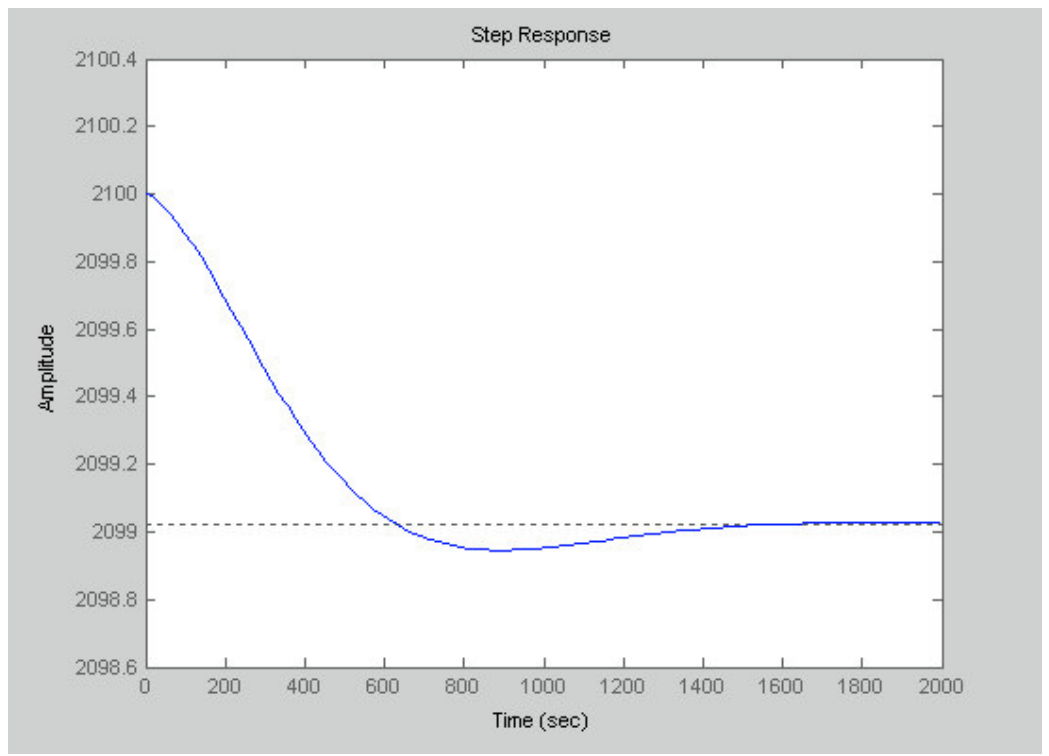

Figure 7.4 Response of Closed-Loop Transfer Function during Working Period for a Step Decrease in Set-Point of $1^{\circ} \mathrm{F}$ 
By cutting down on the heat supplied to the burner, energy can be conserved, which would otherwise have been lost to the walls or to the exhaust. Improvements were made to the existing model of the batch tank incorporating the amount of pulled glass, without a compromise on glass property.

Figure 7.5 shows the temperature and natural gas flow variation for the 72 -hour period. The improved design reduced the amount of energy spent during the working period.

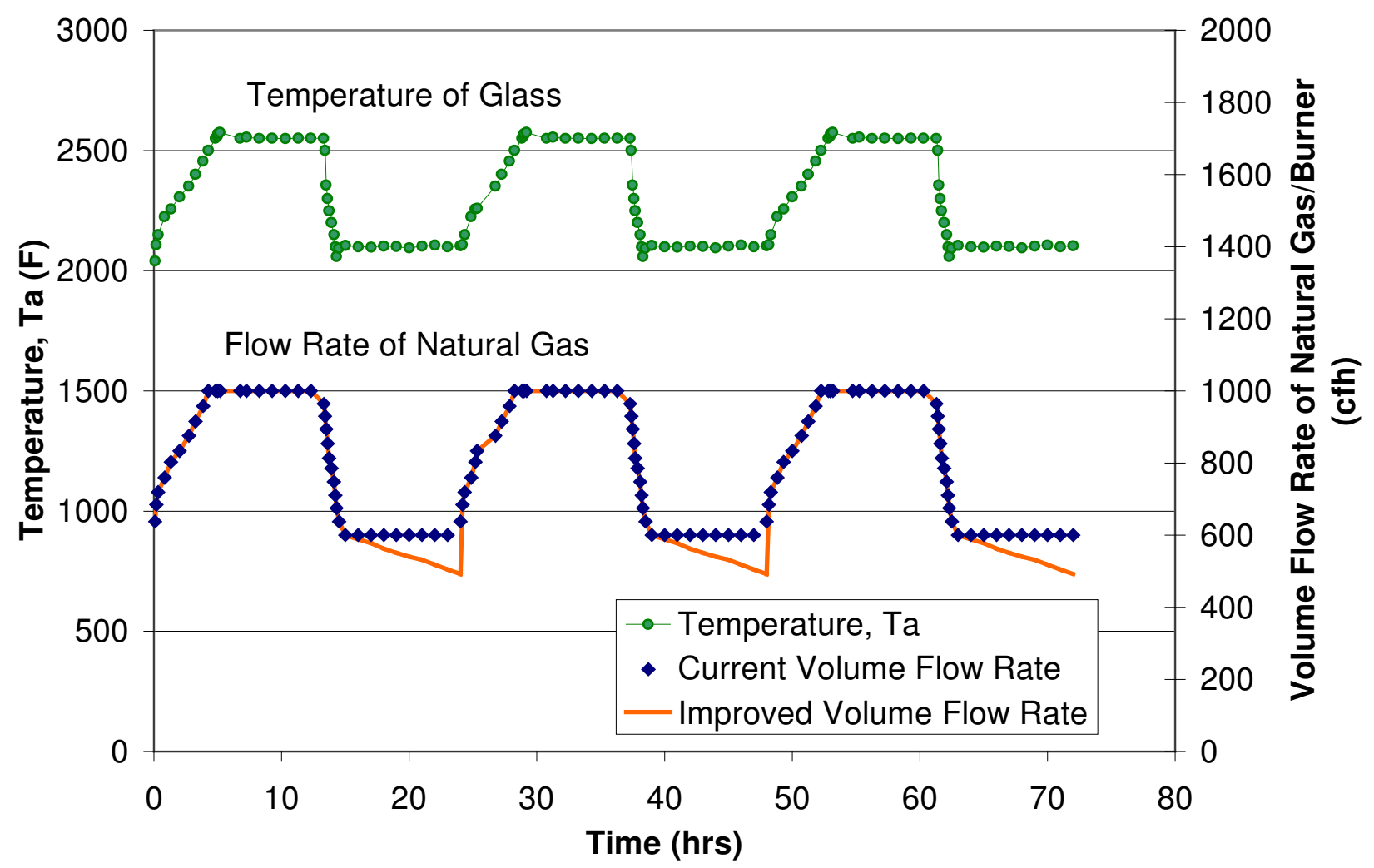

Figure 7.5 Time Profiles of Measured Temperature and Flow Rate of Natural Gas with Present and Enhanced Controllers

A similar graph can be plotted for the variation of oxygen flow during a 72-hour period as shown in Figure 7.6. 


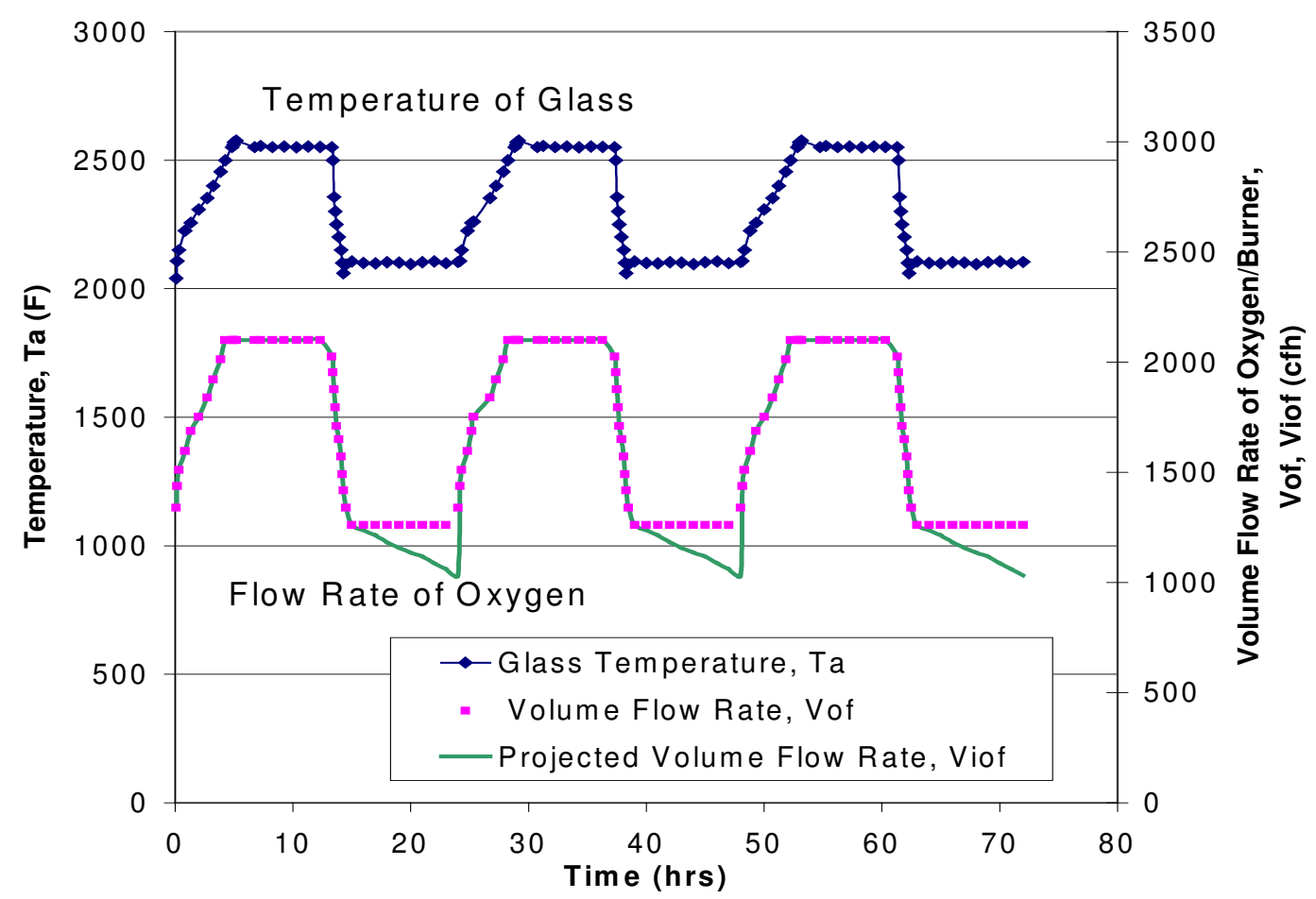

Figure 7.6 Time Profile of Temperature and Flow Rate of Oxygen with

Present and Enhanced Controller

One can analyze the savings obtained with the enhanced model. The reduction in energy consumed during the working period is $120 \mathrm{MJ}$ or $114,000 \mathrm{BTU} /$ ton of glass melted. The batch tanks in operation now have an energy consumption of $6800 \mathrm{MJ} / \mathrm{ton}$ of glass melted during the working period. With the enhanced model, this value can be brought down to $6600 \mathrm{MJ} /$ ton of glass melted. The reduction in energy requirements with the enhanced model can be represented as shown in Figure 7.7. 


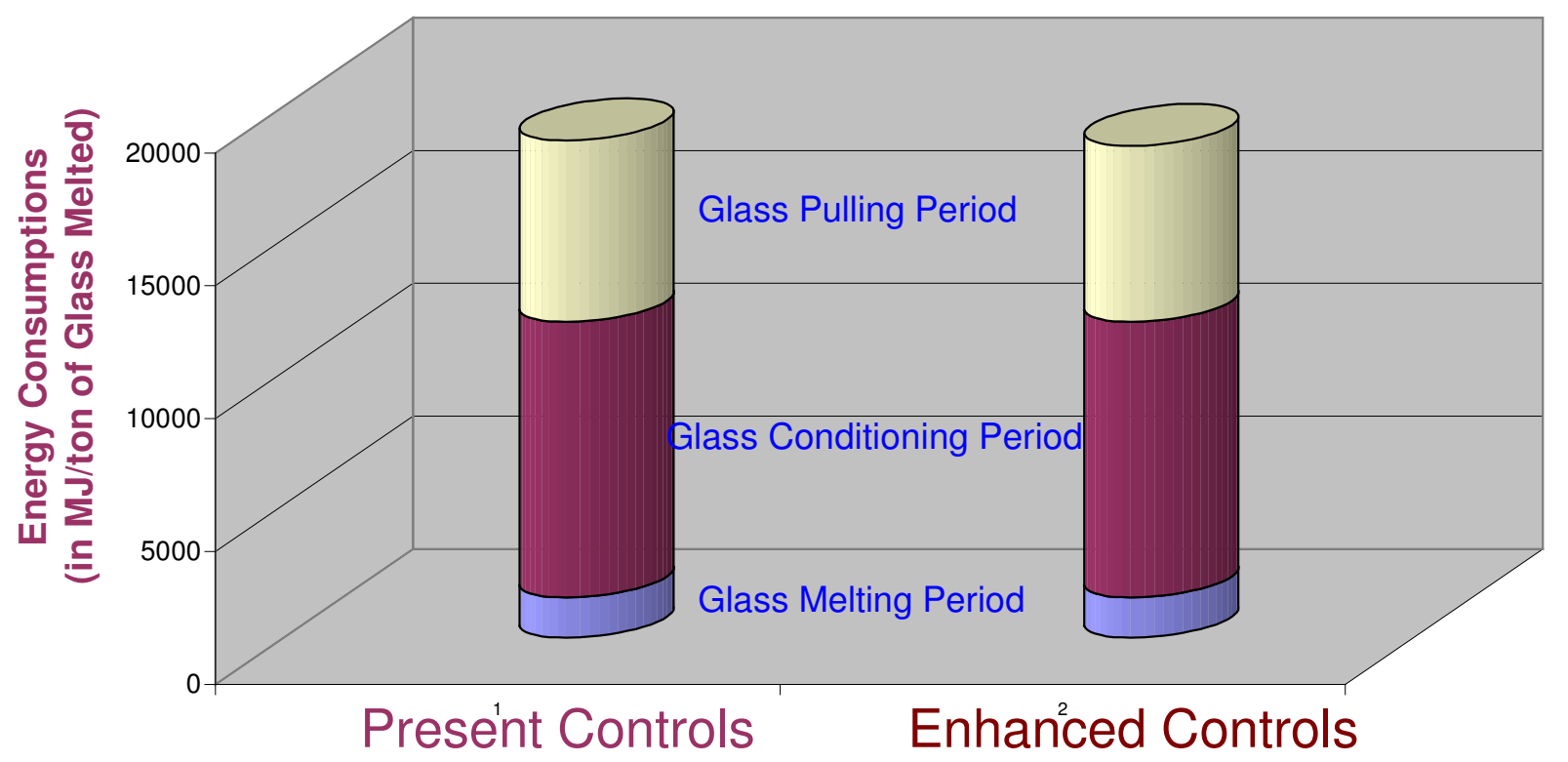

$3 \%$ Reduction

Figure 7.7 Comparison of Energy Consumptions with Present and Enhanced Controllers 


\section{Chapter 8. Contributions and Future Research}

\subsection{Contributions}

The thesis contributed a detailed description of the batch tank model and its transient behavior during the working period.

The key contributions from this thesis can be listed as shown below:

1. Developed theoretical and Simulink models for the electrically-actuated control valve for natural gas and oxygen (See Section 3.1). In order to be consistent with real world systems, the effects of gear reduction in motor, external crank-arm linkage and position feedback were also considered. Transfer function models were also developed for the burner (See Section 3.2) and the thermocouple (See Section 3.3).

2. Identified the key combustion/control parameters to develop enhanced theoretical and Simulink models for the transient behavior of oxy-fuel batch tank (See Section 4.3). These are the heat transfer resistance of the glass $\left(\mathrm{R}_{\mathrm{G}}\right)$, capacitance of the glass $\left(\mathrm{C}_{\mathrm{G}}\right)$, the sensed temperature inside the batch tank $\left(\mathrm{T}_{\mathrm{A}}\right)$ and the pull rate of glass $\left(\mathrm{M}_{\mathrm{GP}}\right)$. The level of glass in the tank $\left(\mathrm{L}_{\mathrm{G}}\right)$ and the mass of glass inside the tank $\left(\mathrm{M}_{\mathrm{G}}\right)$ directly influence the heat transfer resistances and capacitances of the glass. The parameters influencing the temperature of the batch tank were analyzed to develop the mathematical model for the batch tank.

3. Developed a closed-loop model for the oxy-fired batch tank (See Section 4.6). The performance of the batch tank was analyzed using Bode plots and a lead-lag controller was designed to achieve reasonable gain and phase margins (See Section 5.3). Developed a LabVIEW application to monitor temperatures acquired using a 
thermocouple, inside the batch tank (See Section 6.3). This endeavor can be used to develop a PC based controller for the oxy-fuel tank in the future.

4. Explained the transient behavior of oxy-fuel batch tank as a function of average glass pull rate. The decrease in level of glass and increase of combustion volume in the batch tank changed the resistances and the capacitances of glass and combustion products. The effect of these changes on the temperature inside the batch tank was investigated (See Section 4.2).

5. Specified pull rate of glass as a significant factor to be considered when analyzing transient behavior of oxy-fuel batch tank. For the existing batch tank with a modified controller design, energy savings of 3\% reduction was obtained during the working period. The reduction in energy consumption of 189,700 BTU/ton (200 MJ/ton) of glass melted, with the modified model justifies the inclusion of the pull rate of glass as a combustion/control parameter (See Section 4.7).

\subsection{Future Research}

1. In this research, the pull rate of glass, $\mathrm{M}_{\mathrm{PG}}$, was assumed as a constant and the effects of the pulling on the batch tank parameters were analyzed. But in the real world, glass may not be pulled at a constant rate. The pull rate of glass can be made a variable for future research.

2. The next step for this research would be the development of transient controls considering the level of glass as a control variable rather than pull rate of glass. This research assumed that glass was pulled at constant rate. But this may not be the operating policy of many existing batch tanks. A level sensor, capable of withstanding the high temperatures inside the batch tank need to be identified for this purpose. Stainless steel 
has been used to make floats in high temperature environments. Research is also on to employ fiber-optics technology for tank level sensors for high temperature environments. The voltage signal from such a float sensor could be used as a feedback signal to the controller.

3. State Space Approach can also be used for modeling the oxy-fuel batch tank. State space models are created from linear differential equation describing the system dynamics. The state-space representation is best suited for numerical computations. For highest accuracy, transfer functions need to be converted to state-space prior to combinations and simulations. MATLAB can be used to convert the transfer functions to the state space domain.

4. Adaptive control has been limited to aerospace applications due to technical considerations. However, increasing economic pressure and environmental concern have caused new interest in adaptive control applications for industries. Adaptive control has penetrated the glass industry too. This technology has been used in controlling the temperature of molten glass for the production of glass containers [31]. Batch tanks may operate under different operating conditions. Even within a 24-hour period, the PID or lead-lag parameters need to be changed during the melting period. To cope with these problems, advanced controllers have adaptive features like gain scheduling and selftuning.

Gain scheduling involves experimentation to determine optimal PID parameter values according to the operating policies. These values are then stored and later recalled for use according to prevailing conditions. 
Self-tuning controllers use various techniques such as Ultimate Sensitivity method developed by Ziegler and Nichols, the Reaction Curve method, etc. to determine the optimal values for tuning. However, these methods rely on the introduction of a disturbance and subsequent analysis of the process reaction. 


\section{REFERENCES}

[1] C. Q. Jian, W. W. Wolf, and M. Greenman, "Glass Melting Technology of the

Future: A Project of the Glass Manufacturing Industry Council”, Proceedings of the 62nd Conference on Glass Problems, 2001, pp. 135-151.

[2] James Rhodes, "Transfer Function Model for Oxy-Fuel Fired Batch Tank", Masters Thesis, West Virginia University, Morgantown, 2000, pp. 36-38.

[3] C. J. Hoogendoorn, J. A. Wieringa and L. Post, "Modelling of Combustion and Heat Transfer in Glass Furnaces", Glastechnische Berichte, January 1990, pp. 7-12.

[4] Dominique Jouvaud, Jean-Francois l'Huissier, et al., "Glass Melting with Pure Oxygen Combustion: Modeling of Convective and Radiative Heat Transfer", Ceramic Engineering and Science Proceedings, 1988, pp. 221-231.

[5] A. D. Gosman, F. C. Lockwood, et al, "The Prediction of the Flow, Reaction and Heat Transfer in the Combustion Chamber of a Glass Furnace", In: AIAA $18^{\text {th }}$ Aerospace Sciences Meeting, 1980.

[6] M. G. Carvalho, D. F. G. Durao and J. C. F. Pereira, "Prediction of the Flow, Reaction and Heat Transfer in an Oxy-Fuel Glass Furnace", Engineering Computations, 1987, pp. 23-34.

[7] A. Ungan, and R. Viskanta, "Three-Dimensional Modeling of Circulation and Heat Transfer in a Glass Melting Tank", Glastechnische Berichte, 1987, pp. 115-124.

[8] F. Simonis, and R. C. G. Beerkens, "Influence of Furnace Design and Operation Parameters on the Residence Time Distribution of Glass Tanks", predicted by 3-D Computer Simulations, Collected Papers from the XIV International Congress on Glass, 1986, pp. 118-128. 
A. P. Roychowdhury and J. Srinivasan, " The Modeling of Radiation Heat Transfer in Forehearths units in Glass Melting", Waerme-und Stoffuebertragung, 1995, pp. 71-75.

[10] D. Farmer, M. V. Heitor and A. T. Vasconcelos, “ New Methodology for Furnace Monitoring, analysis and control", Glass Industry, 1992, pp. 10-16.

[11] A. S. Victor, J. P. Costeira, and J. Sentieiro, “ A Computer Vision System for the Characterization of Flame in Glass Furnaces", Proceedings of the IEEE Industry Applications Society Annual Meeting, pp. 77-86.

[12] M. Q. Quay, B.W. Webb, et al., "Combustion Measurements in an Industrial GasFired Flat-Glass Furnace", Journal of the Institute of Energy, June 1997, pp. 71-81.

[13] Daniel Wishnick and Andrew McIver, “A Discussion of Burner Technologies for Glass Making", Technical Documentation provided at the Corporate Website of Eclipse Inc., www.eclipsenet.com/ct/burnertech/burnertech.htm.

[14] Conversations with Mr. Harry Fontana about Oxy-Fuel Batch Tanks during February 2001-May 2002, Mr. Harry Fontana, L. E. Smith Glass Company, Mt. Pleasant, PA, Tel: (724) 547-3544 ext.435.

[15] B. C. Hoke, Jr., J. L. Inskip, “ A Comparison of Oxygen-Enhanced Combustion Technologies", Proceedings of the 62nd Conference on Glass Problems, 2001, pp. 135-151.

[16] Dan Ertl, "Pipe Train Design for Oxy-Fuel Systems", Glass Industry, April 1998, pp. 37-38.

[17] Product Brochure of Oxy-Therm LE Gas or Oil Burner, Bulletin 4650, Maxon Corporation, Muncie, IN, p 4655. 
[18] Data Bulletins and Handbooks provided at the Corporate Website of Eurotherm Controls, http://www.eurotherm.com/products/actuators/ea50,60_doc.htm.

[19] Conversations with Mr. Bob Jones, Weiss Instrument Inc on the working of electric-actuated control valves in January 2001, Tel: (412) 344-5504

[20] Picture of Electric-Actuated Control Valve in use at the L. E. Smith Glass Company, Mt. Pleasant, PA.

[21] Edwin C. Barbe, Linear Control Systems, International Textbook Company, 1963, pp. 385-390.

[22] Based on Product Specifications of 40 W Induction Motors from 2000-2001 Oriental Motor General Catalog.

[23] T. G. Beckwith, N. Lewis Buck, Mechanical Measurements, AddisonWesley Publishing Company Inc., pp. 86-89.

[24] Product Brochure of Adjustable Port Valves (Bulletin 1008) provided at the Corporate Website of North American Manufacturing Company, www.namfg.com

[25] John LeBlanc, Dick Marshall, et al., "BOC Rapid Melting Process", Proceedings of the $62^{\text {nd }}$ Conference on Glass Problems, 2001, pp. 107-118.

[26] K. L. Jorgenson, S. Ramadhyani, R. Viskanta, "Numerical Modeling of Combustion and Heat Transfer in a Laboratory Scale Glass Melting Furnace", Proceedings of the A.S.M.E. Heat Transfer Division, Vol. 2., 1999, pp. 425-431.

[27] Guosheng Kang, "Enhanced Design for Oxy-Fuel Fired Batch Tanks using CFD Methods", Ph.D. Dissertation, West Virginia University, Morgantown, WV, 2000, pp. $13-60$.

[28] Franklin D'Souza, Design of Control Systems, pp. 51-53, 1993. 
[29] K. A. Lievre and R. J. Hewertson, “ Environmental Benefits and Lower Cost”, Proceedings of the $62^{\text {nd }}$ Conference on Glass Problems, 2001, pp. 121-124.

[30] Technical Documentation provided for Control System Toolbox at the corporate website of The Mathworks Inc., http://www.mathworks.com/

[31] Bill Gough and Dan Matovich, Predictive-Adaptive Temperature Control of Molten Glass, Technical Documentation provided at the Corporate Website of Universal Dynamics Inc., http://www.udgroup.com/pdf/p53.pdf 


\section{Appendix A - MATLAB \& Simulink Code for Transfer Functions}

The transfer functions for the electric-actuated valve, burner, etc. were derived in

Chapter 3. Appendix A illustrates the operations used in the development of the transfer functions. The analyses were performed in MATLAB and Simulink. The MATLAB code for the calculations is listed.

Transfer Function for the Electric-Actuated Control Valve, $\mathrm{G}_{\mathrm{CV}}(\mathrm{s})$

$\% \mathrm{gm}$ is the transfer function for the actuator motor when it runs clockwise

$\mathrm{nm}=[3660]$;

$\mathrm{dm}=\left[\begin{array}{lll}1 & 5 & 0\end{array}\right]$;

$\mathrm{gm}=\mathrm{tf}(\mathrm{n} 1, \mathrm{~d} 1)$;

$\% \mathrm{gcm}$ is the transfer function for the actuator motor when it runs counter-clockwise

$\mathrm{gcw}=-\mathrm{gm}$;

$\%$ gtd is the transfer function which incorporates the time delay in the execution of the counter-clockwise motion of the actuator motor. The time delay of 0.005 seconds is approximated by Pade approximation. The equivalent transfer function is given by,

$\operatorname{gtd}=\left(1-\left(\mathrm{Td}^{*} \mathrm{~s} / 2\right)\right) /(1+(\mathrm{Td} * \mathrm{~s}) / 2)$

where $\mathrm{Td}$ is the time delay in seconds.

$\mathrm{Td}=0.005$;

$\mathrm{nd}=[-\mathrm{Td} / 21]$

$\mathrm{dd}=[\mathrm{Td} / 21]$;

$\operatorname{gtd}=\mathrm{tf}(\mathrm{nd}, \mathrm{dd})$;

$\%$ gccw is the transfer function for the actuator motor running counter-clockwise with a delay of 0.005 seconds.

$\mathrm{gccw}=\mathrm{gtd}^{*} \mathrm{gcw}$;

$\%$ gcp is the transfer function for the current-to-position part of the electric-actuated control valve. It is the cumulative effect of the motor running clockwise and counterclockwise

$\mathrm{gcp}=\mathrm{gm}+\mathrm{gccw}$

$\% \mathrm{gL}$ is the transfer function for the parallel link mechanism 
$\mathrm{gL}=\operatorname{zpk}([],[],[1.2])$;

$\% \mathrm{gv}$ is the transfer function for the flow part of the electric-actuated control valve $\operatorname{gv}=\operatorname{zpk}([],[],[15.34])$;

$\% \mathrm{gcv}$ is the overall transfer function for the electric-actuated control valve

$\mathrm{gcv}=\mathrm{gcp} * \mathrm{gL} * \mathrm{gv}$

$\%$ gpt is the overall transfer function for the pipe train

$\mathrm{gpt}=\mathrm{gcv}$;

Figure A.1 shows the Simulink model for the equivalent transfer function for the actuator portion of the electric-actuated control valve.

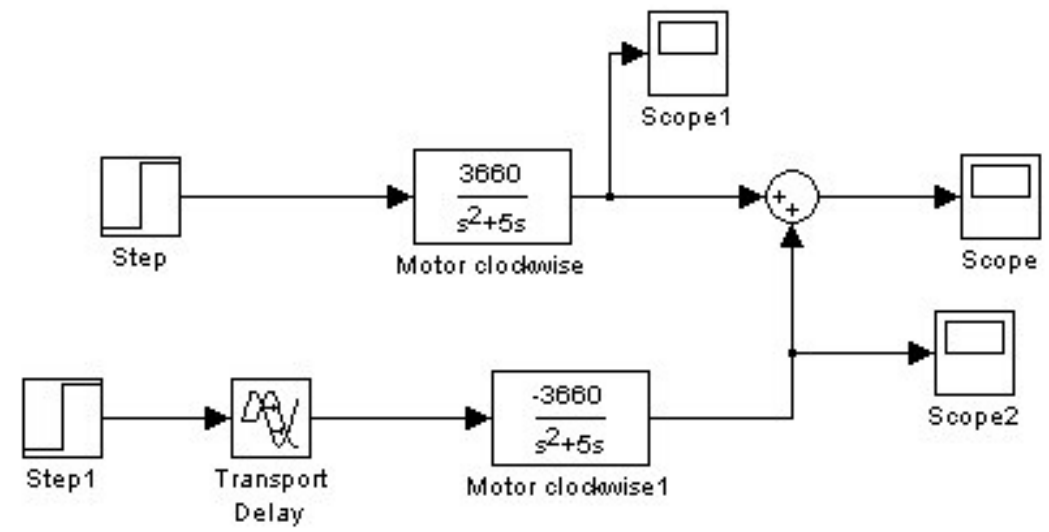

Figure A.1 Simulink Model for Equivalent Transfer Function of Electric-Actuated Control Valve

Figure A.2 shows the Simulink model for the transfer function for the electricactuated control valve. The If subsystem in Simulink was used to represent the action of the triacs. If the error signal to the If subsystem is positive, then the Action subsystem corresponding to the first triac is activated and the other subsystems are ignored. Similarly, if the error signal is negative, then the Action subsystem corresponding to the second triac is activated. The functioning of the If subsystem was discussed in Section 3.1.10. 


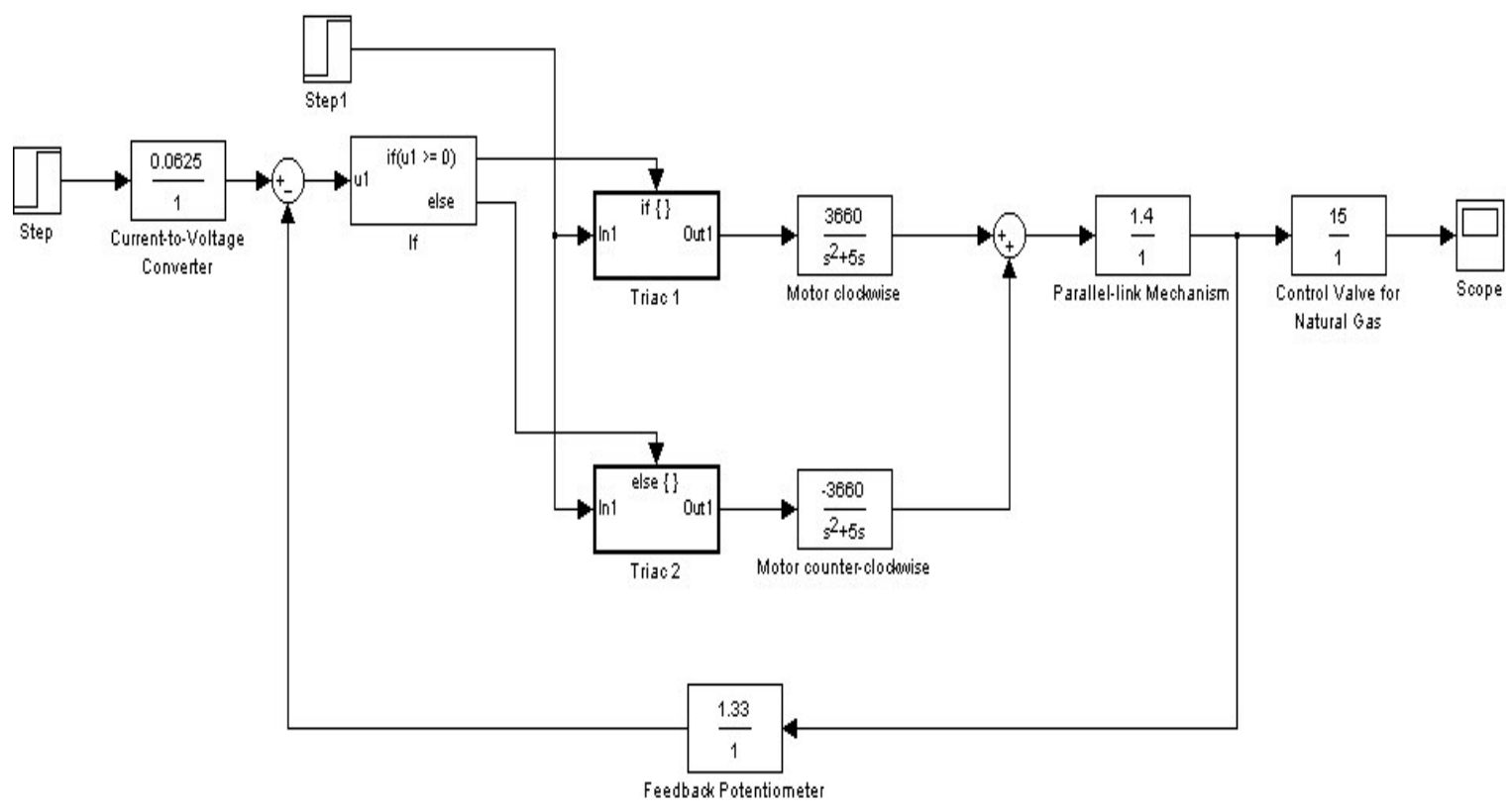

Figure A.2 Simulink Model for Transfer Function of Electric-Actuated Control Valve

Transfer Function for the Burner, $\mathrm{G}_{\mathrm{B}}(\mathrm{s})$

$\mathrm{gb}=\operatorname{tf}(900,1)$;

Transfer Function of Glass Element during Glass Working Period, $\mathrm{G}_{\mathrm{GP}}(\mathrm{s})$

ngp $=8 \mathrm{e}-4 *[0.0520 .00185]$;

$\operatorname{dgp}=\left[\begin{array}{lll}1 & 4.51 & 0.00037\end{array}\right]$;

$\operatorname{ggp}=\operatorname{tf}(\operatorname{ngp}, \operatorname{dgp})$

Transfer Function of Feedback Thermocouple, $\mathrm{H}_{\mathrm{T}}(\mathrm{s})$

ht $=\mathrm{tf}(0.0228,[1.451])$;

Overall Batch Tank Transfer Function for Cooling Period, $G_{B T P}(s)$

gbtp =gpt*gb*ggp;

Transfer Function for Temperature to Voltage Converter, $\mathrm{G}_{\mathrm{TV}}(\mathrm{s})$

gtv $=0.0228$; 


\section{Appendix B - MATLAB and Simulink Code for Controller}

This appendix shows the MATLAB code for the development of the controller for the working period. Sisotool of the Control System Toolbox was used to analyze the performance of the closed-loop model.

Transfer Function of Controller during Working Period

$\mathrm{gcpu}=\mathrm{zpk}(-5.6,-0.005,0.0075)$;

Transfer Function of Closed-Loop Batch Tank during Working Period, $\mathrm{T}_{\mathrm{BTP}}(\mathrm{s})$

gp1 = gcpu* gbtp;

gp2 =feedback (gp1,ht);

gcbtp $=g t v^{*} \mathrm{gp} 2$;

Figure B.1 shows the Simulink model for the closed-loop transfer function for the batch tank during the working period, $\mathrm{T}_{\mathrm{BTP}}(\mathrm{s})$.

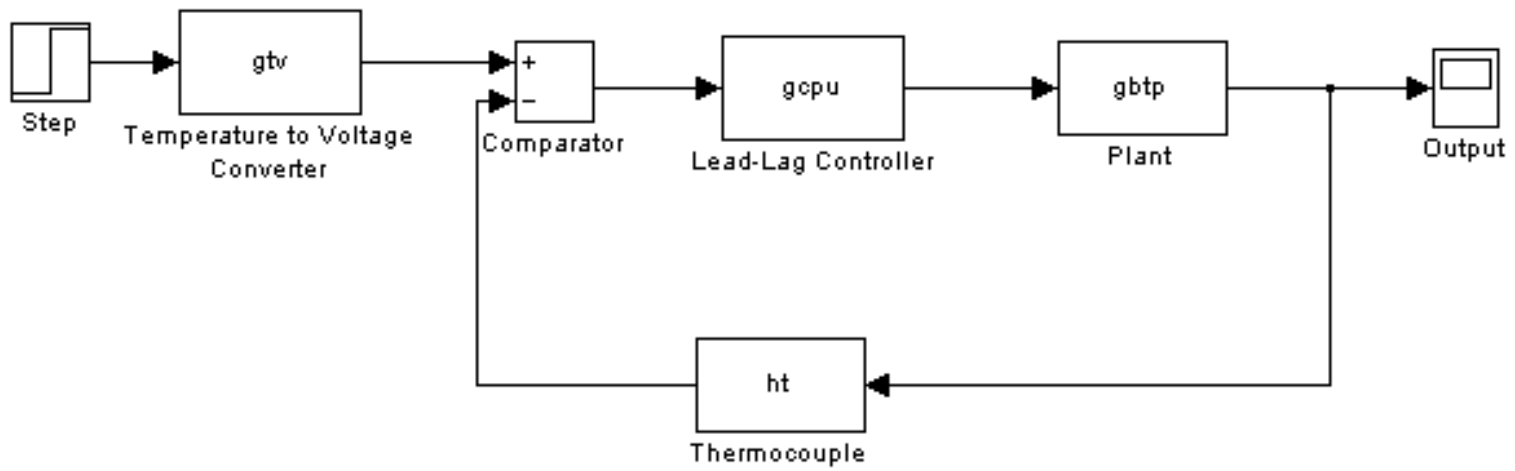

Figure B.1 Simulink Model for Closed-Loop Batch Tank Transfer Function during Working Period, $\mathrm{T}_{\mathrm{BTP}}(\mathrm{s})$

Figure B.2 shows the Simulink model for the overall transfer function for the batch tank during the working period, $\mathrm{G}_{\mathrm{BTP}}(\mathrm{s})$. 


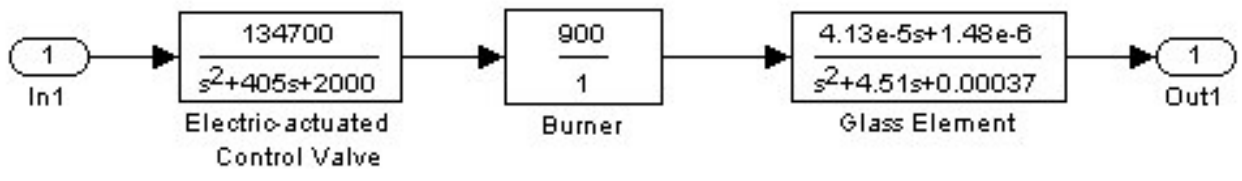

Figure B.2 Simulink Model for Plant Transfer Function during Working Period, $\mathrm{G}_{\mathrm{BTP}}(\mathrm{s})$ 


\section{Appendix C - Transfer Function Model for Electric-Actuated Control Valve for Oxygen}

The transfer function for the electric-actuated control valve is essentially the same as the one for natural gas. The only difference lies in the flow part of the control valve. The oxygen valve flow rate is greater in order to have an oxy-fuel ratio of 2.1:1.

Experimental data collected at the L. E. Smith Glass Company was used to obtain the transfer function for the flow part of the oxygen control valve. The volume flow rate through the pipe train corresponding to different positions of valve opening was measured. The data collected from the natural gas pipe in the plant has been plotted in Figure C.1.

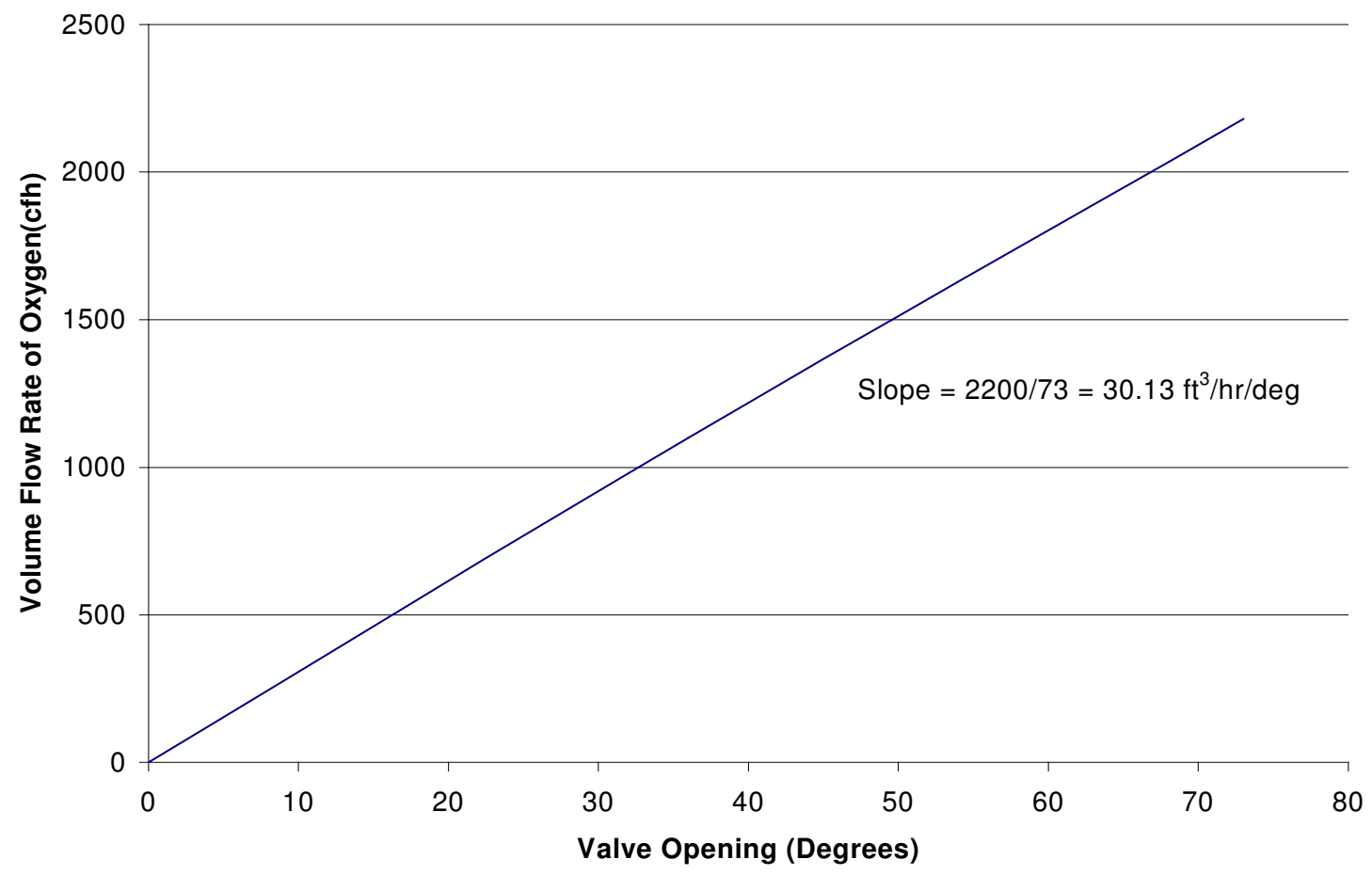

Figure C.1 Valve Flow Characteristics of Electric-Actuated Control Valve in Oxygen Pipe Train 
Linearizing the data, the slope of the above graph is obtained as $30.1 \mathrm{cfh} / \mathrm{deg}$. Based on the experimental data above, one can write the transfer function for flow part of the control valve for oxygen $\mathrm{G}_{\mathrm{OV}}(\mathrm{s})$, as shown in Equation C.1.

$$
G_{O V}(s)=\frac{s V_{F}(s)}{\Delta \Theta^{\prime}(s)}=30.1\left[\frac{\mathrm{ft}^{3} / \mathrm{hr}}{\text { degrees }}\right]
$$

where

$\dot{V_{O F}}(s)$ - Volume flow rate of oxygen through the control valve, $\mathrm{ft}^{3} / \mathrm{hr}$.

$\Delta \Theta^{\prime}(s)-\quad$ Angular opening of the oxygen valve, degrees.

Figure C.2 shows a block diagram representation of the elements in the electricactuated control valve for oxygen.

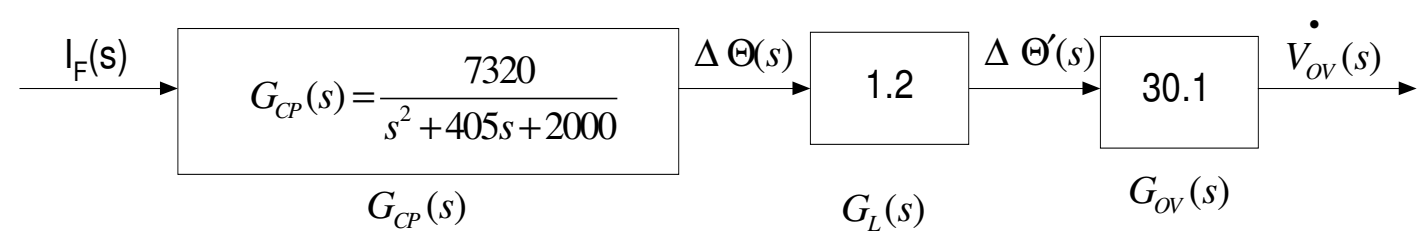

Figure C.2 Block Diagram Representation of Control Valve for Oxygen

Using the fundamentals of block diagram manipulation, one can write the output signal from the control valve, $\mathrm{V}_{\mathrm{OF}}(\mathrm{s})$, as shown in Equation C.2

$$
s V_{O F}(s)=I_{F}(s) \cdot G_{C P}(s) \cdot G_{L}(s) \cdot G_{O V}(s)
$$

Substituting for the values of different transfer functions from Equations 3.19, 3.20 and C.2, one obtains the transfer function for the control valve for oxygen, $\mathrm{G}_{\mathrm{OCV}}(\mathrm{s})$, as shown in Equation C.3.

$$
G_{O C V}(s)=\frac{s V_{O F}(s)}{I_{F}(s)}=\frac{269400}{\left(s^{2}+405 s+2000\right)}\left[\frac{f t^{3} / h r}{m A}\right]
$$




\section{Appendix D - Calculation of Transient Aspects during Glass Working Period}

This section features the calculation of the transient parameters defining the heat transferred to the glass described in Section 4.3. The level of glass remains the same till the end of the conditioning period. At the end of this period, the level of glass decreases at a rate determined by the pull rate of glass. The pull rate of glass was assumed to be 2 $\mathrm{ft}^{3} / \mathrm{hr}$.

Calculation of Thermal Capacitance for Radiant Heat from Hot Gases to Glass, $\mathrm{C}_{\mathrm{E}}$

The thermal capacitance for the radiant heat transfer, $\mathrm{C}_{\mathrm{E}}$, is given by Equation 4.3.

Pressure inside Batch Tank

$\mathrm{P}=14.67 ; \% \mathrm{psi}$

Universal Gas Constant

$\mathrm{R}=19.36 ; \%$ psi-ft3/lbmol-K

Mass mole fraction of carbon dioxide

$\mathrm{y}_{\mathrm{CO} 2}=1 / 3$;

Mass mole fraction of water vapor

$\mathrm{y}_{\mathrm{H} 20}=2 / 3$;

Volume of Batch Tank

$\mathrm{V}=36.5 ; \% \mathrm{ft}^{3}$

Temperature of Combustion

$\mathrm{T}_{\mathrm{e}}=2700 ; \% \mathrm{~K}$

Molecular mass of carbon dioxide

$\mathrm{M}_{\mathrm{CO} 2}=44 ; \% \mathrm{lbm} / \mathrm{lbmol}$

Molecular mass of water vapor

$\mathrm{M}_{\mathrm{H} 2 \mathrm{O}}=18 ; \% \mathrm{lbm} / \mathrm{lbmol}$

Mass of carbon dioxide

$\mathrm{m}_{\mathrm{co} 2}=\left(\mathrm{y}_{\mathrm{co} 2} * \mathrm{~V} * \mathrm{P} * \mathrm{M}_{\mathrm{CO} 2}\right) /\left(\mathrm{R} * \mathrm{~T}_{\mathrm{e}}\right) ; \% \mathrm{lbmol}$ 
Mass of water vapor

$\mathrm{m}_{\mathrm{H} 2 \mathrm{O}}=\left(\mathrm{y}_{\mathrm{H} 2 \mathrm{O}} * \mathrm{~V} * \mathrm{P} * \mathrm{M}_{\mathrm{H} 2 \mathrm{O}}\right) /\left(\mathrm{R}^{*} \mathrm{~T}_{\mathrm{e}}\right) ; \%$ lbmol

Specific heat of carbon dioxide

$\mathrm{Cp}_{\mathrm{CO} 2}=0.2 ; \% \mathrm{Btu} / \mathrm{lb}^{\circ} \mathrm{F}$

Specific heat of water vapor

$\mathrm{Cp}_{\mathrm{H} 2 \mathrm{O}}=0.482 ; \% \mathrm{Btu} / \mathrm{lb}^{\circ} \mathrm{F}$

Capacitance for radiant heat transfer

$\mathrm{C}_{\mathrm{E}}=\mathrm{m}_{\mathrm{co} 2} * \mathrm{Cp}_{\mathrm{CO} 2}+\mathrm{m}_{\mathrm{H} 2 \mathrm{O}} * \mathrm{Cp}_{\mathrm{H} 2 \mathrm{O}} ; \% \mathrm{Btu} /{ }^{\circ} \mathrm{F}$

Calculation of Thermal Resistance for Glass Transfer Function, $\mathrm{R}_{\mathrm{G}}$

The thermal resistance for the glass transfer function, $\mathrm{R}_{\mathrm{G}}$, is given by Equation

4.4. MATLAB codes for the calculation of the shape factor, $\mathrm{S}_{\mathrm{G}}$, Prandtl number, Pr,

Grashof Number, Gr, Nusselt number, $\mathrm{Nu}$, and the coefficient of convective heat transfer,

$h_{W}$ and the thermal resistance of the glass transfer function, $R_{G}$, is given below.

Dimensions of Batch Tank

$\mathrm{L}=7 ; \% \mathrm{ft}$

$\mathrm{w}=5.5 ; \% \mathrm{ft}$

$\mathrm{t}=0.75 ; \% \mathrm{ft}$

Lg = 'Level of Glass'; \% obtained from Table D.1, feet

Conditions inside Batch Tank

$\mathrm{Tg}=2300 ; \%$ Glass Temperature, in F

$\mathrm{Tw}=2500 ; \%$ Temperature of Hot Gases, in F

Shape Factor of Glass

$\mathrm{Sg}=2(\mathrm{w}-2 \mathrm{t})(\mathrm{L}-2 \mathrm{t})+2(\mathrm{Lg}-2 \mathrm{t})(\mathrm{L}-2 \mathrm{t})+(\mathrm{Lg}-2 \mathrm{t})(\mathrm{w}-2 \mathrm{t})+4 * 0.54 \mathrm{w}+4 * 0.54 \mathrm{~L}+$ $4 * 0.54 * \operatorname{Lg}+8 * 0.15 \mathrm{t}$

Characteristic Length, $\mathrm{L}_{\mathrm{C}}$

$\mathrm{Lc}=(\mathrm{L}-2 \mathrm{t})(\mathrm{Lg}) /[(\mathrm{L}-2 \mathrm{t})+\mathrm{Lg}] ; \% \mathrm{ft}$ 
Calculation of Prandtl Number

Dynamic viscosity of gas inside batch tank

$\mathrm{mu}=39.8 ; \% \mathrm{~N}-\mathrm{s} / \mathrm{sq} . \mathrm{m}$

Specific heat of glass

$\mathrm{cp}=837.4 ; \% \mathrm{~J} / \mathrm{kg}-\mathrm{K}$ ( Equivalent to $0.2 \mathrm{Btu} / \mathrm{lbm}$ )

Thermal conductivity of glass

$\mathrm{kg}=3.35 ; \% \mathrm{~W} / \mathrm{m}-\mathrm{K}$ (Equivalent to $1.94 \mathrm{Btu} / \mathrm{hr}-\mathrm{ft}-\mathrm{F}$ )

Prandtl Number

$\operatorname{Pr}=\mathrm{mu}^{*} \mathrm{cp} / \mathrm{kg}$

Calculation of Grashof Number

Volumetric Thermal Expansion Coefficient

beta $=2.6 \mathrm{e}-5 ; \% \mathrm{~K}^{-1}$

Acceleration due to Gravity

$\mathrm{g}=9.81 ; \% \mathrm{~m} / \mathrm{s}^{2}$

Difference in Temperature

Theta $=\mathrm{Tw}-\mathrm{Tg} ; \% \mathrm{~F}$

Mass Density of Glass

rho $=2643 ; \% \mathrm{~kg} / \mathrm{m}^{\wedge} 3$

Dynamic Viscosity of Glass

$\mathrm{nu}=\mathrm{mu} / \mathrm{rho} ; \% \mathrm{~m}^{\wedge} 2 / \mathrm{s}$

Grashof Number

$\mathrm{Gr}=\left(\right.$ beta $^{*} \mathrm{~g}^{*}$ theta $\left.* \mathrm{Lc}^{\wedge} 3\right) / \mathrm{nu}^{\wedge} 2 ;$

Nusselt Number

$\mathrm{Nu}=0.53 *(\mathrm{Gr} * \operatorname{Pr})^{\wedge} 0.25$;

Thermal conductivity of refractory walls

$\mathrm{kr}=2.01 ; \% \mathrm{~W} / \mathrm{m}-\mathrm{K}$ (Equivalent to $1.16 \mathrm{Btu} / \mathrm{hr}-\mathrm{ft}-\mathrm{F})$ 
Coefficient of Convective Heat Transfer Coefficient

$\mathrm{hw}=\mathrm{Nu} * \mathrm{kr} / \mathrm{Lc} ; \% \mathrm{~J} / \mathrm{m}^{\wedge} 2-\mathrm{s}-\mathrm{K}$

hwus $=\mathrm{hw}^{*} 0.1761 ; \%$ Btu/hr-ft^2-F

Area of Walls in contact with Glass

Awg $=2 *(L-2 t)^{*} \operatorname{Lg}+2 *(w-2 t)^{*} \operatorname{Lg} ; \% \mathrm{ft}^{\wedge} 2$

Surface Area of Glass

$\mathrm{Ag}=(\mathrm{L}-2 \mathrm{t})^{*}(\mathrm{w}-2 \mathrm{t}) ; \% \mathrm{ft}{ }^{\wedge} 2$

Resistance of Glass Transfer Function

$\operatorname{Rg}=\operatorname{Lg} /(\mathrm{kg} * \mathrm{Ag})+1 /(\mathrm{kr} * \mathrm{Sg})+1 /($ hwus*Awg); \% hr-F/Btu

Calculation of Thermal Capacitance for Glass Transfer Function, $\mathrm{C}_{\mathrm{G}}$

The thermal capacitance for the glass transfer function, $\mathrm{C}_{\mathrm{G}}$, is given by Equation

4.5. MATLAB codes for the calculation of the weight of glass, $\mathrm{Wg}$ and the thermal capacitance of the glass transfer function, $\mathrm{C}_{\mathrm{G}}$, is given below.

Weight Density of Glass

$\mathrm{dg}=165 ; \% \mathrm{lb} / \mathrm{ft}^{\wedge} 3$

Weight of Glass

$\mathrm{Wg}=\mathrm{dg} * \mathrm{Ag} * \mathrm{Lg} ; \% \mathrm{lb}$

Specific Heat of Glass

$\mathrm{cpg}=0.2 ; \% \mathrm{Btu} / \mathrm{lbm}-\mathrm{F}$

Capacitance of Glass Transfer Function

$\mathrm{Cg}=\mathrm{Wg} / 9.81 * \operatorname{cpg} ; \% \mathrm{Btu} / \mathrm{F}$

Table D.1 shows the spreadsheet to determine the variation of these parameters during a glass making cycle. 
Table D.1 Variation of Heat Transfer Parameters with Time

\begin{tabular}{|c|c|c|c|c|c|c|c|}
\hline $\begin{array}{l}\text { Time } \\
\text { (in hrs.) }\end{array}$ & $\begin{array}{l}L_{G} \text {, Level } \\
\text { of Glass(ft) }\end{array}$ & 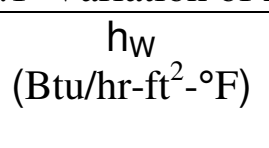 & $\begin{array}{l}A_{W G} \\
\text { (sq. ft) }\end{array}$ & $\mathrm{S}_{\mathrm{G}}$ & $\begin{array}{c}\mathrm{R}_{\mathrm{G}} \\
\left(\mathrm{hr}-{ }^{\circ} \mathrm{F} / \mathrm{Btu}\right)\end{array}$ & $\begin{array}{l}\text { Weight of } \\
\text { Glass } \\
\text { (lb) }\end{array}$ & $\begin{array}{l}\mathrm{C}_{\mathrm{G}} \\
(\mathrm{B})\end{array}$ \\
\hline 0 & 1.66 & 19.38 & 31.54 & 46.69 & 0.0590 & 6025 & 123 \\
\hline 1 & 1.66 & 19.38 & 31.54 & 46.69 & 0.0590 & 6025 & 123 \\
\hline 2 & 1.66 & 19.38 & 31.54 & 46.69 & 0.0590 & 6025 & 123 \\
\hline 3 & 1.66 & 19.38 & 31.54 & 46.69 & 0.0590 & 6025 & 123 \\
\hline 4 & 1.66 & 19.38 & 31.54 & 46.69 & 0.0590 & 6025 & 123 \\
\hline 5 & 1.66 & 19.38 & 31.54 & 46.69 & 0.0590 & 6025 & 123 \\
\hline 6 & 1.66 & 19.38 & 31.54 & 46.69 & 0.0590 & 6025 & 123 \\
\hline 7 & 1.66 & 19.38 & 31.54 & 46.69 & 0.0590 & 6025 & 123 \\
\hline 8 & 1.66 & 19.38 & 31.54 & 46.69 & 0.0590 & 6025 & 123 \\
\hline 9 & 1.66 & 19.38 & 31.54 & 46.69 & 0.0590 & 6025 & 123 \\
\hline 10 & 1.66 & 19.38 & 31.54 & 46.69 & 0.0590 & 6025 & 123 \\
\hline 11 & 1.66 & 19.38 & 31.54 & 46.69 & 0.0590 & 6025 & 123 \\
\hline 12 & 1.66 & 19.38 & 31.54 & 46.69 & 0.0590 & 6025 & 123 \\
\hline 13 & 1.66 & 19.38 & 31.54 & 46.69 & 0.0590 & 6025 & 123 \\
\hline 14 & 1.66 & 19.38 & 31.54 & 46.69 & 0.0590 & 6025 & 123 \\
\hline 15 & 1.66 & 19.38 & 31.54 & 46.69 & 0.0590 & 6025 & 123 \\
\hline 16 & 1.545 & 19.65 & 29.36 & 45.23 & 0.0570 & 5608 & 114 \\
\hline 17 & 1.456 & 19.88 & 27.66 & 44.10 & 0.0555 & 5285 & 108 \\
\hline 18 & 1.367 & 20.13 & 25.97 & 42.98 & 0.0540 & 4962 & 101 \\
\hline 19 & 1.278 & 20.41 & 24.28 & 41.85 & 0.0526 & 4639 & 95 \\
\hline 20 & 1.189 & 20.71 & 22.59 & 40.72 & 0.0512 & 4316 & 88 \\
\hline 21 & 1.100 & 21.05 & 20.90 & 39.60 & 0.0498 & 3993 & 81 \\
\hline 22 & 1.011 & 21.42 & 19.21 & 38.47 & 0.0485 & 3670 & 75 \\
\hline 23 & 0.922 & 21.84 & 17.52 & 37.34 & 0.0473 & 3347 & 68 \\
\hline 24 & 0.833 & 22.33 & 15.83 & 36.22 & 0.0461 & 3023 & 62 \\
\hline
\end{tabular}

Calculation of Glass Transfer Function Terms

The general transfer functions for the glass element, $\mathrm{G}_{\mathrm{G}}(\mathrm{s})$, is shown in Equation 4.12. The values of the resistance and capacitances of the glass element were calculated in Table D.1. Using these values, one can determine the values of the different terms of the transfer function shown in Equation 4.12. The revised transfer function for the glass element is shown in Equation 4.14.

MATLAB code to determine the terms of the transfer function during the working stage is listed below. 


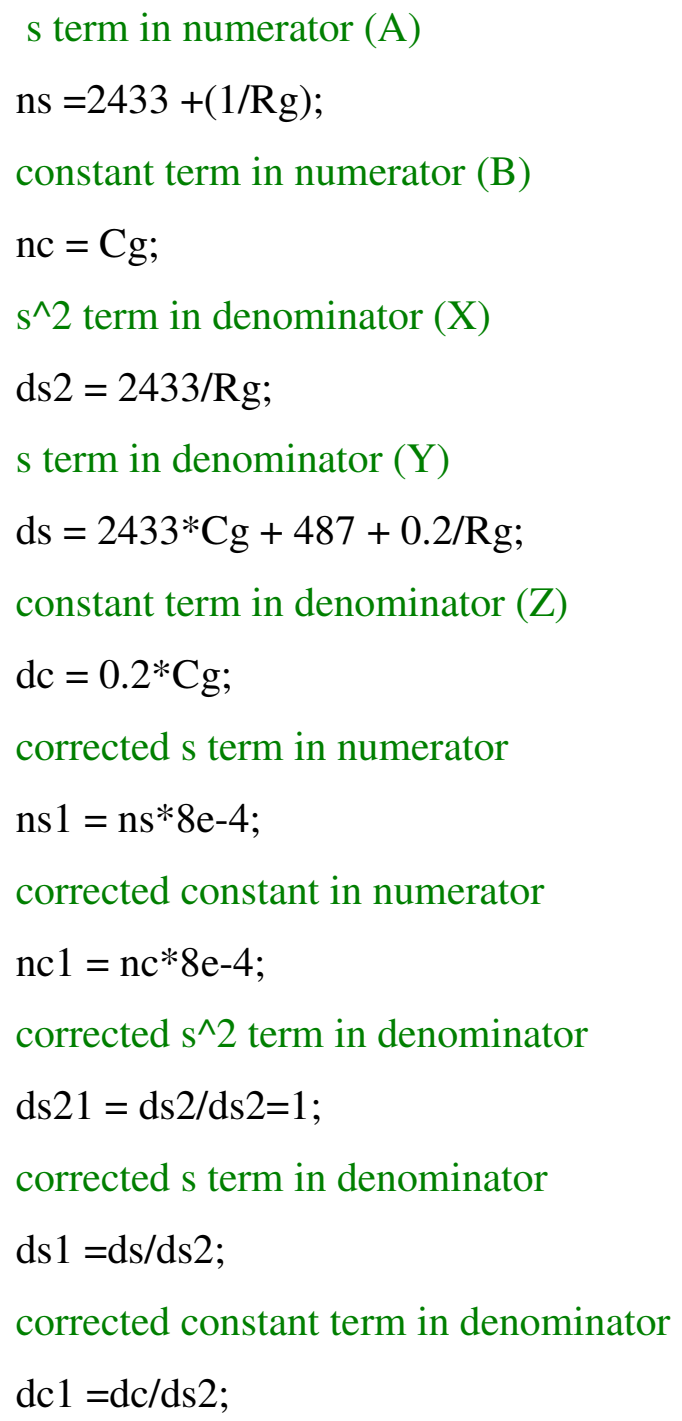

The general transfer functions for the glass element, $\mathrm{G}_{\mathrm{G}}(\mathrm{s})$, can be represented as shown in Equation 4.17.

$$
G_{G}(s)=\frac{T_{A}(s)}{s Q_{B}(s)}=\frac{A s+B}{X s^{2}+Y s+Z}\left[\frac{{ }^{\circ} F}{B t u / h r}\right]
$$

The values of $\mathrm{A}, \mathrm{B}, \mathrm{X}, \mathrm{Y}$ and $\mathrm{Z}$ obtained from the MATLAB code above are substituted in Equation D.1 to obtain the transfer functions in Table 4.8. Table D.2 features the spreadsheet program to determine the transfer functions for the glass element during the working period shown in Table 4.8 . 
Table D.2 Transfer Function Terms of Glass during Working Period

\begin{tabular}{|r|c|r|r|r|r|r|r|r|}
\hline $\begin{array}{r}\text { Time } \\
\text { (hrs) }\end{array}$ & $\begin{array}{c}\mathrm{s} \\
\text { term } \\
\text { in } \\
\begin{array}{c}\text { Nr. } \\
(\mathrm{A})\end{array}\end{array}$ & $\begin{array}{c}\mathrm{s}^{\wedge} \text { term } \\
\text { ter } \mathrm{Dr} \\
(\mathrm{X})\end{array}$ & $\begin{array}{c}\text { s term } \\
\text { in } \mathrm{Dr} \\
(\mathrm{Y}) .\end{array}$ & $\begin{array}{c}\text { Constant } \\
\text { term in } \\
\text { Dr. } \\
(\mathrm{Z})\end{array}$ & $\begin{array}{c}\text { Corrected } \\
\text { s term } \\
\text { in Nr. }\end{array}$ & $\begin{array}{c}\text { Corrected } \\
\text { Constant } \\
\text { in Nr. }\end{array}$ & $\begin{array}{c}\text { Corrected } \\
\text { s term } \\
\text { In Dr. }\end{array}$ & $\begin{array}{c}\text { Corrected } \\
\text { Constant } \\
\text { in Dr. }\end{array}$ \\
\hline 15 & 2450 & 41240 & 299400 & 25 & $4.75 \mathrm{E}-05$ & $2.38 \mathrm{E}-06$ & 7.26 & 0.0006 \\
\hline 16 & 2451 & 42690 & 278700 & 23 & $4.59 \mathrm{E}-05$ & $2.14 \mathrm{E}-06$ & 6.53 & 0.00054 \\
\hline 17 & 2451 & 43850 & 262700 & 22 & $4.47 \mathrm{E}-05$ & $1.97 \mathrm{E}-06$ & 5.99 & 0.00049 \\
\hline 18 & 2452 & 45060 & 246600 & 20 & $4.35 \mathrm{E}-05$ & $1.8 \mathrm{E}-06$ & 5.47 & 0.00045 \\
\hline 19 & 2452 & 46290 & 230600 & 19 & $4.24 \mathrm{E}-05$ & $1.63 \mathrm{E}-06$ & 4.98 & 0.00041 \\
\hline 20 & 2453 & 47550 & 214600 & 18 & $4.13 \mathrm{E}-05$ & $1.48 \mathrm{E}-06$ & 4.51 & 0.00037 \\
\hline 21 & 2453 & 48840 & 198500 & 16 & $4.02 \mathrm{E}-05$ & $1.33 \mathrm{E}-06$ & 4.07 & 0.00033 \\
\hline 22 & 2454 & 50140 & 182500 & 15 & $3.91 \mathrm{E}-05$ & $1.19 \mathrm{E}-06$ & 3.64 & 0.0003 \\
\hline 23 & 2454 & 51440 & 166500 & 14 & $3.82 \mathrm{E}-05$ & $1.06 \mathrm{E}-06$ & 3.24 & 0.00027 \\
\hline 24 & 2455 & 52720 & 150500 & 12 & $3.72 \mathrm{E}-05$ & $9.35 \mathrm{E}-07$ & 2.85 & 0.00022 \\
\hline
\end{tabular}
Nr. - Numerator
Dr. - Denominator 


\section{Appendix E - MATLAB Code for Savings from Enhanced Controls}

$\%$ Volume flow rate of Natural Gas during Melting Period/Burner: vngf, in cfh.

vngf $=1000$;

$\%$ Volume flow rate of Natural Gas at the Beginning of Working Period/Burner: vng1, in cfh.

vng1=600;

$\%$ Volume flow rate of Natural Gas at the End of Working Period/Burner: vng2, in cfh.

vng2=564;

$\%$ Oxy-Fuel Ratio: ofr

ofr $=2.1$;

$\%$ Volume flow rate of Oxygen during Melting Period/Burner: vO2f, in cfh.

vO2f=vngf*ofr;

$\mathrm{vO} 2 \mathrm{f}=(1000)(2.1)=2100$

$\%$ Volume flow rate of Oxygen at the Beginning of Working Period/Burner: vO21, in cfh.

vO21=vng $1 *$ ofr;

$\mathrm{vO} 21=(600)(2.1)=1260$

$\%$ Volume flow rate of Oxygen at the End of Working Period/Burner: vO22, in cfh.

$\mathrm{vO} 22=\mathrm{vng} 2 *$ ofr;

$\mathrm{vO} 22=(564)(2.1)=1184.4$

$\%$ Number of Burners: $n$

$\mathrm{n}=2$;

$\%$ Hours of Operation: t, in hrs.

$\mathrm{t}=9$;

$\%$ The amount of gas saved is equal to the area under the curve. In this case it is the area of the triangle bound by the hours of operation and the difference in flow rates at the beginning and end of working period.

$\%$ Amount of Natural Gas saved from cutting back on Natural Gas supply: ngs, in cu.ft ngs $=0.5 * t * n *(\operatorname{vng} 1-\mathrm{vng} 2)$; 
ngs $=(0.5)(9)(2)(600-564)=324$

$\%$ Amount of Commercial Oxygen saved from cutting back on Commercial Oxygen supply: Os, in cu.ft

Os $=0.5 * \mathrm{t}^{*} \mathrm{n} *(\mathrm{vO} 21-\mathrm{vO} 22)$;

$\mathrm{Os}=(0.5)(9)(2)(1260-1184.4)=680.4 \mathrm{ft}^{3}$.

\% Cost of Natural Gas: cng, in dollars/1000 cf.

cng $=7$;

$\%$ Dollars saved by cutting back on Natural Gas supply over the 9 hour Working Period: ngm, in dollars.

ngm $=($ cng*ngs $) / 1000$;

$\mathrm{ngm}=(7)(324) / 1000=\$ 2.27$

$\%$ Cost of Commercial Oxygen: cng, in dollars/1000 cf.

$\mathrm{cO} 2=20$;

$\%$ Dollars saved by cutting back on Commercial Oxygen supply during the 9 hour Working Period: Om, in dollars.

$\mathrm{Om}=(\mathrm{cO} 2 * \mathrm{Os}) / 1000$;

$\mathrm{Om}=(20)(680.4) / 1000=\$ 13.61$

$\%$ Total savings from cutting back on Natural Gas and Oxygen during the 9 hour Working Period: Tm, in dollars.

Tm=ngm+Om;

$\mathrm{Tm}=2.27+13.61=\$ \mathbf{1 5 . 8 8}$ 


\section{Appendix F - Development of Transfer Function of Plant and Controller for Melting and Conditioning Periods}

In this section, transfer functions have been developed for the batch tank during the melting and conditioning periods. Closed-loop models for the batch tank were developed for melting and cooling responses.

F.1 Open-Loop Transfer Function for Batch Tank during Melting and Conditioning Periods

Figure F.1 shows the block diagram representation of the transfer function for the batch tank.

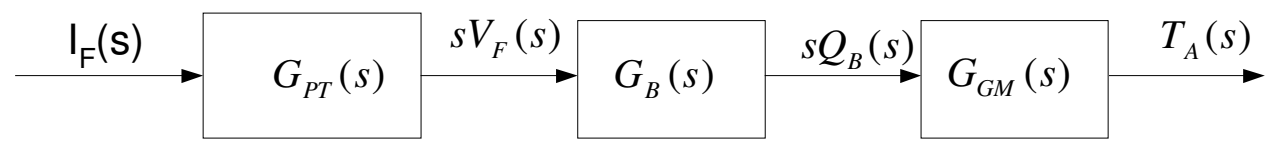

Figure F.1 Block Diagram of Batch Tank Transfer Function during Melting and Conditioning Periods

The transfer function for the batch tank during the melting and conditioning periods, $\mathrm{G}_{\mathrm{BTM}}(\mathrm{s})$, can be obtained as shown in Equation F.1.

$$
G_{B T M}(s)=\frac{T_{A}(s)}{I_{F}(s)}=G_{P T}(s) \cdot G_{B}(s) \cdot G_{G M}(s)\left[\frac{{ }^{\circ} F}{m A}\right]
$$

Substituting the values for different transfer functions from Equations 3.23, 3.24, 3.27 and 4.12 in Equation F.1, one obtains the transfer function for the batch tank during the melting and conditioning periods, $\mathrm{G}_{\mathrm{BTM}}(\mathrm{s})$ as shown in Equation F.2.

$$
G_{B T M}(s)=\frac{T_{A}(s)}{I_{F}(s)}=\frac{5760 s+288}{s^{4}+412 s^{3}+4940 s^{2}+1.45 \times 10^{4} s+1.2}\left[\frac{{ }^{\circ} F}{m A}\right]
$$




\section{F.2 Closed-Loop Models of the Batch Tank}

F.2.1 Closed-Loop Models of the Batch Tank during Melting and Conditioning Periods During the melting process, the molten glass is heated from a temperature of about $2100{ }^{\circ} \mathrm{F}$ to $2500^{\circ} \mathrm{F}$ in about 6 hours and held at that temperature for conditioning. This corresponds to the first 14 hours of the working cycle, shown in Figure 4.1. Since the mass of the glass remains the same during this process, the transfer function for the plant, $\mathrm{G}_{\text {Plant }}(\mathrm{s})$, is represented by the overall batch transfer function for melting, $\mathrm{G}_{\mathrm{BTM}}(\mathrm{s})$ as shown in Section F.1. The controller design for the melting period is shown in Section F.3.1. The closed-loop transfer function with the controller for the melting period, $\mathrm{T}_{\mathrm{BTM}}(\mathrm{s})$, can be developed from Figure 4.10 as shown in Equation F.3.

$$
T_{B T M}(s)=\frac{T_{A}(s)}{T_{R}(s)}=G_{T V}(s) \cdot \frac{G_{C M}(s) \cdot G_{B T M}(s)}{1+G_{C M}(s) \cdot G_{B T M}(s) \cdot H_{T}(s)}\left[\frac{{ }^{\circ} F}{{ }^{\circ} F}\right]
$$

where

$\mathrm{G}_{\mathrm{CM}}(\mathrm{s}) \quad-\quad$ Transfer function of controller for melting period

$\mathrm{G}_{\mathrm{BTM}}(\mathrm{s}) \quad-\quad$ Transfer function of batch tank during melting and conditioning periods

$\mathrm{H}_{\mathrm{T}}(\mathrm{s}) \quad$ - $\quad$ Transfer function of feedback thermocouple

Substituting Equation 4.24, Equation F.2, Equation 3.30 and Equation F.7 in Equation F.3, one obtains the closed-loop batch tank transfer function with the controller for the melting period, $\mathrm{T}_{\mathrm{BTM}}(\mathrm{s})$, as shown in Equation F.4.

$$
T_{B T M}(s)=\frac{5.42 \times 10^{4} s^{3}+4.01 \times 10^{4} s^{2}+1877 s+0.17}{s^{7}+1663 s^{6}+5.21 \times 10^{5} s^{5}+6.55 \times 10^{6} s^{4}+2.24 \times 10^{7} s^{3}+1.26 \times 10^{7} s^{2}+2910 s+0.17}\left[\frac{{ }^{\circ} F}{{ }^{\circ} F}\right] \text { F.4 }
$$

The desired behavior of the batch tank during the melting and cooling processes are featured in Table F.1. 
Table F.1 Desired Performance of Closed-Loop Models during Melting and Cooling Processes

\begin{tabular}{|c|c|c|c|}
\hline Period & Gain Margin, dB & Phase Margin, deg & Settling Time, hr \\
\hline Melting & INF & 90 & 6 \\
\hline Cooling & INF & 90 & 1 \\
\hline
\end{tabular}

\section{F.2.2 Closed-Loop Model of the Batch Tank during Cooling Process}

During the cooling process, the temperature of the molten glass is brought down from $2500{ }^{\circ} \mathrm{F}$ to $2100^{\circ} \mathrm{F}$ in less than an hour. This corresponds to the period between the $14^{\text {th }}$ and $15^{\text {th }}$ hour of the working cycle shown in Figure 4.1. Since the mass of the glass remains the same during this process, the transfer function for the plant, $G_{\text {Plant }}(s)$, is represented by the overall batch transfer function for melting, $\mathrm{G}_{\mathrm{BTM}}(\mathrm{s})$ as shown in Section F.1. The controller design for the cooling period is shown in Section F.3.2. The closed-loop transfer function with the transfer function for the cooling period can be developed from Figure 4.10 as shown in Equation F.5.

$$
T_{B T C}(s)=\frac{T_{A}(s)}{T_{R}(s)}=G_{T V}(s) \cdot \frac{G_{C C}(s) \cdot G_{B T M}(s)}{1+G_{C C}(s) \cdot G_{B T M}(s) \cdot H_{T}(s)} \quad\left[\frac{{ }^{\circ} F}{{ }^{\circ} F}\right] \quad \text { F.5 }
$$

where

$\mathrm{G}_{\mathrm{CC}}(\mathrm{s}) \quad-\quad$ Transfer function of controller for cooling period

$\mathrm{G}_{\mathrm{BTM}}(\mathrm{s}) \quad-\quad$ Transfer function of batch tank during melting and conditioning periods

$\mathrm{H}_{\mathrm{T}}(\mathrm{s}) \quad-\quad$ Transfer function of feedback thermocouple

Substituting Equation 4.24, Equation F.2, Equation 3.30 and Equation F.8 in Equation F.5, one obtains the closed-loop batch tank transfer function with the controller for the cooling period, $\mathrm{T}_{\mathrm{BTC}}(\mathrm{s})$, as shown in Equation F.6.

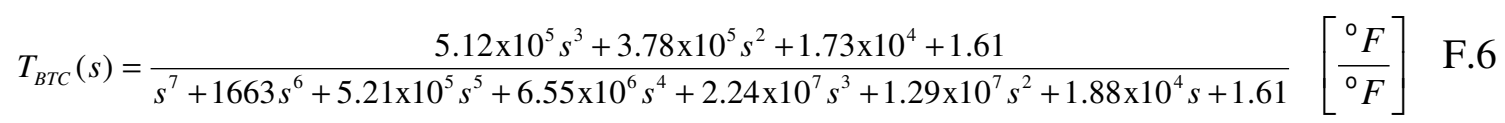




\section{F.3 Design of Controllers for Glass Making Cycles}

The sisotool function of the Control System Toolbox in MATLAB was used to develop the controllers for the glass making cycles. This enables a user to modify the controller parameters and view the results instantaneously.

\section{F.3.1 Controller Design for the Melting Period}

A controller was designed using the sisotool of MATLAB to achieve the behavior shown in Table 5.1. Equation F.7 shows the transfer function for the controller for the melting period.

$$
G_{C M}(s)=\frac{413\left(s+9.09 \times 10^{-5}\right)}{s(s+1250)}\left[\frac{m A}{V}\right]
$$

The closed-loop response of the transfer function with the controller for step input is shown in Figure F.2.

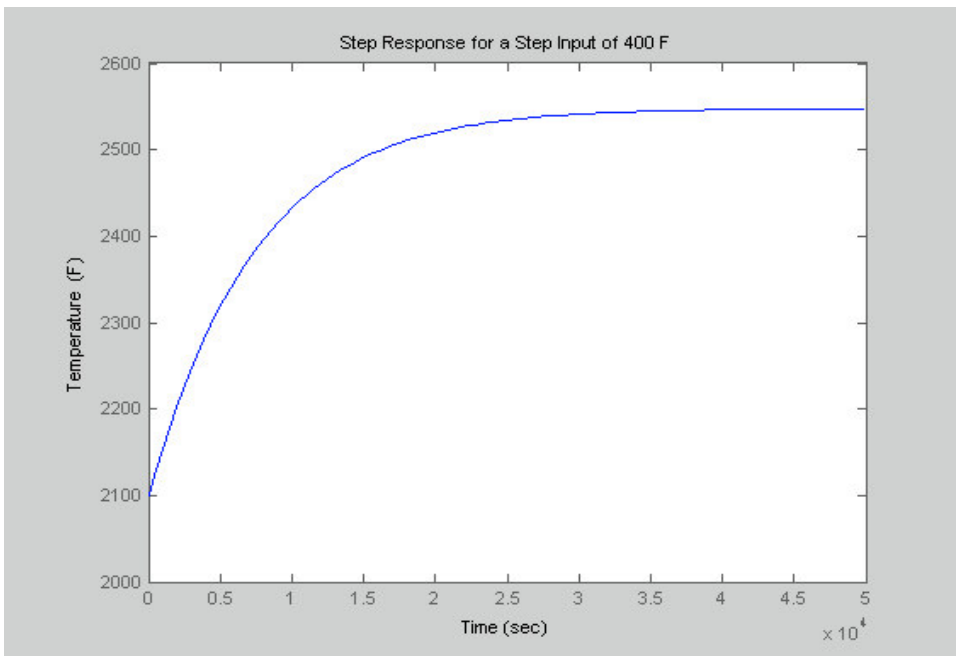

Figure F.2 Response of Closed-Loop Transfer Function for Melting for a Step Increase in Set Point by $400^{\circ} \mathrm{F}$.

The response indicates that the settling time for an increase of $400^{\circ} \mathrm{F}$ in the setpoint is about 6 hours, which satisfies the requirements for melting. 
Figure F.3 shows the root locus of the closed-loop model for melting with the controller.

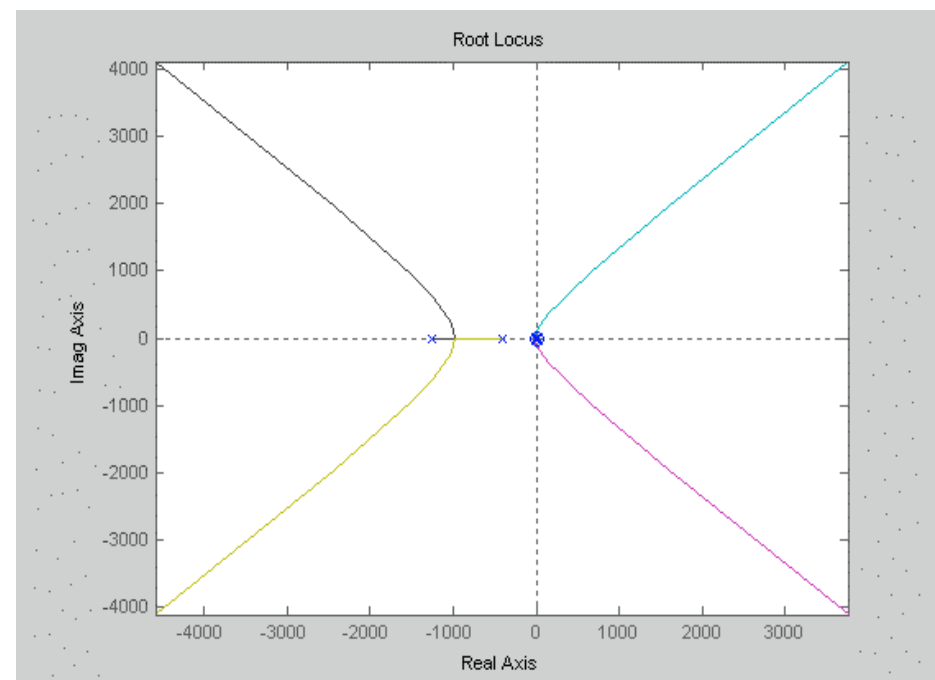

Figure F.3 Root Locus Plot of Closed-Loop Transfer Function for Melting

Figure F.4 shows the Bode plot of the closed-loop during melting.

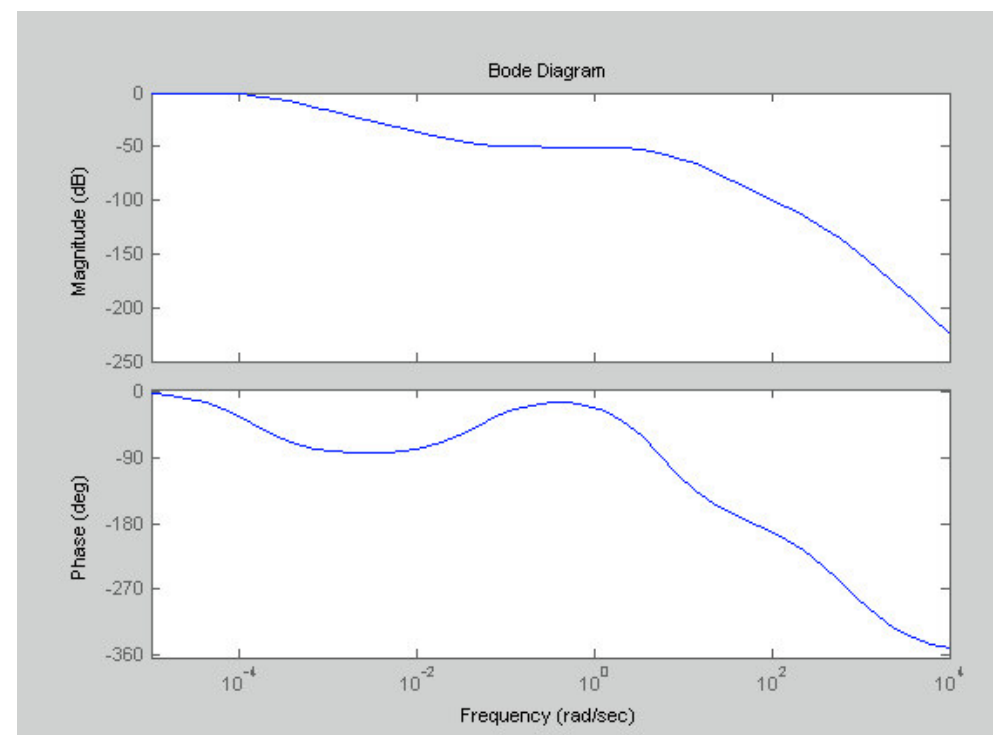

Figure F.4 Bode Plot of Closed-Loop Transfer Function for Melting

The Bode plot in Figure F.4 indicates that the closed-loop transfer function has a Gain Margin of about $90 \mathrm{~dB}$ and a Phase Margin of $180^{\circ}$. Though these do not match the 
desired stability margins shown in Table 5.1, these stability margins will satisfy stability requirements.

\section{F.3.2 Controller Design for the Cooling Period}

Equation F.8 shows the transfer function, $\mathrm{G}_{\mathrm{CC}}(\mathrm{s})$, for the controller for the cooling period.

$$
G_{C C}(s)=\frac{3.9 \times 10^{3}\left(s+9.09 \times 10^{-5}\right)}{s(s+1250)}\left[\frac{m A}{V}\right]
$$

Figure F.5 shows the step response of the closed-loop transfer function for a step decrease in the set-point from $2500{ }^{\circ} \mathrm{F}$ to $2100{ }^{\circ} \mathrm{F}$. The decrease in temperature is reached in about 45 minutes.

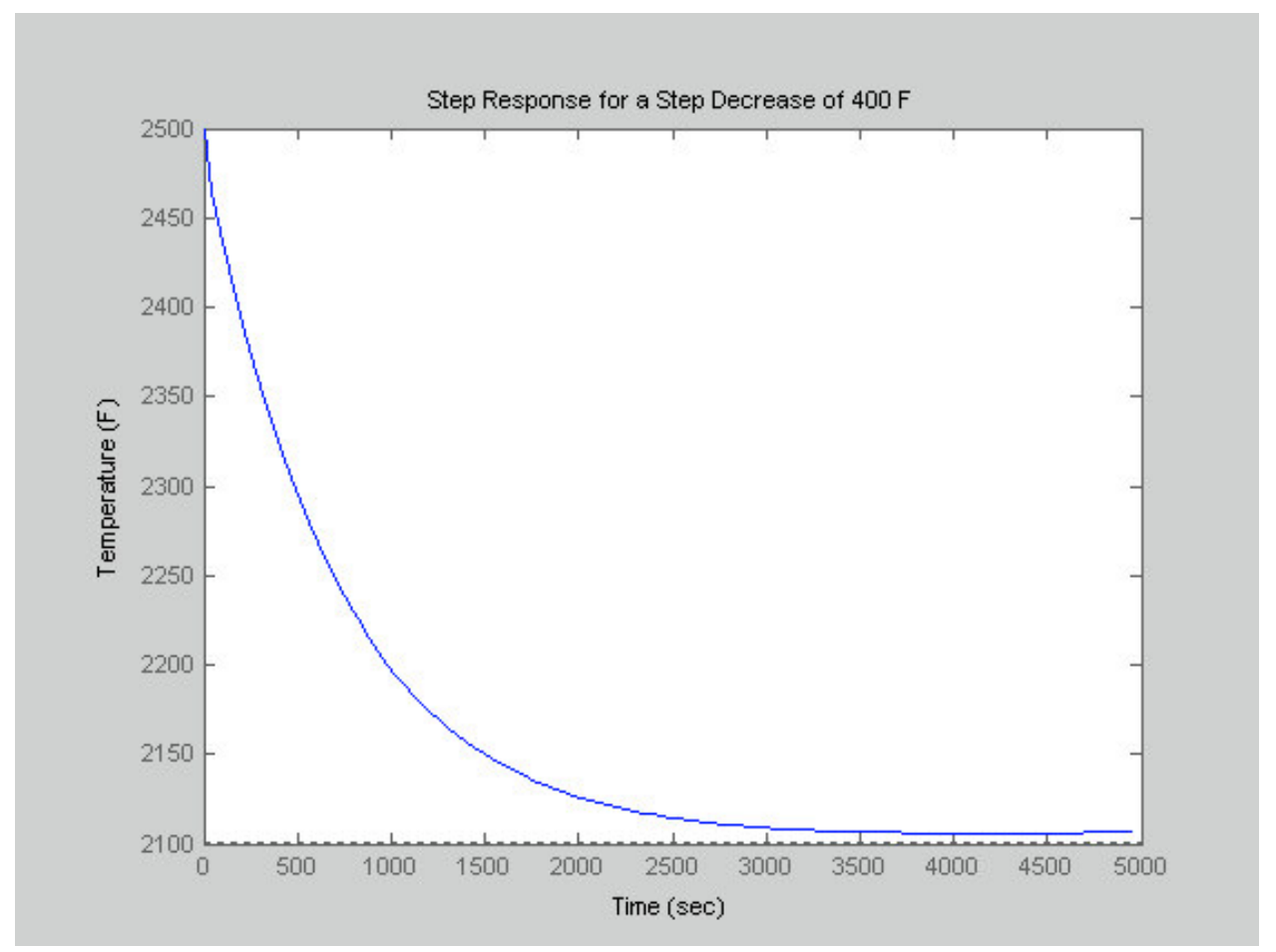

Figure F.5 Response of Closed-Loop Transfer Function for Cooling for a Step Decrease in Set-Point of $400^{\circ} \mathrm{F}$. 
Figure F.6 shows the closed-loop Bode plot of the transfer function for cooling.

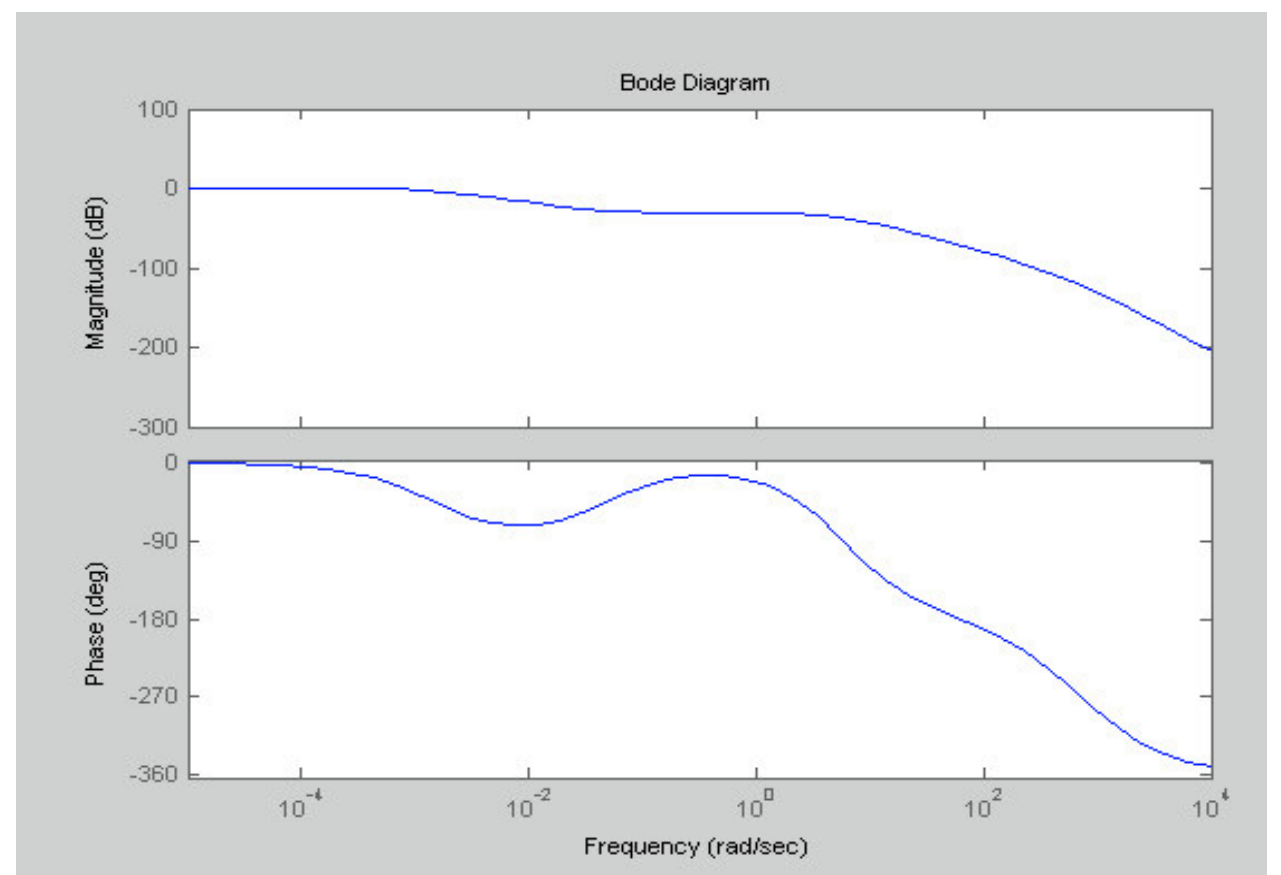

Figure F.6 Bode Plot of Closed-Loop Transfer Function for Cooling

Comparing the controllers for the melting and cooling responses in Equation F.7 and Equation F.8, one notices that the difference only lies in the gain constant. This would mean that the root locus of the cooling response would be the same as that for the melting response shown in Figure F.3.

F.5 MATLAB and Simulink Programs for Melting and Conditioning Periods

Section F.5 shows MATLAB and Simulink programs for the transfer function for the melting and conditioning periods.

Transfer Function of Glass Element during Melting and Conditioning Periods, $\mathrm{G}_{\mathrm{GM}}(\mathrm{s})$ ngm $=8 \mathrm{e}-4 *[0.0590 .003]$;

$\operatorname{dgm}=\left[\begin{array}{lll}1 & 7.26 & 0.0006\end{array}\right]$;

$\operatorname{ggm}=\mathrm{tf}(\mathrm{ngm}, \mathrm{dgm})$;

Overall Batch Tank Transfer Function for Melting and Conditioning Periods, $\mathrm{G}_{\mathrm{BTM}}(\mathrm{s})$ gbtm $=\mathrm{gpt}^{*} \mathrm{gb}^{*} \mathrm{ggm}$; 
Transfer Function of Controller during Melting

$\mathrm{gcm}=\mathrm{zpk}(-9.09 \mathrm{e}-5,[0-1.25 \mathrm{e} 3], 413)$;

Transfer Function of Controller during Cooling

gcc $=\operatorname{zpk}(-9.09 \mathrm{e}-5,[0-1.25 \mathrm{e} 3], 3.9 \mathrm{e} 3)$;

$\%$ Transfer Function of Closed-Loop Batch Tank during Melting, $\mathrm{T}_{\text {Втм }}(\mathrm{s})$

$\mathrm{gm} 1=\mathrm{gcm} * \mathrm{gbtm}$;

$\mathrm{gm} 2=$ feedback $(\mathrm{gm} 1, \mathrm{ht})$;

tbtm $=g t v^{*} g m 2$;

Transfer Function of Closed-Loop Batch Tank during Cooling, $\mathrm{T}_{\mathrm{BTC}}(\mathrm{s})$

$\mathrm{gc1}=\mathrm{gcc} * \mathrm{gbtm}$;

$\mathrm{gc} 2=$ feedback $(\mathrm{gc} 1, \mathrm{ht})$;

tbtc $=g^{*} v^{*} \mathrm{gc} 2$;

Figure F.7 shows the Simulink model for the closed-loop transfer function for the batch tank during the melting period, $\mathrm{T}_{\mathrm{BTM}}(\mathrm{s})$.

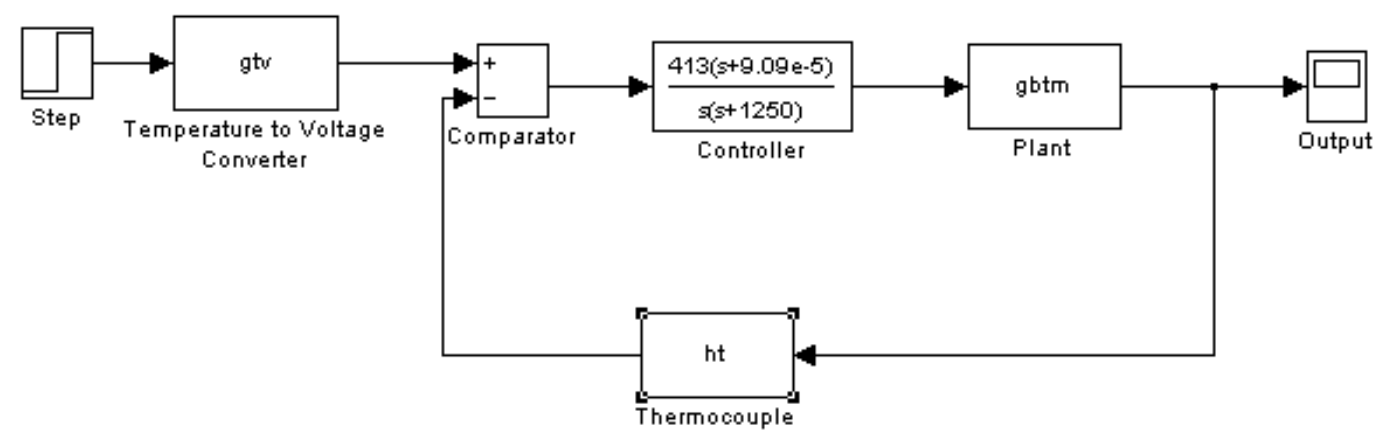

Figure F.7 Simulink Model for Closed-Loop Batch Tank Transfer Function during Melting Period, $\mathrm{T}_{\mathrm{BTM}}(\mathrm{s})$

Figure F.8 shows the Simulink model for the overall transfer function for the batch tank during the melting and conditioning periods, $\mathrm{G}_{\mathrm{BTM}}(\mathrm{s})$.

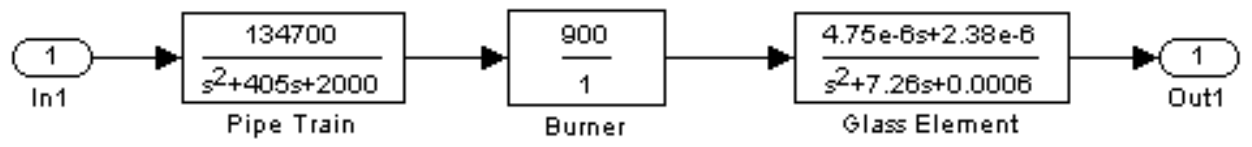

Figure F.8 Simulink Model for Open-Loop Batch Tank Transfer Function during Melting and Conditioning Periods, $\mathrm{G}_{\mathrm{BTM}}(\mathrm{s})$ 
Figure F.9 shows the Simulink model for the closed-loop transfer function for the batch tank during the cooling period, $\mathrm{T}_{\mathrm{BTC}}(\mathrm{s})$.

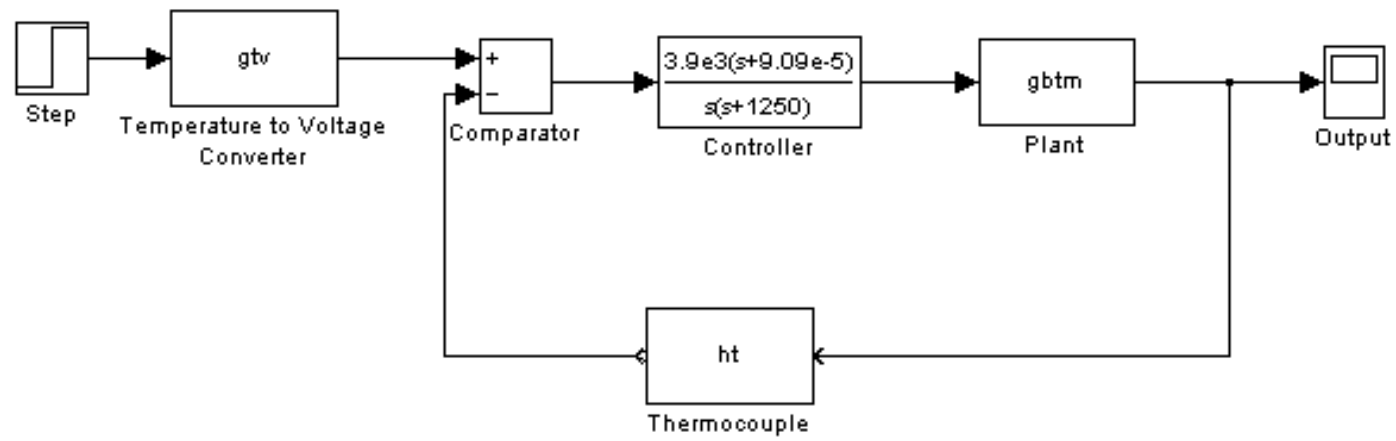

Figure F.9 Simulink Model for Closed-Loop Batch Tank Transfer Function during Cooling Period, $\mathrm{T}_{\mathrm{BTC}}(\mathrm{s})$ 


\section{Appendix G - LabVIEW Application for Acquiring Temperature}

LabVIEW is a graphical programming language that has a wide range of applications in controls and data acquisition. The advantage of using LabVIEW is that as a high level language, it increases productivity by decreasing the time required to develop applications. It uses icons to represent subroutines and one wires icons together to determine the flow of data through the program.

LabVIEW programs or Virtual Instruments (VIs) have a Front Panel which serves as the graphical user interface containing program inputs and outputs, and a graphical source code area called the Block Diagram. Every object on the Front Panel has an associated terminal on the Block Diagram that allows one to perform various operations and analysis on the data that it contains.

This application is for acquiring a single analog temperature signal from a single channel. The key parameters of this application can be summarized as described below.

This LabVIEW application writes the time-stamped acquired temperature to a file in ASCII format that is readable from spreadsheet applications. This program will open a new file or overwrite an old one to store the acquired data. It converts an array of data to a row of tab-separated columns, prepends to it the timestamp column, and terminates the row with the end-of-line character. The acquired temperature can be obtained in Fahrenheit or Celsius.

The different sub-Virtual Instruments (subVIs) required for the proper functioning of the designed VI are: Acquire Waveform.vi and Convert C to F.vi. These subVIs are available in all the recent versions of LabVIEW. 
Figure G.1 shows the front panel of the VI for acquiring temperature from the batch tank.

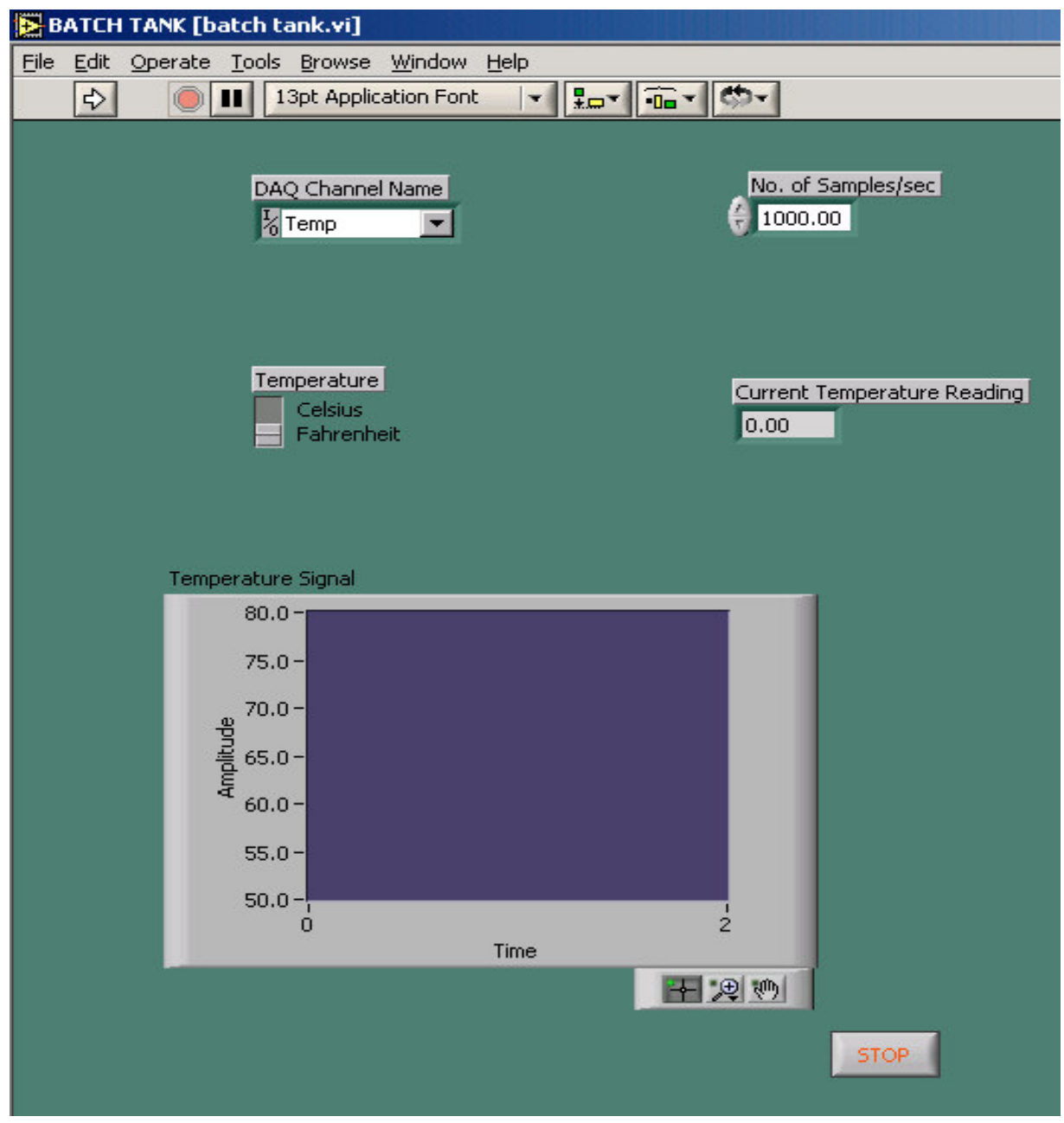

Figure G.1 Front Panel of LabVIEW Application for Acquiring Temperature

Figure G.2 shows the block diagram of the VI for acquiring temperature from the batch tank. 


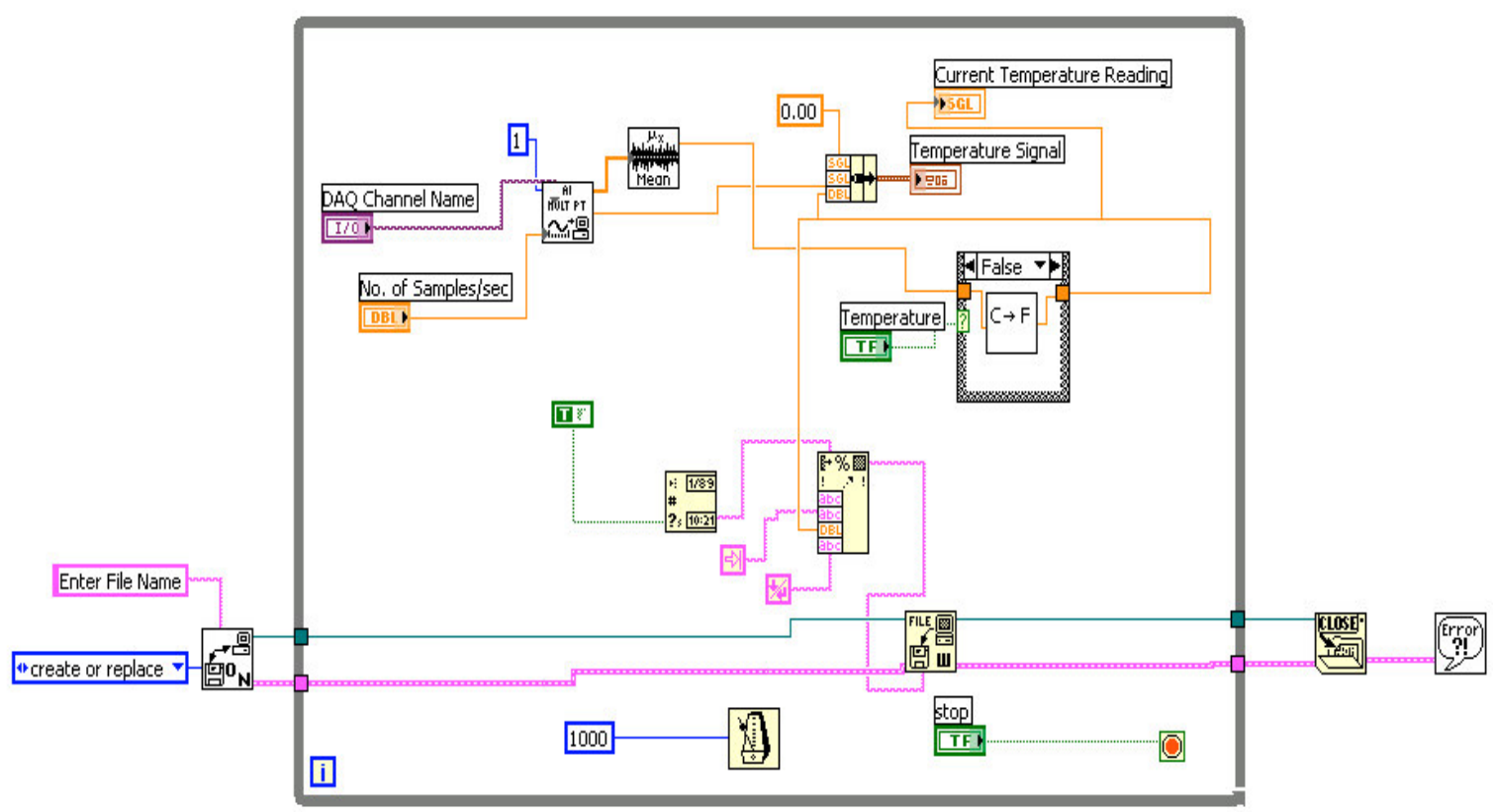

Figure G.2 Block Diagram of LabVIEW Application for Acquiring Temperature

Figure G.3 shows the block diagram for the conversion of temperature from Celsius to Fahrenheit scale.

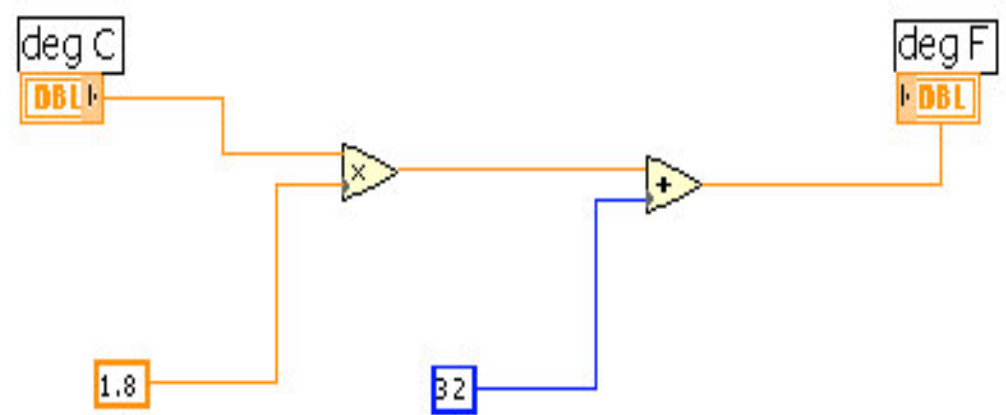

Figure G.3 Block Diagram of LabVIEW for Temperature Conversion

The advantage of this particular application was that for each data acquired, the timestamp was attached. A separate timer was not required to get a regular interval. 


\section{VITA}

Ranjit Menon Unnikrishnan was born on March 29, 1979 in Alleppey, India. He did his schooling at Modern Senior Secondary School in Chennai, India. He received a Bachelor of Technology Degree in Mechanical Engineering from Mahatma Gandhi University, India in May 2000. He is currently a candidate for a Masters of Science Degree in Mechanical Engineering degree from West Virginia University. 